\title{
Forecasting Daily Global Solar Radiation in Hot Semi-Arid Climate Using a Novel Hybrid Machine Learning Paradigm
}

Mehdi jamei ( $\square$ mehdi.jamei59@gmail.com )

Shohadaye Hoveizeh university of technology

Iman Ahmadianfar

Behbahan Khatam Alanbia University of Technology

Mozhdeh Jamei

Ferdowsi University of Mashhad

Masoud Karbasi

University of Zanjan

Ali Asghar Heidari

Tehran University: University of Tehran

Huling Chen

Wenzhou University

\section{Research Article}

Keywords: Global Solar Radiation, Sunshine hours, LSSVM-ISA, MARS, GRNN, MLRI

Posted Date: February 9th, 2021

DOl: https://doi.org/10.21203/rs.3.rs-164879/v1

License: (9) (i) This work is licensed under a Creative Commons Attribution 4.0 International License.

Read Full License 


\title{
Forecasting daily global solar radiation in hot semi-arid climate using a novel hybrid machine learning paradigm
}

\author{
Mehdi Jamei $^{\mathrm{a}}$, Iman Ahmadianfar ${ }^{\mathrm{b}}$, Mozhdeh Jamei ${ }^{\mathrm{c}, \mathrm{d}}$, Masoud Karbasi ${ }^{\mathrm{e}}$, Ali Asghar Heidari ${ }^{\mathrm{f}, \mathrm{g}}$, \\ Huling Chen $*$ h \\ ${ }^{a}$ Faculty of Engineering, Shohadaye Hoveizeh University of Technology, Dasht-e Azadegan, Susangerd, Iran \\ m.jamei@shhut.ac.ir \\ ${ }^{\mathrm{b}}$ Dept. of Civil Engineering, Behbahan Khatam Alanbia University of Technology, Behbahan, Iran \\ i.ahmadianfar@bkatu.ac.ir \\ ${ }^{\mathrm{c}}$ Water Science and Engineering Dept., Ferdowsi University of Mashhad, Mashhad, Iran \\ ${ }^{\mathrm{d}}$ Khuzestan Water and Power Authority, Ahvaz, Iran \\ mozhdeh.jamei@gmail.com \\ ${ }^{\text {e }}$ Faculty of Agriculture, University of Zanjan, Zanjan, Iran \\ m.karbasi@znu.ac.ir \\ ${ }^{\mathrm{f}}$ School of Surveying and Geospatial Engineering, College of Engineering, University of Tehran, Tehran, Iran \\ as_heidari@ut.ac.ir, aliasghar68@gmaill.com \\ ${ }^{\mathrm{g}}$ Department of Computer Science, School of Computing, National University of Singapore, Singapore, \\ Singapore \\ aliasgha@comp.nus.edu.sg, t0917038@u.nus.edu \\ ${ }^{\mathrm{h}}$ College of Computer Science and Artificial Intelligence, Wenzhou University, Wenzhou, \\ Zhejiang 325035, China \\ chenhuiling.jlu@gmail.com \\ Corresponding author: Mehdi. Jamei (e-mail:m.jamei@shhut.ac.ir)
}

\section{Abstract}

Solar energy is one of the most important renewable energy sources. Assessing the solar potential of area needs analyzed information about the dataset of the measured global solar radiation (GSR). Recently, researches detected the high potential of state-of-the-art artificial intelligence (AI) methods in estimating the GSR successfully. In this study, a novel hybrid AI-based tool consisting of least square support vector machine (LSSVM) integrated with improved simulated annealing (ISA) is proposed to predict the GSR over the Ahvaz synoptic station located in the South-West of Iran. The potential of the proposed hybrid paradigm socalled LSSVM-ISA was evaluated by using multivariate adaptive regression spline (MARS), generalization regression neural network (GRNN), and multivariate linear regression with 
interactions (MLRI). For precise assessment of efficiency of the AI models, various statistical metrics and validation methods were used to assess the precision of the developed models. A comparison of the obtained results indicated that the LSSVM-ISA method performed better than the MARS, GRNN, and MLRI models. The achieved RMSE values of the MARS, GRNN, and MLRI models were decreased by $9 \%, 16 \%$, and $30 \%$ using the LSSVM-ISA model. Finally, the results demonstrated that the LSSVM-ISA model could be successfully employed for accurately predicting GSR.

Keywords: Global Solar Radiation, Sunshine hours, LSSVM-ISA, MARS, GRNN, MLRI.

\section{Introduction}

Solar energy is the electromagnetic energy emitted from the sun. Solar radiation is referred to as global solar radiation (GSR) that is the total of direct shortwave radiation received from the sun and diffuse sky radiation that has been scattered across the atmosphere (WMO 2014). The GSR data are essential for several theoretical and practical applications such as solar energy systems, architecture, agriculture, meteorological, and climatological models (Moradi 2009). Pyranometers use thermoelectric, photoelectric, pyroelectric, or bimetallic elements as sensors to measure the global solar irradiance (Radiant flux density $/ \mathrm{m}^{2}$ ) at the meteorological stations (WMO 2014). However, the GSR measurements are limited and only available at a few meteorological stations, due to the high cost of solar measuring instruments, the accurate equipment calibration, installation, and maintenance requirements. Besides, the missing GSR data, incorrect data, measurements in a short and discontinuous period are other problems at many stations (Rahimikhoob 2010, Samadianfard et al. 2019).

Therefore, these problems have resulted in the recommendations for alternative techniques to determine the GSR accurately, including the utilize of empirical, deterministic, 
and artificial intelligence (AI) methods (Kisi et al. 2019, Mohammadi et al. 2016). Recently, AI methods have been broadly applied to predicting the GSR. (Behrang et al. 2010) assessed the ability of ANN and radial basis function (RBF) methods for estimation of daily GSR in the station in Dezful at the southern West of Iran. They used various combinations of meteorological variables as the input dataset. Their results demonstrated that more precision could be obtained by using five variables of average air temperature, sunshine hours, relative humidity, wind speed, and day of the year as the input dataset. (Mostafavi et al. 2013) introduced a hybrid model by using the GP and simulated annealing (SA) model for predicting the GSR in Iran. They showed that maximum and minimum air temperatures are more effective input parameters to predict the GSR.

(Kisi 2014) introduced the fuzzy genetic (FG) model to predict the SR in Turkey. The proposed model generated good results during the testing stage and provided better performance compared with the MLP and ANFIS models. Hatice Citakoglu (2015) employed the adaptive neuro-fuzzy inference system (ANFIS), artificial neural network (ANN), multiple linear regression (MLR), and four empirical equations for prediction of the solar radiation (SR) in Turkey (Citakoglu 2015). The author showed that the ANN method has a better performance to predict the SR than the other empirical equations. Shamshirband et al. (2016) proposed to utilize the extreme learning machine (ELM), support vector machine (SVM), genetic programming (GP), and ANN methods to estimate monthly GSR in Iran (Shamshirband et al. 2016). The authors indicated that the ELM method could outperform the ANN, GP, and SVR models. (Belaid \&Mellit 2016) used an SVM for the estimation of daily and monthly GSR in Ghardaïa (Algeria). They compared the proposed SVM model with multiple layer perceptron (MLP) and indicated that the proposed model had good accuracy. (Ibrahim \&Khatib 2017) introduced a hybrid model for predicting the hourly GSR utilizing the random forest $(\mathrm{RF})$ and firefly algorithm (FA). 

support vector regression (SVR) methods with the empirical models for estimating daily GSR. Based on the obtained results, the XGB and SVR were more precise than the empirical models (Fan et al. 2018). Li et al. (2019) developed the MARS model for estimating the hourly SR and compared it with ANN and logistic regression (LR) models (Li et al. 2019). The results demonstrated that the MARS method could provide more promising results compared with the ANN and LR methods. Kisi et al. (2019) developed a dynamic ANFIS model for modeling the SR and compared it with multivariate adaptive regression spline

(MARS), M5 model tree, and least square support vector regression (LSSVM) (Kisi et al. 2019). The results showed that the proposed method could enhance the SR prediction ability over the MARS, M5 model tree, and LSSVR models. Gürel et al. (2020) compared the ability of the ANN method with empirical models, time series (holt-winters (HW)), and response surface methodology (RSM) for modeling the GSR in Turkey (Gürel et al. 2020). Regarding the results, the ANN presented the best results in comparison with the other peers. Fan et al. (2020) proposed three hybrid SVM with bat algorithm (SVM-BAT), particle swarm optimization (SVM-PSO), and whale optimization algorithm (SVM-WOA) for the prediction of daily diffuse solar radiation (Fan et al. 2020). These methods were compared with the SVM, MARS, and XGB methods. Their results indicated that the SVM-BAT could further enhance the prediction precision in diffused solar radiation when compared to the SVM, SVM-PSO, SVM-WOA, and EGB models. Alizamir et al. (2020) evaluated the potential of six machine learning methods, MLP, gradient boosting tree (GBT), MARS, classification and regression tree (CART), and ANFIS based on fuzzy c-means clustering (ANFIS-FCM) and subtractive clustering (ANFIS-SC) to forecast the SR from two stations in Turkey and USA (Alizamir et al. 2020). The results indicated that the GBT method provided better accuracy in modeling the SR than the MLP, MARS, ANFIS, and CART models. 

motivation for exploring more accurate and reliable AI methods is still a challenging task. Among different AI methods, the LSSVM methods are one of the robust and reliable AI methods that has a promising predictive ability. Generally, AI models, especially the LSSVM model, are susceptible to their setting parameters that incorrect selection of these parameters yields to an optimal local solution. To address this, combining AI models with meta-heuristic algorithms can be a suitable approach to succeed. Hence, this paper introduces a new hybrid of the LSSVM with an improved version of the SA (ISA) method to optimize the control parameters of the LSSVM. For evaluation purposes, the LSSVM-ISA model was compared empirical equations.

The rest of this study is described as follows. Section 2 expresses the materials and methods, including empirical models, the dataset used in this paper, the procedure for data quality control, the introduction of the hybrid SA and the LSSVM model. It also provides a summary of other AI models employed in this study (i.e., MARS, GRNN, and MLRI). The results are discussed in Section 3. Validation of the proposed model with traditional approaches is presented in Section 4. Uncertainty analysis is implemented in Section 5. Finally, the study conclusions are expressed in Section 6.

\section{Materials and methods}

\subsection{Empirical models to estimate global solar radiation}

Numerous empirical models have been developed to estimate the GSR based on meteorological variables such as minimum daily temperature, maximum daily temperature, monthly temperature, sunshine hour, extraterrestrial radiation, relative humidity, albedo, precipitation, cloudiness, and evaporation. (Liu et al. 2009, Menges et al. 2006). The 
important empirical models and their equations forms are illustrated in Table 1. Some of these models were modified to solve the problem of the availability of meteorological data by researchers.

\subsection{Study area and data processing}

The current study focuses on global solar radiation assessment at Ahvaz city. The meteorological data collected from Ahvaz synoptic station, belong to the IR of Iran Meteorological Organization (IRIMO), over historical data of 10 years (1 July 2009-1 July 2019). Ahwaz station is located in the Khuzestan province in the southwest of Iran with Latitude 3120 N, Longitude 4840 E, and elevation 22.5 m (Fig. 1). Ahwaz has a hot semiarid climate with hot and long summers and moderate and short winters. The annual mean, maximum, and minimum air temperature of this region are $26.3,33.4,19.2{ }^{\circ} \mathrm{C}$, respectively. The annual mean precipitation is $202 \mathrm{~mm}$, and the annual mean relative humidity is $43.3 \%$ (IRIMO). The collected meteorological data were including the average daily temperature $\left(\mathrm{T}_{\text {ave }},{ }^{\circ} \mathrm{C}\right)$, sunshine hours $\left(\mathrm{S}_{\mathrm{h}}, \mathrm{hr}\right)$, relative humidity $\left(\mathrm{R}_{\mathrm{h}, \%}\right)$, average wind velocity $\left(\mathrm{W}_{\mathrm{s}}, \mathrm{m} / \mathrm{s}\right)$ at $10 \mathrm{~m}$ and day of the year in the range of [1 366]. These data were used as input values to estimate the predictive daily global solar radiation (GSR, Kw-h/m²/day) of the AI-based models. The predictor time series and observed values of GSR were shown in 10 years (3653 days) in Fig.2. Moreover, Table 2 summarized the descriptive statistics of the input time series for ten years.

(1)

4

5

56

\section{7}

58


Table 1. The most cited empirical models for predicting global solar radiation

\begin{tabular}{|c|c|c|c|}
\hline Model & Equation & $\begin{array}{l}\text { Empirical } \\
\text { coefficient } \\
\text { (Parameter) }\end{array}$ & Source \\
\hline $\begin{array}{l}\text { Angstrom and } \\
\text { Prescott }\end{array}$ & $R_{s}=\left(a+b\left(\frac{n}{N}\right)\right) R_{a}$ & $a, b$ & (Prescott 1940) \\
\hline $\begin{array}{l}\text { Swartman and } \\
\text { Ogunlade }\end{array}$ & $R_{S}=a+b\left(\frac{n}{N}\right)+c \cdot R H$ & $a, b, c$ & $\begin{array}{l}\text { (Swartman } \\
\text { \&Ogunlade } \\
1967)\end{array}$ \\
\hline Hargreaves & $R_{s}=a \sqrt{\left(T_{\max }-T_{\min }\right)} \cdot R_{a}$ & $a$ & $\begin{array}{c}\text { (Hargreaves } \\
1981)\end{array}$ \\
\hline $\begin{array}{l}\text { Bristow and } \\
\text { Campbell }\end{array}$ & $R_{s}=a\left(1-\exp \left(-b\left(T_{\max }-T_{\min }\right)^{c}\right)\right) R_{a}$ & $a, b, c$ & $\begin{array}{l}\text { (Bristow } \\
\text { \&Campbell } \\
1984)\end{array}$ \\
\hline $\begin{array}{l}\text { De Jong and } \\
\text { Stewart }\end{array}$ & $R_{s}=a\left(T_{\max }-T_{\min }\right)^{b} \cdot\left(1+c P+d P^{2}\right) R_{a}$ & & $\begin{array}{c}\text { (Jong \&Stewart } \\
\text { 1993) }\end{array}$ \\
\hline Allen & $R_{s}=a\left(\sqrt{T_{\max }-T_{\min }}\right) R_{a}$ & & (Allen 1997) \\
\hline $\begin{array}{c}\text { Donatelli and } \\
\text { Campbell }\end{array}$ & $R_{S}=a\left(1-\exp \left(-b \cdot \frac{\left(T_{\max }-T_{\min }\right)^{c}}{\left(T_{\text {month }}\right)}\right)\right) R_{a}$ & $a, b, c$ & $\begin{array}{l}\text { (Donatelli } \\
\text { \&Campbell } \\
\text { 1998) }\end{array}$ \\
\hline Hunt & $R_{s}=a \sqrt{\left(T_{\max }-T_{\min }\right)} \cdot R_{a}+b$ & $a, b$ & $\begin{array}{c}\text { (Hunt et al. } \\
\text { 1998) }\end{array}$ \\
\hline Hunt & $\begin{array}{c}R_{s}=a \sqrt{\left(T_{\max }-T_{\min }\right)} \cdot R_{a}+b T_{\max }+c P \\
+d P^{2}+e\end{array}$ & $a, b, c, d, e$ & $\begin{array}{c}\text { (Hunt et al. } \\
\text { 1998) }\end{array}$ \\
\hline $\begin{array}{l}\text { Goodin,Hutchin } \\
\text { son, anderlip } \\
\text { and Knapp }\end{array}$ & $R_{s}=a\left(1-\exp \left(-b \cdot \frac{\left(T_{\max }-T_{\min }\right)^{c}}{\left(R_{a}\right)}\right)\right) R_{a}$ & $a, b, c$ & $\begin{array}{l}\text { (Goodin et al. } \\
\text { 1999) }\end{array}$ \\
\hline $\begin{array}{l}\text { Elagib and } \\
\text { Mansell }\end{array}$ & $R_{S}=a\left(\exp \left(b \cdot\left(\frac{n}{N}\right)\right)\right) R_{a}$ & $a, b, c$ & $\begin{array}{l}\text { (Elagib } \\
\text { \&Mansell } \\
\text { 2000) }\end{array}$ \\
\hline $\begin{array}{l}\text { Chen, Ersi, } \\
\text { Yang, Lu and } \\
\text { Zhao }\end{array}$ & $R_{s}=\left(\right.$ a. $\left.\ln \left(T_{\max }-T_{\min }\right)+b \cdot\left(\frac{n}{N}\right)^{c}+d\right) R_{a}$ & $a, b, d$ & $\begin{array}{c}\text { (Chen et al. } \\
\text { 2004) }\end{array}$ \\
\hline
\end{tabular}
of sunshine (hr); $N$, maximum possible duration of sunshine or daylight hours (hr); $\mathrm{n} / \mathrm{N}$, relative sunshine

161 duration; $T_{\min }$, minimum daily air temperature $\left({ }^{\circ} \mathrm{C}\right) ; T_{\max }$, maximum daily air temperature $\left({ }^{\circ} \mathrm{C}\right) ; T_{\text {Month }}$, mean air temperature of the month $\left({ }^{\circ} \mathrm{C}\right) ; R H$, the relative humidity $(\%) ; P$, daily precipitation $(\mathrm{mm})$. 
164 probability density function of the normal distribution are illustrated in Fig.3. According to

165 the Fig.3 and Table 1, the mean daily sunshine hours and average daily temperature dataset

166 have the highest skewness and kurtosis, respectively. However, corresponding to (George

167 2011), the skewness and kurtosis values for the range of [-1.96 +1.96] are acceptable to prove

168 normal univariate distribution. Also, a visual correlation matrix between the predictor

169 variables (Day, $S_{h}, T_{a v e}, W_{s}$, and $R_{h}$ ) and the target variable (GSR) for Ahwaz synoptic station

170 was indicated to survey the degree of influence of predictive parameters on GSR in Fig.4. 


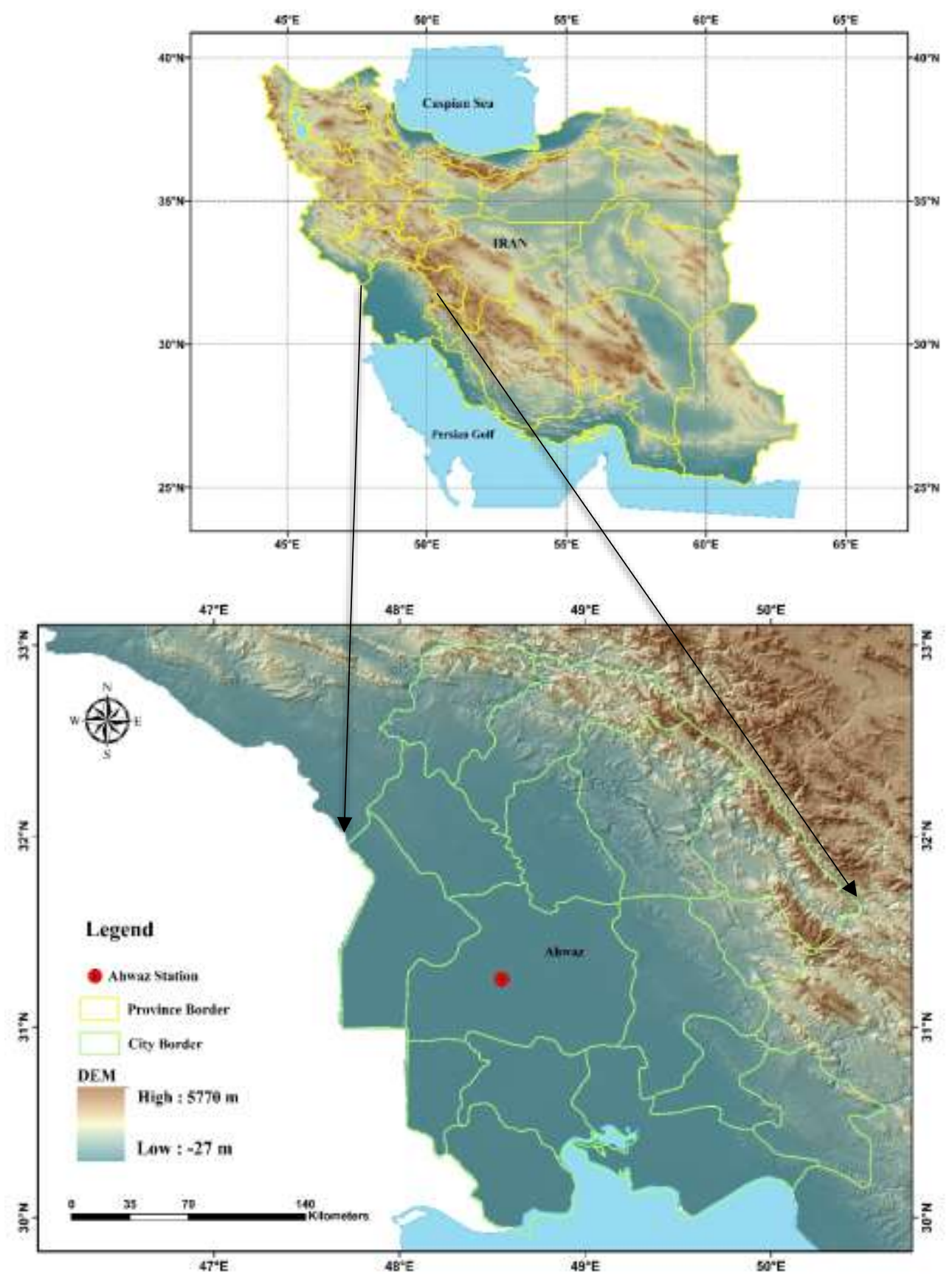

Fig.1. Study area: location of Ahvaz synoptic station.

According to each provided scatterplot and Pearson correlation coefficient (Chen et al.

173 2014), it seems the average daily temperature $\left(T_{\text {ave }}\right)$, relative humidity $\left(R_{h}\right)$. Daily sunshine hours $\left(S_{h}\right)$ due to having the highest Pearson correlation $\left(r_{p}=0.79,-0.78\right.$, and 0.77, respectively) with the target are a more significant element in GSR forecasting whereas the day and mean wind velocity $\left(\mathrm{W}_{\mathrm{s}}\right)$ by yielding the lowest magnitude of the correlation $\left(\mathrm{r}_{\mathrm{p}}=-\right.$ 
0.06 and 0.24 , respectively) play a weaker role in daily GSR forecasting process. However, a certain degree of the above analysis depends on the amount of nonlinearity dependence of the predictive variables with the objective parameter.

There is one 'thumb of rule' for data partitioning, and the researcher utilized different divisions between training and testing datasets, which has influenced the results of problems (Deo et al. 2016). In this research, the daily time-series from 01-July-2009 to 1- July -2019 were split into $80 \%$ (01-July-2009 to 1 - July -2017) for the training dataset and $20 \%$ (02July- 2017 to 1 - July -2019) as the test set. Furthermore, all the datasets were normalized between zero and 1 range based on equation 1 :

$$
x_{\text {nor }}=\frac{x-x_{\min }}{x_{\max }-x_{\min }}
$$

where $x$ is the original variable value, $x_{n o r}$ is the normalized value, and $x_{\max }$ and $x_{\min }$ are the maximum and minimum of the variable $(\mathrm{x})$, respectively.

\subsection{The methodology of Predictive models}

\subsubsection{Improved simulated annealing}

(Kirkpatrick et al. 1983) introduced the simulated annealing (SA) as a single-based optimizer. The annealing process inspired this algorithm in metallurgy. SA has two main phases: heating and cooling. The proposed method employs a temperature factor $(t)$ to transition from the heating to the cooling. Although the SA is a powerful optimizer, it may be stuck in the local solutions, because it is susceptible to the initial solutions ( $\mathrm{Ji}$ et al. 2006). To alleviate this shortcoming, an improved version of the SA algorithm is used, which is called the ISA in this study. The proposed algorithm can be defined in the following stages:

Stage 1: Initialization: Produce an initial random solution $\left(S_{0}\right)$. Specify the minimum and maximum temperature $\left(t_{\min }\right.$ and $\left.t_{\max }\right)$, and the total number of iterations (MaxIt). Set $t=$ 

$t_{\text {max }}$ and $S_{\text {best }}=S_{0}$ (where $x_{\text {best }}$ is the best-so-far solutions). The objective function of $x_{\text {best }}$ is $Z^{*}\left(Z^{*}=Z\left(S_{\text {best }}\right)\right)$.

201 Stage 2: Main loop: In this step, the local search of the SA is defined. Also, two adaptive 202 parameters $\rho$ and $T$ are formulated. The parameter $\rho$ is a scale factor and sets how the 203 position of solutions changes. The $\mathrm{t}$ parameter is updated in each iteration and is a 204 termination condition for determining the end of a local search operation.

205 While $t>t_{\min }$

206 for $i t=1$ to MaxIt

207 1. Produce the new solution $u_{i t, i}$ :

$u_{i t, i}=S_{i t, i}+\mu \times\left(S_{\max , i}-S_{\min , i}\right) \times \operatorname{randn}$

Table 2. Descriptive statistics of meteorological variables and global solar radiation data for the Ahvaz stations located in Iran.

\begin{tabular}{ccccccc}
\hline Variables & Day & $\mathrm{S}_{\mathrm{h}}(\mathrm{h})$ & $\mathrm{T}_{\text {ave }}\left({ }^{\circ} \mathrm{C}\right)$ & $\mathrm{W}_{\mathrm{s}}(\mathrm{m} / \mathrm{s})$ & $\mathrm{R}_{\mathrm{h}}(\%)$ & $\mathrm{GSR}\left(\mathrm{Kw}-\mathrm{h} / \mathrm{m}^{2} / \mathrm{day}\right)$ \\
\hline Minimum & 1 & 0 & 3.64 & 0.85 & 4.96 & 0.21 \\
Maximum & 366 & 13 & 44.55 & 11.82 & 88.97 & 8.49 \\
Range & 365 & 13 & 40.91 & 10.97 & 84.01 & 8.28 \\
Mean & 183.1 & 8.602 & 26.79 & 3.594 & 30.03 & 5.397 \\
Std. Deviation & 105.4 & 3.442 & 10.25 & 1.351 & 19.41 & 1.918 \\
Skewness & $2.109 \mathrm{E}-05$ & -1.194 & -0.1415 & 0.890 & 0.743 & -0.404 \\
Kurtosis & -1.2 & 0.434 & -1.337 & 1.124 & -0.5069 & -0.889 \\
Correlation with GSR & -0.064 & 0.772 & 0.786 & 0.236 & -0.784 & 1.000 \\
\hline
\end{tabular}



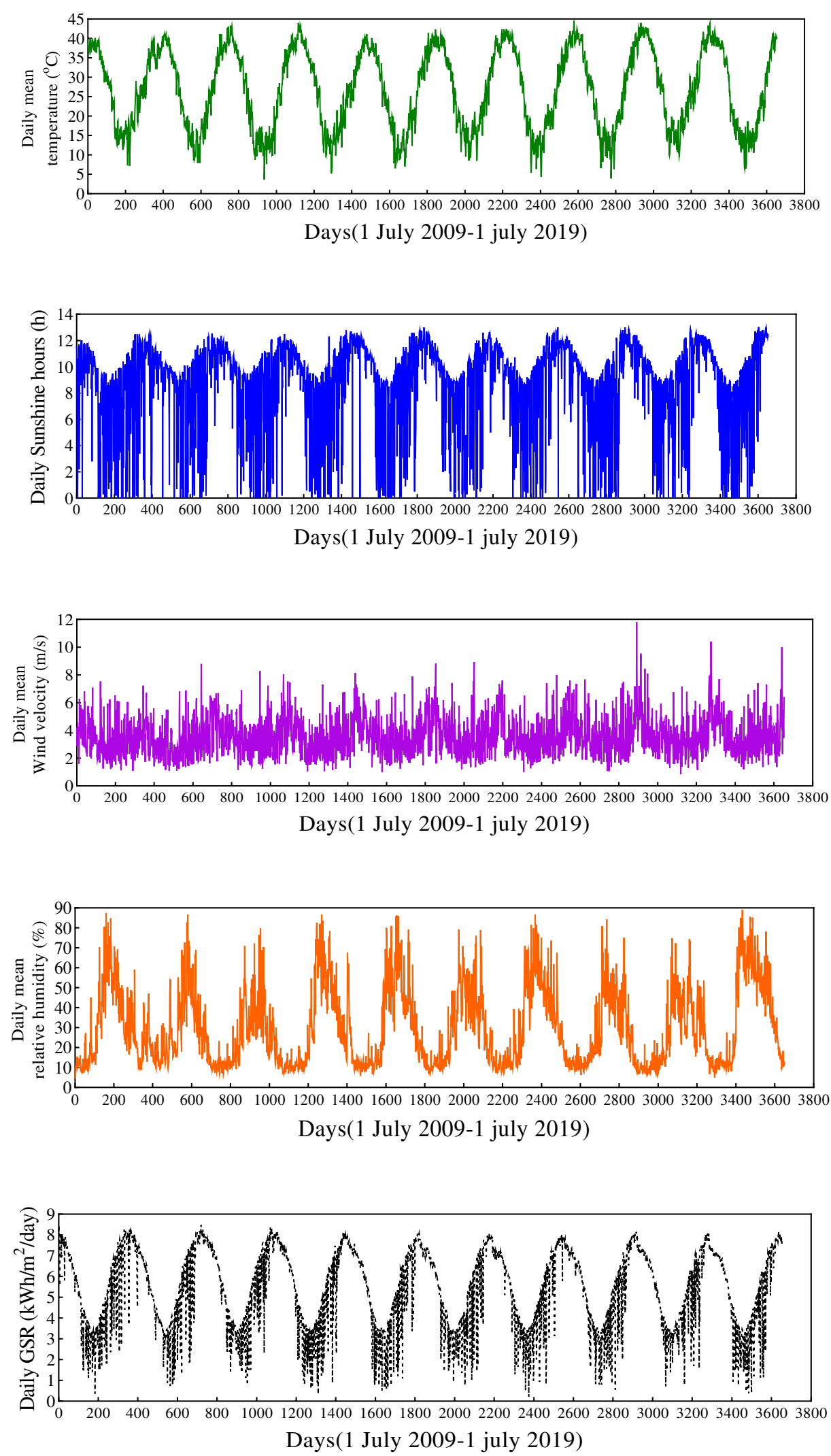

Fig.2. The measured predictive and output variable over 10 years (1 July 2009-1 July 2019) at Ahvaz synoptic station. 

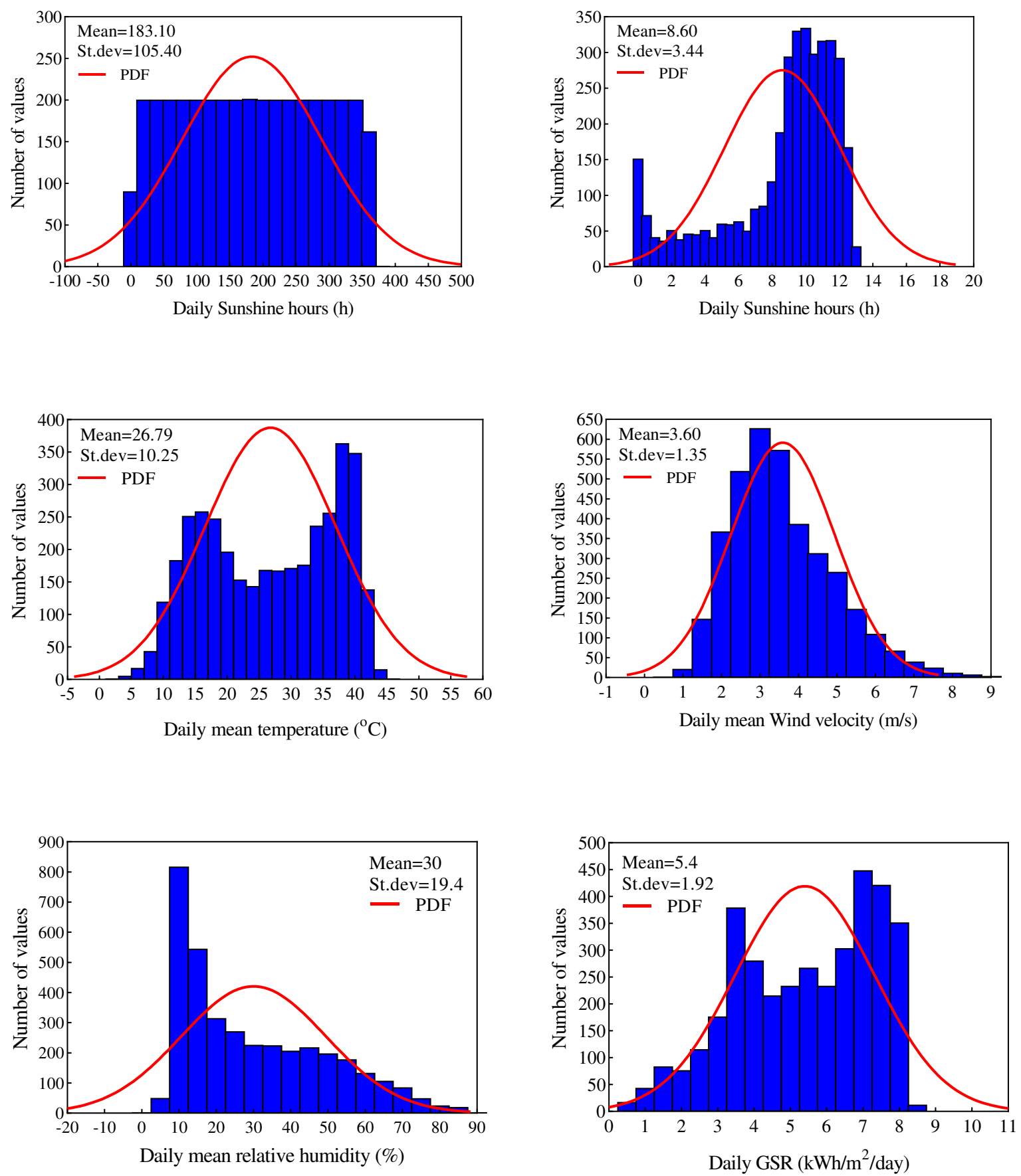

Fig.3. The histogram of the frequency and probability density function of the predictive and objective variable 


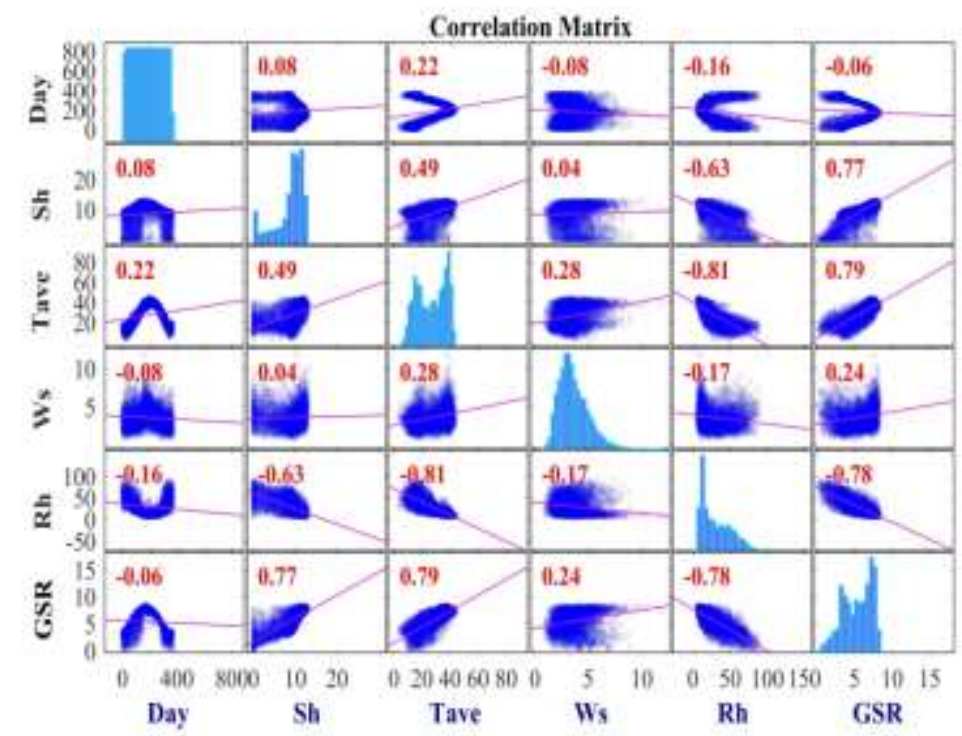

Fig.4. The correlation matrix of the implemented variables

213

214

where $i$ is a randomly chosen integer value from $[1, D] . S_{\min }$ and $S_{\max }$ are the lower and upper bounds of the problem. randn is a random normal distribution number and the (average $=0$ ) and (standard deviation $=1) . \mu$ is an adaptive factor which decreased by the equation $\mu=\mu_{0} \times \exp (-a)$. Based on (Ji et al. 2006), $a=1.01$ and the initial value of $\mu_{0}$ is 1.

(b) Check constraints on the solution $u_{i t, i}$ :

$u_{i t, i}= \begin{cases}S_{\min }+\left(u_{i t, i}-S_{\max }\right) & \text { if } u_{i t, i}>S_{\max } \\ S_{\max }+\left(S_{\min }-u_{i t, i}\right) & \text { if } u_{i t, i}<S_{\min } \\ u_{i t, i} & \text { if } S_{\min } \leq u_{i t, i} \leq S_{\max }\end{cases}$

2. Determine the $\Delta Z^{*}=Z\left(u_{i t, i}\right)-Z^{*}$ and $\Delta Z=Z\left(u_{i t, i}\right)-Z\left(S_{i t, i}\right)$.

3. If $\Delta Z^{*} \leq 0$ set $S_{\text {best }}=u_{i t, i}, Z^{*}=Z\left(S_{\text {best }}\right)$.

4. If $\Delta Z \leq 0$ set $S_{i t+1}=u_{i t, i}$.

5. If $\Delta Z>0$ update the $S_{i}$ with the solution $u$ with probability $\exp \left(-\frac{\Delta Z}{T}\right)$.

end for

Decrease the $T$ utilizing the following equation, 
Stage 3: Presentation of the best solution $S_{\text {best }}$. of the ISA algorithm is displayed in Fig. 5.

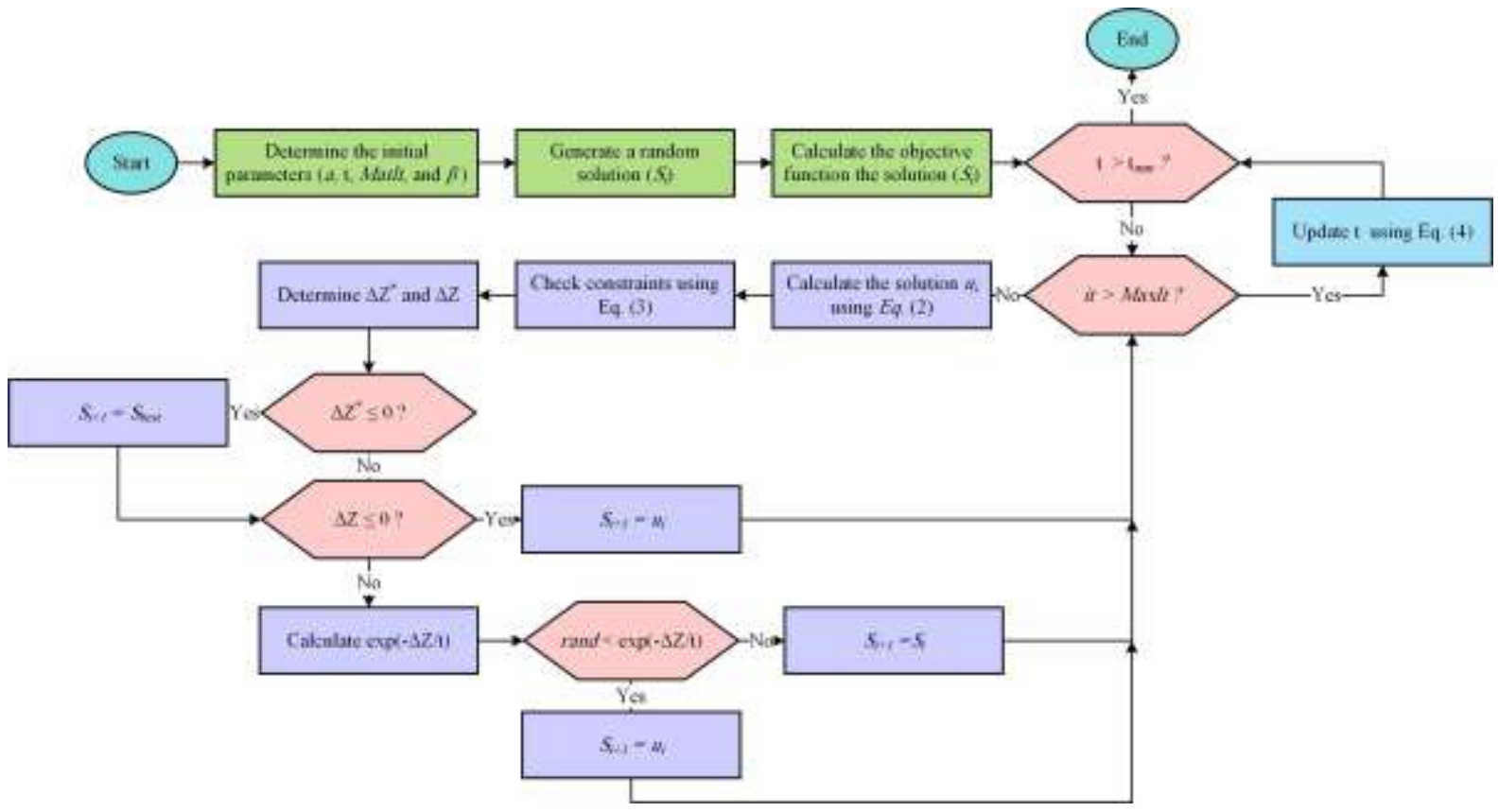

Fig. 5. Flowchart of the ISA algorithm

\subsubsection{Least square support vector machine (LSSVM)}

The LSSVM is a different version of the support vector machine (SVM), which was presented by (Suykens \&Vandewalle 1999). The LSSVM employs a set of linear equations to increase its convergence speed, while the SVM uses a quadratic programming technique for training (Han et al. 2019). The simple structure and high speed of LSSVM convergence make

237 it widely used in regression and classification fields (Han et al. 2019, Zhu et al. 2019). In this model, the training dataset is described by $\left(x_{m}, y_{m}\right), m=1,2, \ldots, M$, where $x_{n}$ and $y_{m}$ are

Minimize $_{\omega, \mathrm{c}, \eta} Z(\omega, \eta)=\frac{1}{2} \omega^{T} \omega+\frac{1}{2} \gamma \sum_{n=1}^{M} \mathrm{p}^{2} \mathrm{ge}_{\mathrm{ge}} \mathbf{1 5}$ of 48 
the input and output dataset. The main formulation of the LSSVM are expressed as:

Subject to:

$y_{m}=\omega^{T} \phi\left(x_{m}\right)+c+\eta_{m}, m=1,2, \ldots, M$

241 where $\omega^{T}$ is the vector of the transposed output layer, $\gamma$ is a penalty parameter, $\eta$ is a

242 regression error, $\phi\left(x_{m}\right)$ is a nonlinear function, $c$ is a bias parameter to be estimated. Using

243 the Lagrange method, the Eqs. (5) and (6) can be defined as,

$L(\omega, c, \eta, \alpha)=Z(\omega, \eta)-\sum_{m=1}^{M} \alpha_{m}\left(\omega^{T} \phi\left(x_{m}\right)+c+\eta_{m}-y_{m}\right)$

244 where $\alpha_{m}$ is Lagrange multiplier. Based on the Karush-Kuhn-Tucker (KKT) conditions, the 245 following solutions are achieved:

$$
\begin{aligned}
& \frac{\partial L}{\partial \omega}=0 \rightarrow \omega=\sum_{m=1}^{M} \alpha_{m} \phi\left(x_{m}\right) \\
& \frac{\partial L}{\partial c}=0 \rightarrow \sum_{m=1}^{M} \alpha_{m}=0 \\
& \frac{\partial L}{\partial \eta_{m}}=0 \rightarrow \alpha_{m}=\gamma \eta_{m} \\
& \frac{\partial L}{\partial \alpha_{m}}=0 \rightarrow \omega^{T} \phi\left(x_{m}\right)+c+\eta_{m}-y_{m}=0
\end{aligned}
$$

$\left[\begin{array}{cc}0 & e_{m}^{T} \\ e_{m} & \text { Kernel }+\gamma^{-1} e\end{array}\right]\left[\begin{array}{l}c \\ \alpha\end{array}\right]=\left[\begin{array}{l}0 \\ y\end{array}\right]$

248 where $e_{m}=[1, \ldots, 1]^{T}, \alpha=\left[\alpha_{1}, \ldots, \alpha_{m}\right]^{T}, y=\left[y_{1}, \ldots, y_{m}\right]^{T}$, and $e$ is the unit matrix. Kernel 249 is the kernel functions, which is expressed as,

$250 \quad K\left(x_{m}, x_{i}\right)=\phi\left(x_{m}\right) \phi\left(x_{i}\right)$

Radial basis functions (RBF) are used as the kernel function in this research, which is defined as: 
$K\left(x_{m}, x_{i}\right)=\exp \left(\frac{-|| x_{m}, x_{i}||}{\delta^{2}}\right)$

where $\delta$ is a constant parameter, which is determined by the ISA algorithm.

In this paper, the ISA algorithm was employed for the optimization of the LSSVM parameters (i.e., $\delta$ and $\gamma$ ). The proposed method is called LSSVM-ISA. Fig. 6 demonstrates the flowchart of the LSSVM-ISA algorithm.

7

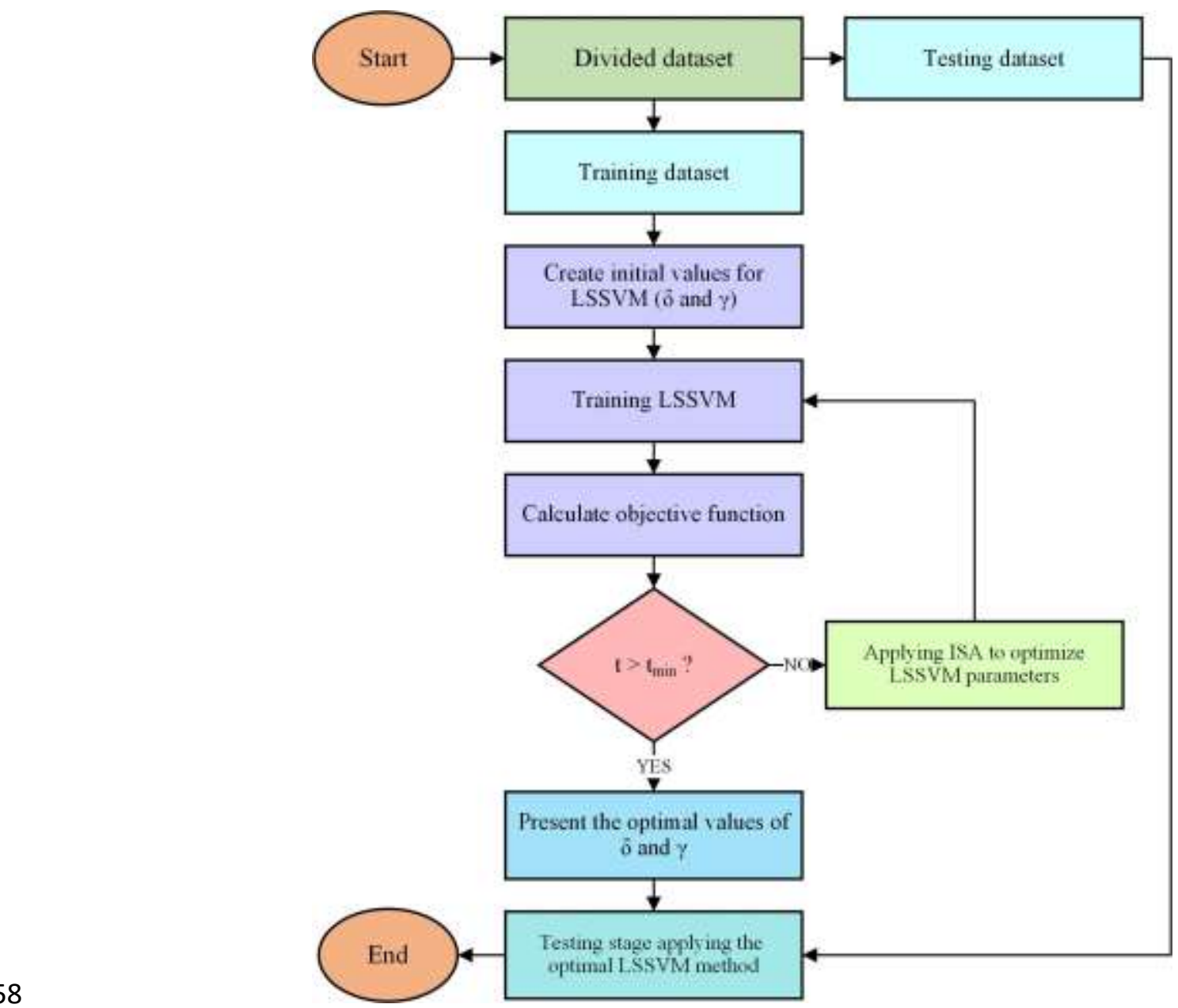

Fig. 6. Flowchart of the LSSVM-ISA method

\subsubsection{Multivariate adaptive regression spline (MARS)}

Multivariate adaptive regression spline (MARS) scheme, as a nonlinear and nonparametric statistical regression model, is one of the most popular machine learning models, which was first introduced by Friedman (1991) (Friedman 1991). The MARS model 
automatically is capable of mapping the intrinsic nonlinearities and interactions between

265

266

267

268

269

270

271

272

273

275

276

$$
Y=f(x)=\beta_{0}+\sum_{i=1}^{N^{*}} \beta_{i} \prod_{j=1}^{K} B_{F j i}\left(x_{v(j i)}\right)
$$
follows: predictors in data without an assumption about the relationships between dependent and predictor variables to predict continuous objective variables accurately (Leathwick et al. 2005). The main concept of MARS is splitting the predictor training data into several piecewise linear disjoint regions (or splines) by specific connection points (called 'knots'). Generally, the MARS model can adequately result in the flexible continuous modeling by fitting piecewise linear regression belong to each segment (spline) and predicting the linear and nonlinear objective (Friedman 1991, Friedman \&Roosen 1995). Splines, which are known as the basis functions (BFs) by the smoothing process connection point, are capable of capturing the nonlinearities, curvatures, and threshold features based on the piecewise linear functions. MARS model involves two-step forward and backward pruning iterative procedures. During the stepwise forward process, the BFs were selected, and the location of potential knots was explored by an adaptive regression algorithm, which mostly leads to a very complex and over-fitted model (Zhang \&Goh 2016, Zheng et al. 2020). Mathematically, the MARS model can explain the relationship between predictors and output variable as

where $Y$ is objective variable; $\beta_{0}$ is the intercept term; $\beta_{n}$ is the coefficient vector of $\mathrm{i}^{\text {th }}$ spline basis functions; $B_{F j i}$ is basis function; $x_{v(j i)}$ is the independent predictor of $\mathrm{i}^{\text {th }}$ and $\mathrm{j}^{\text {th }}$ products; $K$ is the order of interaction limit, and $N^{*}$ is the number of independent predictors. The piecewise linear basis functions implemented in the MARS model are generally expressed as (Mohanta \&Patra 2019):

$B_{F j i}{ }^{+}=\left(x-s_{j i}\right)_{+}=\left\{\begin{array}{cc}x-s_{j i} & x>s_{j i} \\ 0 & \text { therwise }\end{array}\right.$ 
$B_{F j i}{ }^{-}=\left(s_{j i}-x\right)_{+}=\left\{\begin{array}{cc}s_{j i}-x & x<s_{j i} \\ 0 & \text { therwise }\end{array}\right.$

285

292

293

where $B_{F j i}{ }^{+}$and $B_{F j i}{ }^{-}$are the positive and negative parts of spline functions, respectively, and $s_{j i}$ denotes the knot of the spline (threshold value).

Likewise, in the backward stepwise process, the redundant BFs provided among the previous process were eliminated by implementing the generalized cross-validation (GCV) technique until the 'lack of fit' criterion is a minimum and forecasting accuracy enhancement (Wang et al. 2020). The GCV value is given as follows (Mohanta \&Patra 2019, Zheng et al. 2020):

$$
G C V E=\frac{\sum_{j=1}^{N}\left(Y_{i}-\boldsymbol{\Psi}_{i}^{\mathbf{4}}\right)^{2}}{N\left(1-\frac{F+0.5 d^{*}(F-1)}{N}\right)^{2}}
$$

where $Y_{i}$ is the observed value of output variable of $\mathrm{i}^{\text {th }} ; \boldsymbol{\mu}_{i}^{\mathrm{t}}$ is $\mathrm{i}^{\text {th }}$ predicted value by MARS; $\mathrm{N}$ $=$ number of datasets; $\mathrm{F}$ is the number of basis functions and $d^{*}$ is a penalty value for each basis function comprised into the developed model.

\subsubsection{Generalization regression neural network (GRNN)}

Generalized regression neural network (GRNN), as a probabilistic-based neural network, was firstly proposed by Specht (1991) (Specht 1991). GRNN model based on the nonparametric kernel regression network has been widely implemented in the field of classification and regression. It is adequately capable of handling the nonlinear fitting problems with large-scale training samples. Unlike the backpropagation and radial basis function ANN, GRNN has fewer adjustment parameters, and its learning algorithm rarely falls into the local minimum (Yu 2020). GRNN has four-layer comprising the input layer, radial layer, regression layer, and an output layer. The architecture of a GRNN model consists of precisely four layers, with a pattern (radial neurons) layer and a summation 
(regression) layer placed between the input and output layers (Ramsami \&Oree 2015), as it has been illustrated in Fig. 7. The pattern layer contains the clustering of the input data in the training stage, and consequently, the neurons number in that is exactly equal to the number of data samples. Furthermore, the summation layer always has a new neuron in comparison with the output layer, which is devoted to calculating the probability density function whereas rests of neurons are used for output calculation. Eventually, GRNN du to directly selecting an approximate function between predictors and output variables spends less time than other ANNs (Ramsami \&Oree 2015).

\subsubsection{Multivariate linear regression with interactions (MLRI)}

The multivariate linear regression with interactions (MLRIs) is an efficient data-driven model that can obtain a regression by considering the interaction between the predictors $\left(x_{i}\right)$ on the independent variable (outcome) (Coulton \&Chow 1993, Jaccard et al. 2003). An interaction effect happens when a predictor has a different impact on the dependent output variable, depending on the values of another predictor. MLRI can capture the regression relationship considering some interactions between a dependent variable (Y) and independent variables $\left(x_{i}\right)$ by the following logic (Coulton \&Chow 1993, Jaccard et al. 2003):

$$
Y=\theta_{i 0}+\sum_{i=1}^{K} \theta_{i} x_{i}+\sum_{i=1}^{K} \sum_{j=1, j \neq i}^{K} \theta_{i j} x_{i} x_{j}+\varepsilon
$$

where $\theta_{i j}$ is the interaction coefficient; $\varepsilon$ is a random error; and $i, j$ are the index of two considering predictors.

In the framework of the MLRI model, the significance of the interaction effect specifies using analysis of variance (ANOVA). In this process, the p-value or probability value indicates the importance of each integration term in regression by $\alpha=0.05$, as a criterion, which lower values of $p$-values or its corresponding $F$-values show it is the more 
statistically significant. Whenever the $p$-values of each interaction term become less that $\alpha$, that interaction term will be preserved in outcome correlation $(\mathrm{Y})$ and vice versa.

Figure 7 illustrated the flowchart of the proposed procedure and a brief algorithm of each data-driven approaches used in the daily GSR forecasting process is shown in Fig.7

\subsection{Performance evaluation}

To measure the degree of accuracy of the provided models, various visual efficient tools and statistical performance metrics were employed. The graphical tools include scattering plots, error analysis plots, and Taylor diagrams. Taylor diagram is employed for comparing the similarity patterns in polar space between predicted and observed values of GSR as the robust graphical tool. Basically, the Taylor diagram simultaneously demonstrates the correlation coefficient $(R)$, standard deviation $\left(S_{d}\right)$, and centered root mean square error (cRMSE)

(Taylor 2001). The performance criteria consist of the correlation coefficient (R), mean root square error (RMSE), mean absolute percentage error (MAPE), and Nash-Sutcliffe coefficient (NS) (Nash \&Sutcliffe 1970) which are expressed as following relationships:

$$
\begin{aligned}
& R=\frac{\sum_{i=1}^{N}\left(G S R_{p, i}-\overline{G S R}_{p}\right) \cdot\left(G S R_{o, i}-\overline{G S R}_{o}\right)}{\sqrt{\sum_{i=1}^{N}\left(G S R_{p, i}-\overline{G S R}_{p}\right)^{2} \sum_{i}^{N}\left(G S R_{o, i}-\overline{G S R}_{o}\right)^{2}}} \\
& R M S E=\left(\frac{1}{N} \sum_{i=1}^{N}\left(G S R_{\mathrm{o}, \mathrm{i}}-G S R_{\mathrm{p}, \mathrm{i}}\right)^{2}\right)^{0.5} \\
& M A P E=\left(\frac{100}{N}\right) \sum_{i=1}^{N}\left|\frac{\mathrm{GSR}_{\mathrm{o}, \mathrm{i}}-\mathrm{GSR}_{\mathrm{p}, \mathrm{i}}}{\mathrm{GSR}_{\mathrm{o}, \mathrm{i}}}\right| \\
& N S=1-\frac{\sum_{i=1}^{N}\left(\mathrm{GSR}_{\mathrm{o}, \mathrm{i}}-\mathrm{GSR}_{\mathrm{p}, \mathrm{i}}\right)^{2}}{\sum_{i=1}^{N}\left(\mathrm{GSR}_{\mathrm{o}, \mathrm{i}}-\overline{G S R}_{\mathrm{o}}\right)^{2}} \\
& c R M S E=\left(\frac{1}{N} \sum_{i=1}^{N}\left[\left(G S R_{\mathrm{o}, \mathrm{i}}-\overline{G S R}_{\mathrm{o}}\right)-\left(G S R_{p, i}-\overline{G S R}_{\mathrm{p}}\right)\right]^{2},\right.
\end{aligned}
$$




$$
S_{d o}=\frac{1}{\mathrm{~N}} \sum_{\mathrm{i}=1}^{\mathrm{N}}\left(G S R_{\mathrm{o}, \mathrm{i}} \overline{G S R_{\mathrm{o}}}\right)^{2}, \quad S_{d p}=\frac{1}{\mathrm{~N}} \sum_{\mathrm{i}=1}^{\mathrm{N}}\left(G S R_{p, i}-\overline{G S R_{\mathrm{p}}}\right)^{2}
$$

where $\mathrm{GSR}_{\mathrm{o}, \mathrm{i}}$ is the $i^{\text {th }}$ observed daily global solar radiation, $\mathrm{GSR}_{\mathrm{p}, \mathrm{i}}$ is the $i^{\text {th }}$ predicted daily global solar radiation, $\overline{G S R_{\mathrm{o}}}$ is mean value of the $i^{\text {th }}$ observed daily global solar radiation, $\overline{G S R_{\mathrm{p}}}$ is mean value of the $\mathrm{i}^{\text {th }}$ predicted daily global solar radiation, and $N$ is the number of datasets.

\section{Result and discussion}

For the development of predictive models, the employed influential input parameters at Ahvaz station include the day of the year [1 365] (366 for leap year), daily sunshine hours $\left(\mathrm{S}_{\mathrm{h}}\right)$, mean daily air temperature $\left(\mathrm{T}_{\mathrm{ave}}\right)$, mean daily wind velocity $\left(\mathrm{W}_{\mathrm{s}}\right)$, daily relative humidity $\left(\mathrm{R}_{\mathrm{h}}\right)$, and the daily global solar radiation (GSR) was considered as subjective models. In this study, a novel robust data-driven model, namely the LSSVM, together with improved simulated annealing (ISA) approach (LSSVM-ISA), is provided to predict the global solar radiation (GSR) accurately. Three other AI-based models validate the proposed method, namely MARS, GRNN, and MLRI.

To measure the best combination of predictor variables, a combination consists of all influential variables plus five combinations obtained by successively excluding the influence of each predictor were examined for each predictive model by four metrics consist of the R, RMSE, MAPE, and NS. The best possible accuracy of the forecasted datasets could be achieved when $\mathrm{R}=1$, RMSE $=0$, MAPE $<10 \%$, and $\mathrm{NS}=1$. According to the results of the first six combinations, the day and daily sunshine hours were utilized continuously for constructing other combinations due to having a significant impact on the results. According to the above explanations, a total of 10 combinations were examined for each data-driven model. 


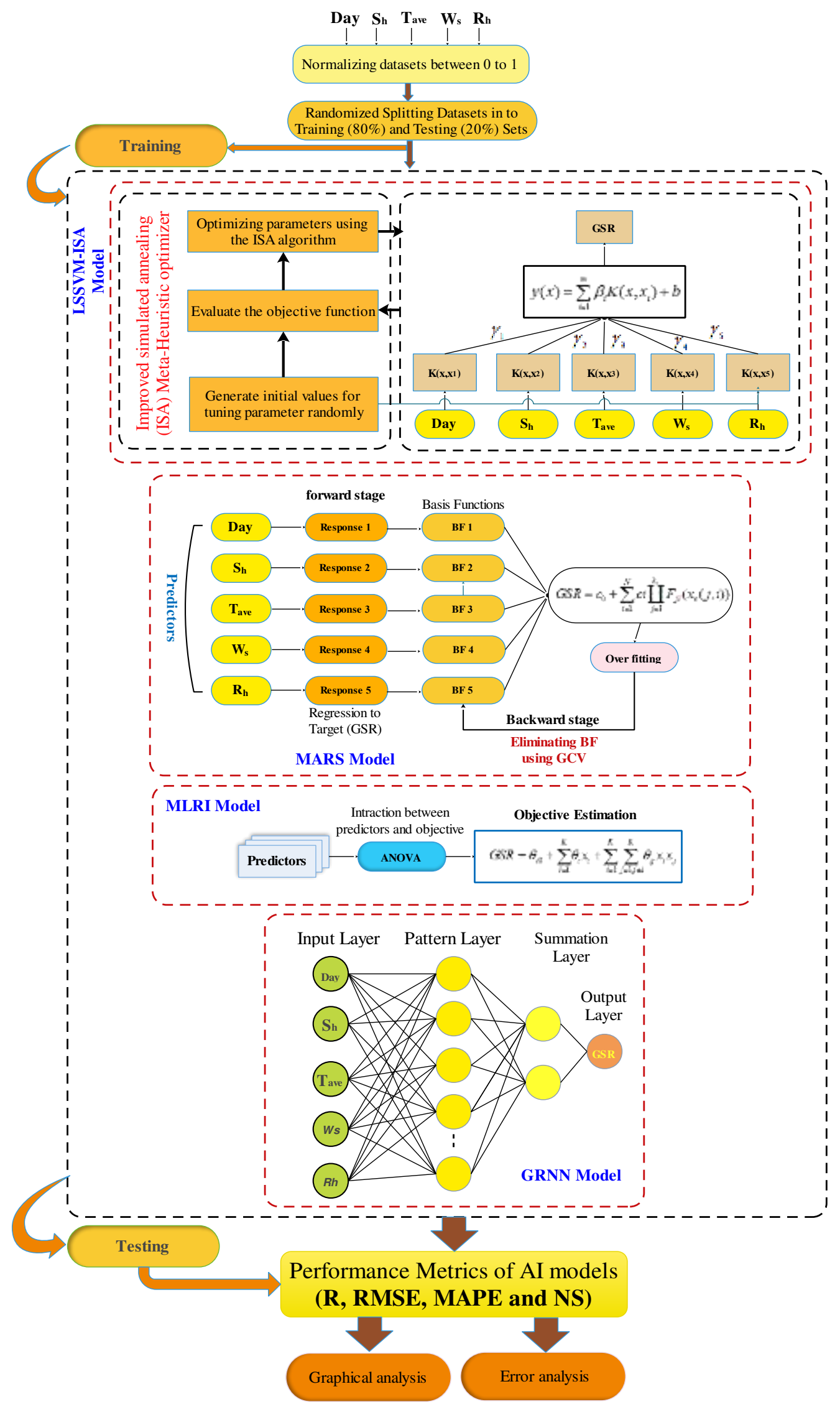

Fig. 7. The flowchart of data-driven models to forecast the daily GSR 
367 in Table 4, we can recognize that the LSSVM-ISA model with the combination of five factors

368 consists of day, $S_{h}, T_{a v e}$, and $R_{h}$ has revealed the best performance in forecasting the daily

369 GSR with the highest $R$ (0.973 and 0.980) and NS (0.947 and 0.957), and lowest RMSE

$370\left(0.442\right.$ and $0.391 \mathrm{Kw}-\mathrm{h} / \mathrm{m}^{2} /$ day $)$ and $\operatorname{MAPE}(8.171 \%$ and $8.233 \%)$ for training and testing

371 modes.

Table 3. Performance of the forecasting skills of the LSSVM-ISA model with various input variables over the training and testing phase.

\begin{tabular}{|c|c|c|c|c|c|c|c|c|c|}
\hline \multirow{2}{*}{ Model } & \multirow{2}{*}{ inputs } & \multicolumn{4}{|c|}{ Train } & \multicolumn{4}{|c|}{ Test } \\
\hline & & $\overline{\mathrm{R}}$ & RMSE & MAPE\% & NS & $\bar{R}$ & RMSE & MAPE\% & $\overline{\mathrm{NS}}$ \\
\hline 1 & $\overline{\text { All }}$ & 0.973 & 0.446 & 8.246 & 0.946 & 0.978 & 0.399 & 8.429 & 0.955 \\
\hline 2 & All-day & 0.940 & 0.659 & 12.639 & 0.883 & 0.935 & 0.687 & 14.055 & 0.866 \\
\hline 3 & All-S $S_{h}$ & 0.930 & 0.710 & 14.481 & 0.864 & 0.935 & 0.672 & 14.687 & 0.872 \\
\hline 4 & All-T & 0.973 & 0.445 & 8.194 & 0.947 & 0.978 & 0.414 & 8.466 & 0.951 \\
\hline 5 & All-W $\mathrm{S}_{\mathrm{s}}$ & 0.973 & 0.442 & 8.171 & 0.947 & 0.980 & 0.391 & 8.233 & 0.957 \\
\hline 6 & All- $R_{h}$ & 0.971 & 0.464 & 8.621 & 0.942 & 0.976 & 0.421 & 9.103 & 0.950 \\
\hline 7 & All-T-W & 0.975 & 0.431 & 7.942 & 0.950 & 0.977 & 0.420 & 8.682 & 0.950 \\
\hline 8 & All-T-R $\mathrm{R}_{\mathrm{h}}$ & 0.971 & 0.458 & 8.493 & 0.944 & 0.974 & 0.445 & 9.435 & 0.944 \\
\hline 9 & All- $\mathrm{W}_{\mathrm{s}}-\mathrm{R}_{\mathrm{h}}$ & 0.972 & 0.449 & 8.311 & 0.946 & 0.976 & 0.425 & 9.085 & 0.949 \\
\hline 10 & All- $W_{s}-R_{h}-T$ & 0.972 & 0.453 & 8.647 & 0.945 & 0.976 & 0.431 & 9.381 & 0.947 \\
\hline$\overline{\text { Optimum }}$ & All-W & 0.973 & 0.442 & 8.171 & 0.947 & 0.980 & 0.391 & 8.233 & 0.957 \\
\hline
\end{tabular}

372 parameters $(\lambda, \sigma)$ are optimized for each combination by improved simulated annealing (ISA), which are tabulated in Table 4. In the current work, an open MATLAB toolbox

376 ARESLab was utilized to develop the MARS model. In order to verify the robustness and

377 efficiency of the MARS performance model, 10-fold cross-validation was considered. In 378 order to provide the MARS model, the maximum number of basis functions in the forward building stage was selected between 15 to 30 numbers by a trial and error procedure, which 

eliminated. Table 5 shows the adjustment parameters of the MARS model.

Table 4. The tuning parameters of LSSVM for each combination (Note: $\sigma=$ kernel width; $\gamma=$ loss-function parameter)

\begin{tabular}{ccrr}
\hline Model & inputs & \multicolumn{2}{c}{ LSSVM-ISA } \\
\hline & & \multicolumn{1}{c}{$\sigma$} & \multicolumn{1}{c}{$\gamma$} \\
\cline { 3 - 4 } 1 & & & \\
2 & All & 25.459 & 577.538 \\
3 & All-day & 1.523 & 2.700 \\
4 & All- $\mathrm{S}_{\mathrm{h}}$ & 2.993 & 4.819 \\
5 & All-T & 8.697 & 272.880 \\
6 & All- $\mathrm{W}_{\mathrm{s}}$ & 4.579 & 16.475 \\
7 & All- $\mathrm{R}_{\mathrm{h}}$ & 8.243 & 68.488 \\
8 & All-T-W & 0.995 & 4.497 \\
9 & All-T- $\mathrm{R}_{\mathrm{h}}$ & 1.574 & 9.171 \\
10 & All- $\mathrm{W}_{\mathrm{s}}-\mathrm{R}_{\mathrm{h}}$ & 1.173 & 6.998 \\
& All- $\mathrm{W}_{\mathrm{s}}-\mathrm{R}_{\mathrm{h}}-\mathrm{T}$ & 0.227 & 1.025 \\
\hline
\end{tabular}

Table 5. Setting parameter of the MARS model for forecasting GSR

\begin{tabular}{cc}
\hline Parameter & value \\
\hline Maximum basis Functions & $15-30$ \\
Maximum Self Interactions & 0 \\
Maximum degree of interactions & $2-3$ \\
Threshold & 0 \\
Prune & Yes \\
\hline
\end{tabular}

387 the combination of 7 comprising day, $S_{h}$ and $R_{h}$ outperformed the other combinations in 388 terms of $R(0.968$ and 0.974$), R M S E\left(0.485\right.$ and $\left.0.426 \mathrm{Kw}-\mathrm{h} / \mathrm{m}^{2} / \mathrm{day}\right), M A P E(9.596 \%$ and 
Table 6. Performance of the forecasting skills of the MARS model with various input variables over the training and testing phase.

\begin{tabular}{|c|c|c|c|c|c|c|c|c|c|}
\hline \multirow{3}{*}{ Model } & \multirow{3}{*}{ inputs } & \multirow{2}{*}{\multicolumn{4}{|c|}{ Train }} & & & & \\
\hline & & & & & & \multicolumn{4}{|c|}{ Test } \\
\hline & & $\mathrm{R}$ & RMSE & MAPE\% & $\mathrm{NS}$ & $\mathrm{R}$ & RMSE & MAPE\% & $\mathrm{NS}$ \\
\hline 1 & All & 0.968 & 0.487 & 9.480 & 0.936 & 0.973 & 0.433 & 9.409 & 0.947 \\
\hline 2 & All-day & 0.928 & 0.717 & 14.118 & 0.862 & 0.930 & 0.692 & 14.109 & 0.864 \\
\hline 3 & All-S $S_{\mathrm{h}}$ & 0.920 & 0.754 & 15.908 & 0.847 & 0.930 & 0.691 & 15.011 & 0.865 \\
\hline 4 & All- $T_{\text {ave }}$ & 0.968 & 0.485 & 9.596 & 0.937 & 0.974 & 0.426 & 9.003 & 0.948 \\
\hline 5 & All- $W_{\mathrm{s}}$ & 0.968 & 0.487 & 9.490 & 0.936 & 0.973 & 0.433 & 9.409 & 0.947 \\
\hline 6 & All- $R_{h}$ & 0.967 & 0.489 & 9.563 & 0.936 & 0.972 & 0.444 & 9.916 & 0.944 \\
\hline 7 & All- $\mathrm{T}_{\text {ave }}-\mathrm{W}_{\mathrm{s}}$ & 0.968 & 0.485 & 9.596 & 0.937 & 0.974 & 0.426 & 9.003 & 0.948 \\
\hline 8 & All- $T_{\text {ave }}-R_{h}$ & 0.968 & 0.485 & 9.505 & 0.937 & 0.972 & 0.444 & 9.923 & 0.944 \\
\hline 9 & All- $\mathrm{W}_{\mathrm{s}}-\mathrm{R}_{\mathrm{h}}$ & 0.967 & 0.489 & 9.563 & 0.936 & 0.972 & 0.444 & 9.916 & 0.944 \\
\hline 10 & All- $\mathrm{W}_{\mathrm{s}}-\mathrm{R}_{\mathrm{h}}-\mathrm{T}_{\text {ave }}$ & 0.968 & 0.485 & 9.505 & 0.937 & 0.972 & 0.444 & 9.923 & 0.944 \\
\hline Optimum & All- $\mathrm{T}_{\text {ave }}-\mathrm{W}_{\mathrm{s}}$ & 0.968 & 0.485 & 9.596 & 0.937 & 0.974 & 0.426 & 9.003 & 0.948 \\
\hline
\end{tabular}

The corresponding basis functions $\mathrm{B}_{\mathrm{F}, \mathrm{i}}$ and the coefficients $\beta_{i}$ of the MARS model for the optimum combination (No.7) are listed in Table 7.

In the GRNN model, the most significant criterion is the spread values that were obtained by a trial and error process for each combination. The spread values for each combination are summarized in Table 8.

The statistical metrics obtained from the GRNN model to predict the daily GSR are tabulated in Table 9. In the GRNN model, the combination (No.10) including day and $\mathrm{S}_{\mathrm{h}}$ provided more precise results in terms of $\mathrm{R}(0.964$ and 0.971$)$ and RMSE $(0.526$ and $0.469 \mathrm{Kw}-$ $\mathrm{h} / \mathrm{m}^{2} /$ day), MAPE (11.042\% and $\left.11.384 \%\right)$ and NS (0.926 and 0.938) in training and testing phases, respectively than the other combinations in assessing the daily GSR. 
Table 7. Basis functions and coefficients obtained to forecast the daily GSR in the optimum combination (Day, $\mathrm{S}_{\mathrm{h}}, \mathrm{R}_{\mathrm{h}}$ ) using the MARS model

\begin{tabular}{ccc}
\hline Basic function & Equation & Coefficient $\beta_{i}$ \\
\hline intercept & $\mathrm{B}_{\mathrm{F} 1}=\max (0, \mathrm{Day}-181)$ & 8.3675 \\
$B_{1}(x)$ & $B_{\mathrm{F} 2}=\max (0,181-$ Day $)$ & -0.028177 \\
$B_{2}(x)$ & $\mathrm{B}_{\mathrm{F} 3}=\max \left(0, \mathrm{~S}_{\mathrm{h}}-10.8\right)$ & -0.023802 \\
$B_{3}(x)$ & $\mathrm{B}_{\mathrm{F} 4}=\max \left(0,10.8-\mathrm{S}_{\mathrm{h}}\right)$ & -0.36892 \\
$B_{4}(x)$ & $\mathrm{B}_{\mathrm{F} 5}=\mathrm{B}_{\mathrm{F} 2} \times \max \left(0, \mathrm{R}_{\mathrm{h}}-31.23\right)$ & -0.78284 \\
$B_{5}(x)$ & $\mathrm{B}_{\mathrm{F} 6}=\mathrm{B}_{\mathrm{F} 2} \times \max \left(0,31.23-\mathrm{R}_{\mathrm{h}}\right)$ & 0.00022022 \\
$B_{6}(x)$ & $\mathrm{B}_{\mathrm{F} 7}=\mathrm{B}_{\mathrm{F} 4} \times \max \left(0, \mathrm{R}_{\mathrm{h}}-25.41\right)$ & -0.0014453 \\
$B_{7}(x)$ & $\mathrm{B}_{\mathrm{F} 8}=\mathrm{B}_{\mathrm{F} 4} \times \max \left(0,25.41-\mathrm{R}_{\mathrm{h}}\right)$ & 0.0086739 \\
$B_{8}(x)$ & $\mathrm{B}_{\mathrm{F} 9}=\mathrm{B}_{\mathrm{F} 4} \times \max (0,317-$ Day $)$ & 0.0026546 \\
$B_{9}(x)$ & $\mathrm{B}_{\mathrm{F} 10}=\mathrm{B}_{\mathrm{F} 3} \max (0$, Day -196$)$ & 0.014655 \\
$B_{10}(x)$ & $\mathrm{B}_{\mathrm{F} 11}=\mathrm{B}_{\mathrm{F} 3} \times \max (0,196-\mathrm{Day})$ & 0.0079019 \\
$B_{11}(x)$ & $\mathrm{B}_{\mathrm{F} 12}=\mathrm{B}_{\mathrm{F} 4} \times \max (0$, Day -133$)$ & 0.0030269 \\
$B_{12}(x)$ & $\mathrm{B}_{\mathrm{F} 13}=\mathrm{B}_{\mathrm{F} 4} \times \max (0,133-$ Day $)$ & -0.0017473 \\
$B_{12}(x)$ & &
\end{tabular}

406

407

408

409

410

411

412

413

414

415

416

417

418 
Table 8. The Spread values of GRNN for each combination

\begin{tabular}{cccccc}
\hline Inputs Combination & All & All-day & All- $\mathrm{S}_{\mathrm{h}}$ & All-T & All-Ws \\
Spread value & 0.1 & 0.05 & 0.05 & 0.05 & 0.05 \\
\cline { 2 - 6 } Inputs Combination & All- $\mathrm{R}_{\mathrm{h}}$ & All-T-W & All-T- $\mathrm{R}_{\mathrm{h}}$ & All-W $_{\mathrm{s}}-\mathrm{R}_{\mathrm{h}}$ & All-W $_{\mathrm{s}}-\mathrm{R}_{\mathrm{h}}-\mathrm{T}$ \\
Spread value & 0.05 & 0.05 & 0.05 & 0.05 & 0.05 \\
\hline
\end{tabular}

Table 9. Performance of the forecasting skills of the GRNN model with various input variables over the training and testing phase.

\begin{tabular}{|c|c|c|c|c|c|c|c|c|c|}
\hline \multirow{3}{*}{ Model } & \multirow{3}{*}{ inputs } & \multirow{2}{*}{\multicolumn{4}{|c|}{ Train }} & \multirow{2}{*}{\multicolumn{4}{|c|}{ Test }} \\
\hline & & & & & & & & & \\
\hline & & $\overline{\mathrm{R}}$ & RMSE & MAPE\% & $\overline{N S}$ & $\overline{\mathrm{R}}$ & RMSE & MAPE\% & NS \\
\hline 1 & $\overline{\text { All }}$ & 0.974 & 0.436 & 8.652 & 0.949 & 0.967 & 0.495 & 10.792 & 0.931 \\
\hline 2 & All-day & 0.967 & 0.494 & 8.543 & 0.934 & 0.927 & 0.724 & 14.443 & 0.851 \\
\hline 3 & All-S $S_{h}$ & 0.948 & 0.615 & 11.790 & 0.898 & 0.917 & 0.752 & 16.142 & 0.840 \\
\hline 4 & All-T & 0.990 & 0.275 & 4.992 & 0.980 & 0.967 & 0.484 & 9.781 & 0.933 \\
\hline 5 & All- $W_{\mathrm{s}}$ & 0.985 & 0.329 & 6.001 & 0.971 & 0.970 & 0.471 & 9.740 & 0.937 \\
\hline 6 & All- $R_{h}$ & 0.986 & 0.322 & 6.116 & 0.972 & 0.970 & 0.474 & 10.239 & 0.936 \\
\hline 7 & All-T-W & 0.965 & 0.511 & 10.518 & 0.930 & 0.966 & 0.488 & 10.714 & 0.933 \\
\hline 8 & All-T- $R_{h}$ & 0.966 & 0.515 & 10.832 & 0.929 & 0.970 & 0.477 & 11.384 & 0.935 \\
\hline 9 & All- $\mathrm{W}_{\mathrm{s}}-\mathrm{R}_{\mathrm{h}}$ & 0.965 & 0.510 & 10.338 & 0.930 & 0.970 & 0.481 & 11.289 & 0.934 \\
\hline 10 & All- $W_{\mathrm{s}}-\mathrm{R}_{\mathrm{h}}-\mathrm{T}$ & 0.964 & 0.526 & 11.042 & 0.926 & 0.971 & 0.469 & 11.384 & 0.938 \\
\hline$\overline{\text { Optimum }}$ & All- $\mathrm{W}_{\mathrm{s}}-\mathrm{R}_{\mathrm{h}}-\mathrm{T}$ & 0.964 & 0.526 & 11.042 & 0.926 & 0.971 & 0.469 & 11.384 & 0.938 \\
\hline
\end{tabular}

423 for ten input combinations. As mentioned before, in the MLRI method, based on the number

424 of predictor parameters and how they interact, the relevant analysis of variance (ANOVA) is 425 performed for each combination. Assessments of 10 combination schemes are given in Table 426 10. The statistical analysis demonstrates that in the MLRI model, the combination (No.6) 427 consists of all predictors excluding the relative humidity $\left(\mathrm{R}_{\mathrm{h}}\right)$ achieved the best prediction by 428 the highest R (0.945 and 0.958) and NS (0.892 and 0.902) in training and testing stages, 429 respectively. The ANOVA associated with the optimum combination (No.6) is given in Table 
431 than other terms and can be eliminated from the forecasting process of daily GSR. Similarly,

432 while the concept of this model is based on the linear dependence between predictors and

433 target, so the average daily temperature $\left(\mathrm{T}_{\mathrm{ave}}\right)$ and sunshine hours $\left(\mathrm{S}_{\mathrm{h}}\right)$ with highest Pearson

434 correlation coefficients $\left(r_{p}=0.79\right.$ and 0.77 , respectively) have the most influence on obtained

435 correlation as below equation:

$$
\begin{aligned}
& G S R=-2.1812+0.0053131 \text { Day }+0.36946 \mathrm{~S}_{\mathrm{h}}+0.25816 T_{\text {ave }}+0.090826 W_{s} \\
& -0.0002626 \text { Day } \times \mathrm{S}_{\mathrm{h}}-0.00039114 \mathrm{Day} \times T_{\text {ave }}-0.0049445 \mathrm{~S}_{\mathrm{h}} \times T_{\text {ave }}-0.00017948 D a y \times W_{s}+ \\
& 0.022838 \mathrm{~S}_{\mathrm{h}} \times W_{s}-0.0072242 T_{\text {ave }} \times W_{s}
\end{aligned}
$$

\begin{tabular}{|c|c|c|c|c|c|c|c|c|c|}
\hline \multirow{3}{*}{ Model } & \multirow{3}{*}{ inputs } & \multirow{2}{*}{\multicolumn{4}{|c|}{ Train }} & \multirow{2}{*}{\multicolumn{4}{|c|}{ Test }} \\
\hline & & & & & & & & & \\
\hline & & $\overline{\mathrm{R}}$ & RMSE & MAPE\% & $\overline{\mathrm{NS}}$ & $\overline{\mathrm{R}}$ & RMSE & MAPE\% & NS \\
\hline 1 & $\overline{\text { All }}$ & 0.949 & 0.612 & 11.231 & 0.899 & 0.956 & 0.584 & 11.567 & 0.903 \\
\hline 2 & All-day & 0.911 & 0.796 & 15.209 & 0.829 & 0.919 & 0.772 & 15.525 & 0.831 \\
\hline 3 & All- $S_{h}$ & 0.883 & 0.918 & 19.692 & 0.773 & 0.883 & 0.902 & 19.784 & 0.769 \\
\hline 4 & All-T & 0.901 & 0.841 & 15.087 & 0.810 & 0.899 & 0.849 & 15.360 & 0.796 \\
\hline 5 & All-W $\mathrm{W}_{\mathrm{s}}$ & 0.947 & 0.625 & 11.435 & 0.895 & 0.955 & 0.599 & 12.080 & 0.898 \\
\hline 6 & All- $R_{h}$ & 0.945 & 0.634 & 11.585 & 0.892 & 0.958 & 0.587 & 12.706 & 0.902 \\
\hline 7 & All-T-W $\mathrm{W}_{\mathrm{s}}$ & 0.896 & 0.861 & 15.323 & 0.801 & 0.895 & 0.867 & 15.417 & 0.787 \\
\hline 8 & All-T- $R_{h}$ & 0.800 & 1.163 & 21.328 & 0.636 & 0.847 & 1.016 & 21.315 & 0.707 \\
\hline 9 & All- $\mathrm{W}_{\mathrm{s}}-\mathrm{R}_{\mathrm{h}}$ & 0.943 & 0.642 & 11.735 & 0.889 & 0.957 & 0.596 & 12.794 & 0.899 \\
\hline 10 & All- $\mathrm{W}_{\mathrm{s}}-\mathrm{R}_{\mathrm{h}}-\mathrm{T}$ & 0.771 & 1.234 & 22.510 & 0.590 & 0.834 & 1.043 & 21.313 & 0.691 \\
\hline$\overline{\text { Optimum }}$ & All- $R_{h}$ & 0.945 & 0.634 & 11.585 & 0.892 & 0.958 & 0.587 & 12.706 & 0.902 \\
\hline
\end{tabular}

Table 10. Performance of the forecasting skills of MLRI model with various input variables over the training and testing phase.

438 Table 12 summarized the best performance of each data-driven model among all input 439 combinations, which demonstrated that the LSSVM-ISA outperformed the MARS, GRNN, 440 and MLRI in forecasting daily GSR in both testing and training stage. Also, MARS and 441 GRNN are identified as the most second and third predictive model for simulating daily GSR, 442 respectively. 
Table 10. ANOVA results for identifying the influence of predictor's interaction in MLRI model for the combination No.6.

\begin{tabular}{cccc}
\hline Terms & Sum of squares & $F$-value & $p$-value \\
\hline Day & 535.37 & 2572.2 & 0 \\
$S_{h}$ & 2222.6 & 10672 & 0 \\
$T_{\text {ave }}$ & 2616.2 & 12561 & 0 \\
$W_{s}$ & 6.635 & 31.858 & $1.818 \mathrm{E}-08$ \\
Day $\times S_{h}$ & 21.044 & 101.04 & $2.16 \mathrm{E}-23$ \\
Day $\times T_{\text {ave }}$ & 234.15 & 1124.2 & 0 \\
$T_{\text {ave }} \times S_{h}$ & 50.380 & 241.92 & 0 \\
Day $\times W_{s}$ & 1.244 & 5.972 & 0.0146 \\
$W_{s} \times S_{h}$ & 23.347 & 112.10 & 0 \\
$W_{s} \times T_{\text {ave }}$ & 13.397 & 64.321 & $1.510 \mathrm{E}-15$ \\
\hline
\end{tabular}

443

444

Table 12. Comparison between the outcomes from 4 data-driven models to forecast daily GSR.

\begin{tabular}{cccccccccc}
\hline \multirow{2}{*}{ Model } & \multirow{2}{*}{$\begin{array}{c}\text { Optimum } \\
\text { combination }\end{array}$} & \multicolumn{4}{c}{ Train } & \multicolumn{4}{c}{ Test } \\
\cline { 3 - 9 } & & R & RMSE & MAPE\% & NS & R & RMSE & MAPE\% & NS \\
\hline LSSVM-ISA & All-W & 0.973 & 0.442 & 8.171 & 0.947 & 0.980 & 0.391 & 8.233 & 0.957 \\
MARS & All-T-W $_{\mathrm{s}}$ & 0.968 & 0.485 & 9.596 & 0.069 & 0.974 & 0.426 & 9.003 & 0.056 \\
GRNN & All-W s $_{\mathrm{h}}-\mathrm{T}$ & 0.964 & 0.526 & 11.042 & 0.926 & 0.971 & 0.469 & 11.384 & 0.938 \\
MLRI & All- $\mathrm{R}_{\mathrm{h}}$ & 0.945 & 0.634 & 11.585 & 0.892 & 0.958 & 0.587 & \multirow{2}{*}{12.706} & 0.902 \\
\hline
\end{tabular}

445

The results in Tables 4, 6, 9, and 10 indicate that the optimal input combination in

447 each data-driven model is different due to the discrepancy in the performance mechanism of

448 each of them. Figure 8 illustrated the bar plot of R, RMSE, MAPE, and NS values for all

449 input combinations and provided models. Based on the shown metric values in Fig.8, the

450 LSSVM-ISA has the best predictive performance in all combinations, whereas the MARS

451 and GRNN models are ranked as the best second and third predictive models, respectively.

452 However, MARS and GRNN in the combination No.2 have similar performance in 


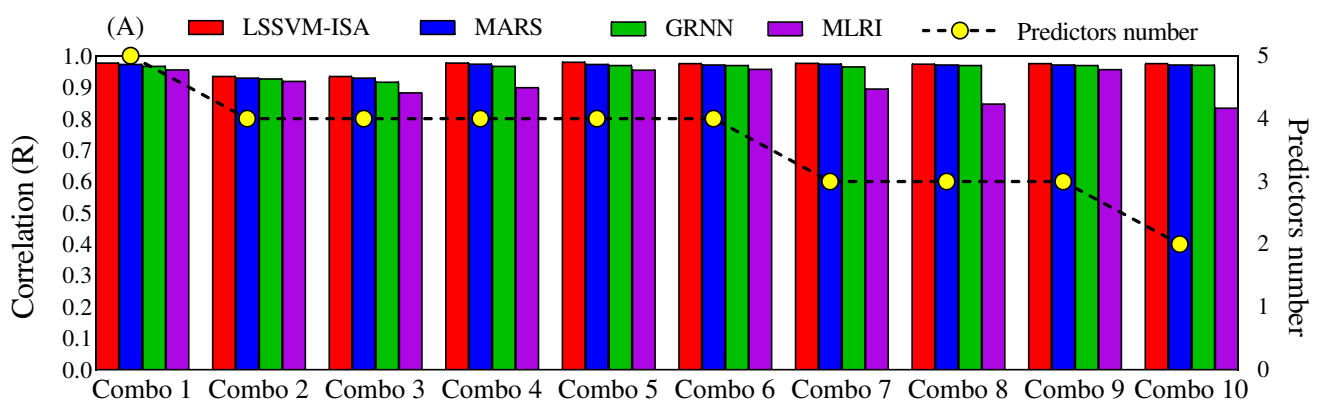

Combinations
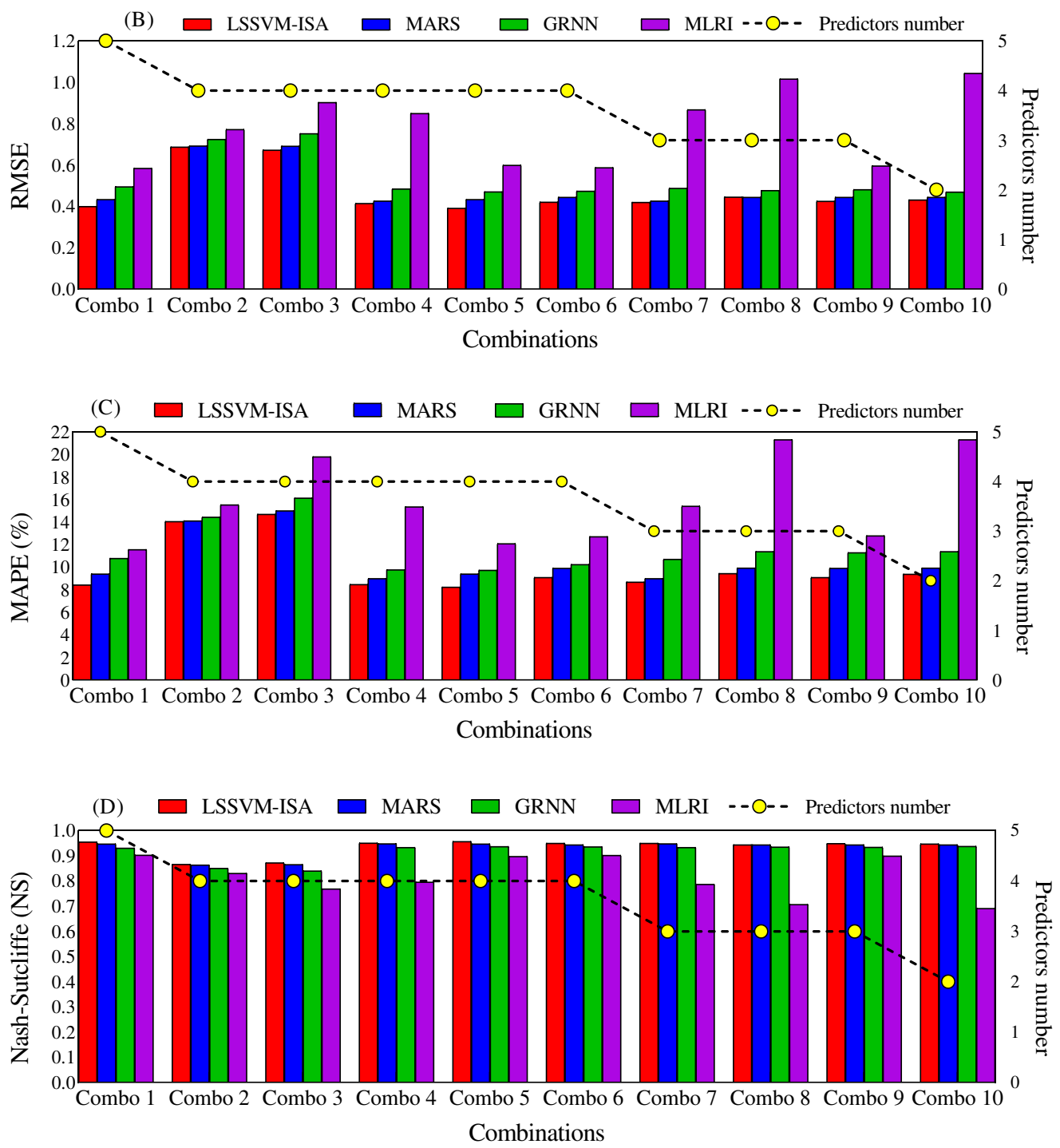

Fig.6. The correlation (R), RMSE, MAPE, and NS values for all AI models in 10 combinations versus predictors number 
457 the daily observed and simulated GSR plots over the training and testing periods (Figs. 7-10).

458 As can be seen in these figures, the GSR values predicted by the LSSVM-ISA model are in 459 better agreement with the observed data than those of MARS, GRNN, and MLRI models in 460 both testing and training stages. Moreover, the scatter plots of the GSR data points simulated by the LSSVM-ISA model is closer to the 1:1 line than those from the other developed datadriven models, which imply the superiority of LSSVM-ISA model in forecasting daily GSR. Moreover, a closer look at the distribution of points at scatter plots reveals that for the range of GSR >4, all provided AI-based models have promising performance in simulation of daily GSR, especially in testing mode.
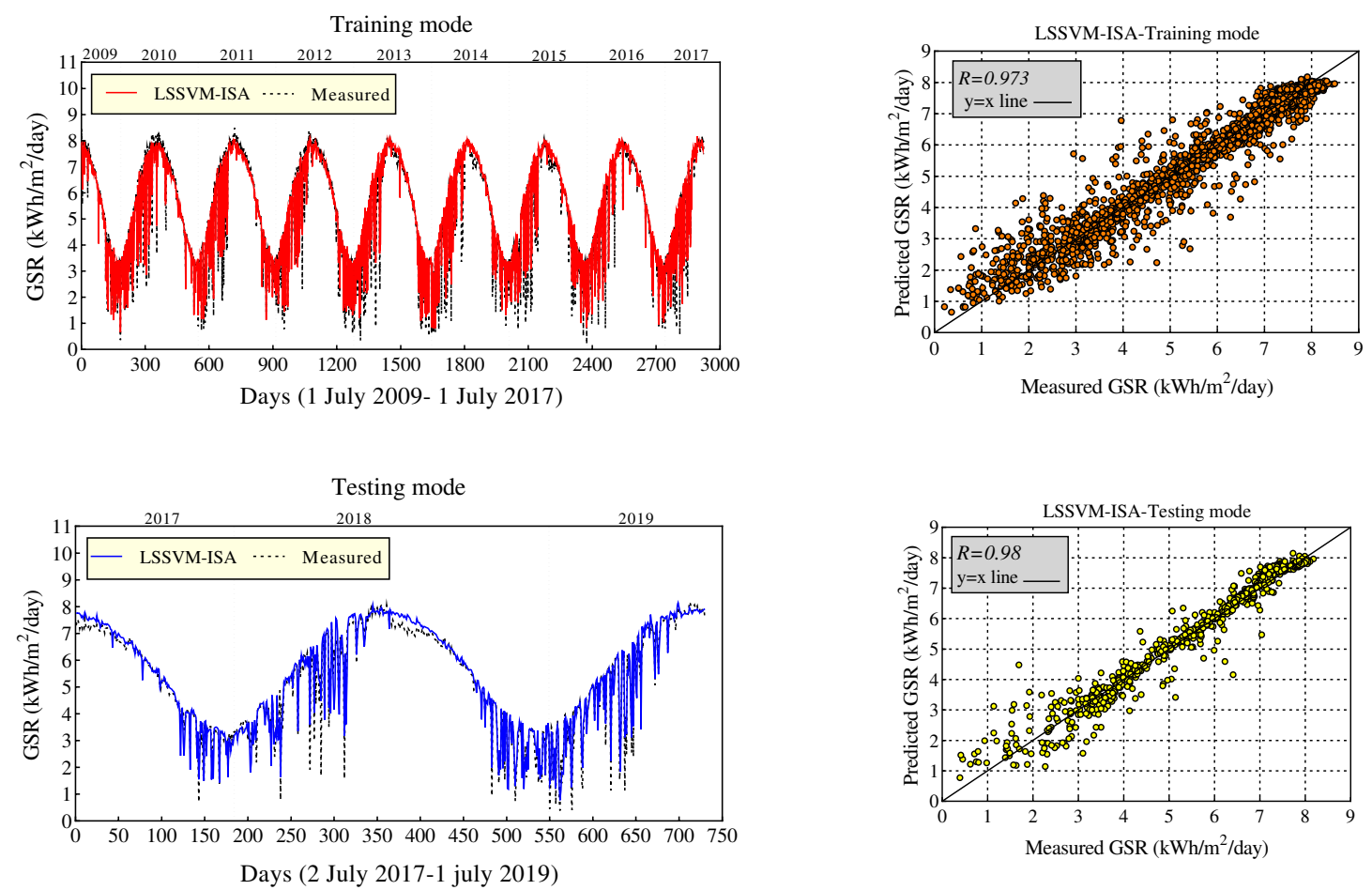

Fig.7. The scatter plots of GSR (Right); Comparison of the measured and predicted GSR (Left) using of LSSVM-ISA model for both training and testing datasets 

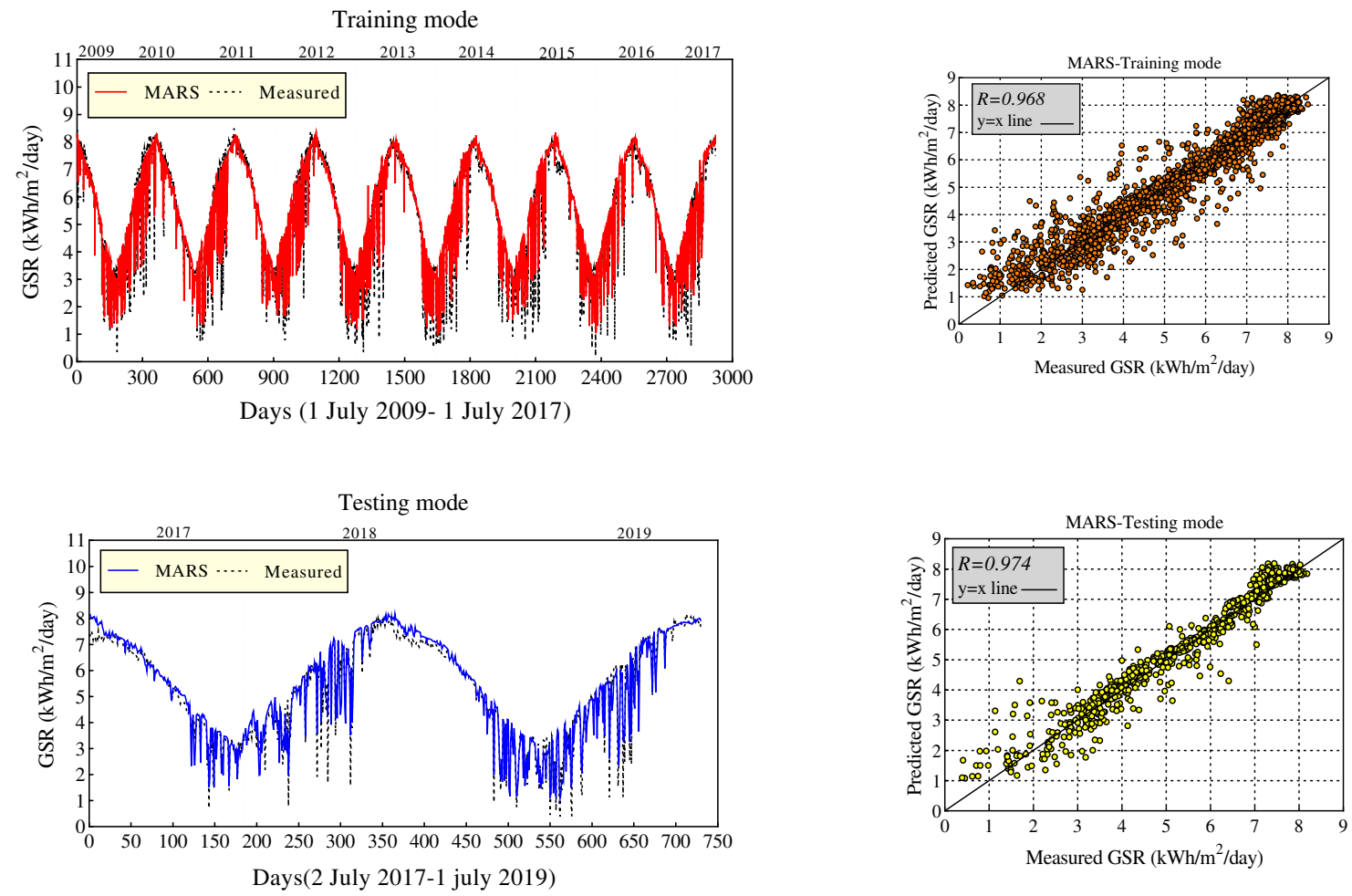

Fig.8. The scatter plots of GSR (Right); Comparison of the measured and predicted GSR (Left) using of MARS model for both training and testing datasets
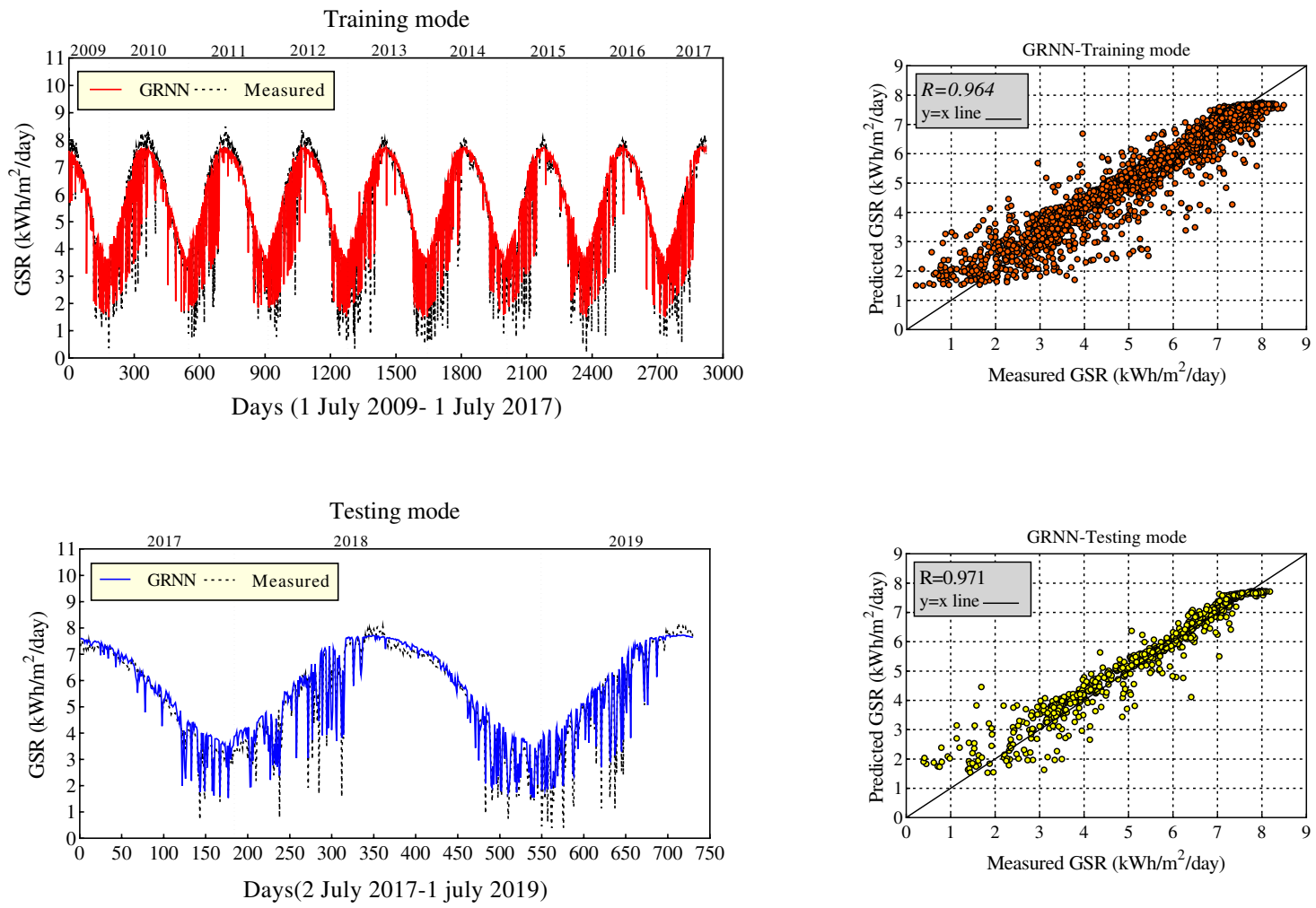

Fig.9. The scatter plots of GSR (Right); Comparison of the measured and predicted GSR (Left) using of GRNN model for both training and testing datasets 

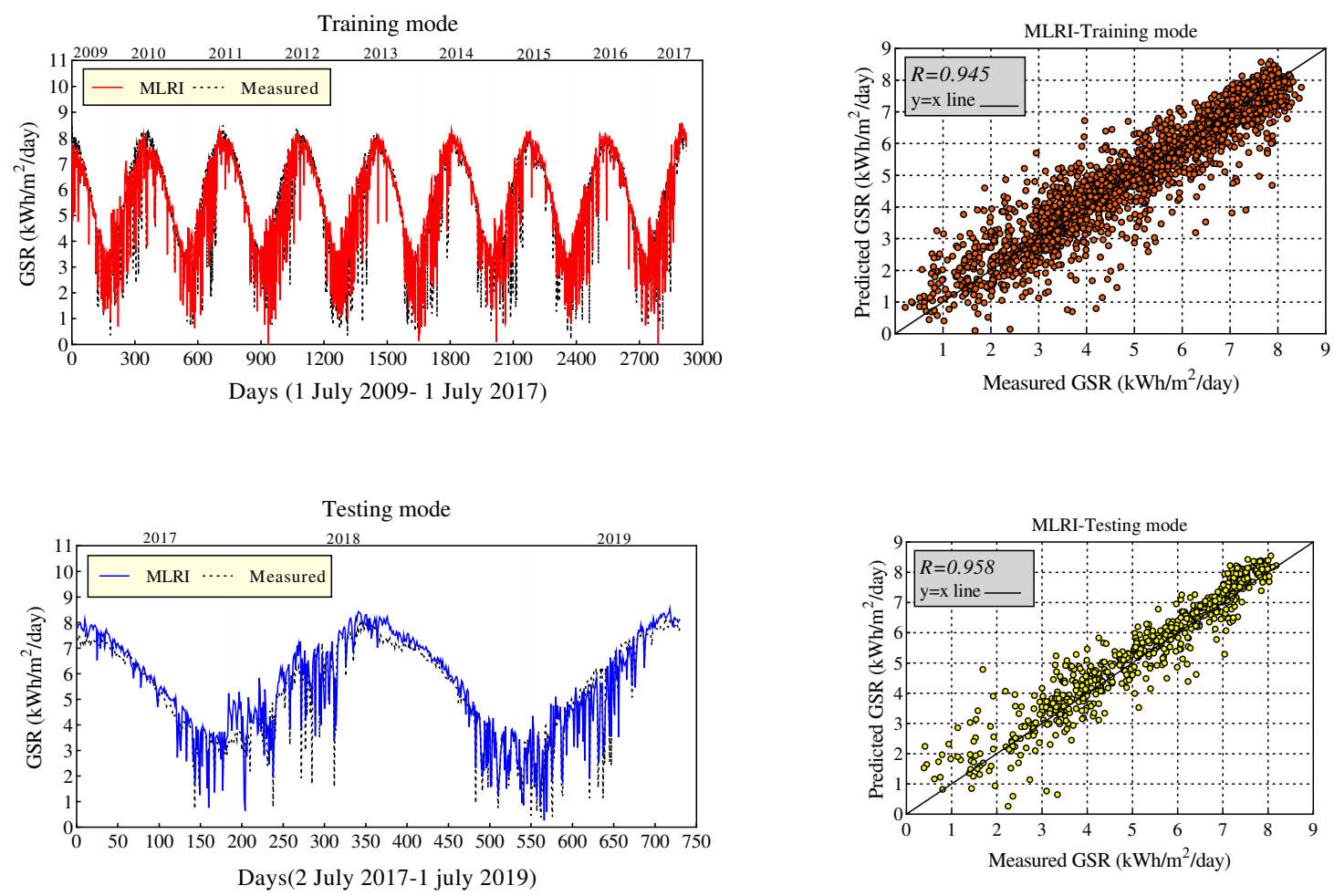

Fig.10. The scatter plots of GSR (Right); Comparison of the measured and predicted GSR (Left) using of MLRI model for both training and testing datasets For visual comparison between the results of the LSSVM-ISA and those of other data-driven approaches, the Fig.11 shows forecasted and observed GSR values over the two selected intervals of (1 June 2013-31 December 2013) and (1 July 2017-1 July 2019) at the training and testing periods, respectively. It is so clear that the LSSVM-ISA performs significantly better than other predictive models due to having the best fit and lowest overestimation and underestimation. However, the MARS and GRNN models, as the next alternatives, can simulate the daily GSR at an acceptable level of precision. The violin plot in Fig.12 shows the distribution of standardized observed and forecasting daily global solar radiation (GSR) using the LSSVM-ISA, MARS, GRNN and MLRI model for both testing and training modes in the best input combinations. Distribution of predicted GSR values in violin plot for training (Fig.12-A) and testing (Fig.12-B) stages reveal that all predictive models have relatively similar forecasting performance in the median 50 percentile (thick solid line). In contrast, the LSSVM-ISA model is energetically superior to other data-driven 
models in upper and lower quartiles (dashed lined) of violin plots in comparison with observational daily GSR. Also, the MARS model with having the second-best consistency of distribution with observational values has acceptable performance in forecasting daily GSR.
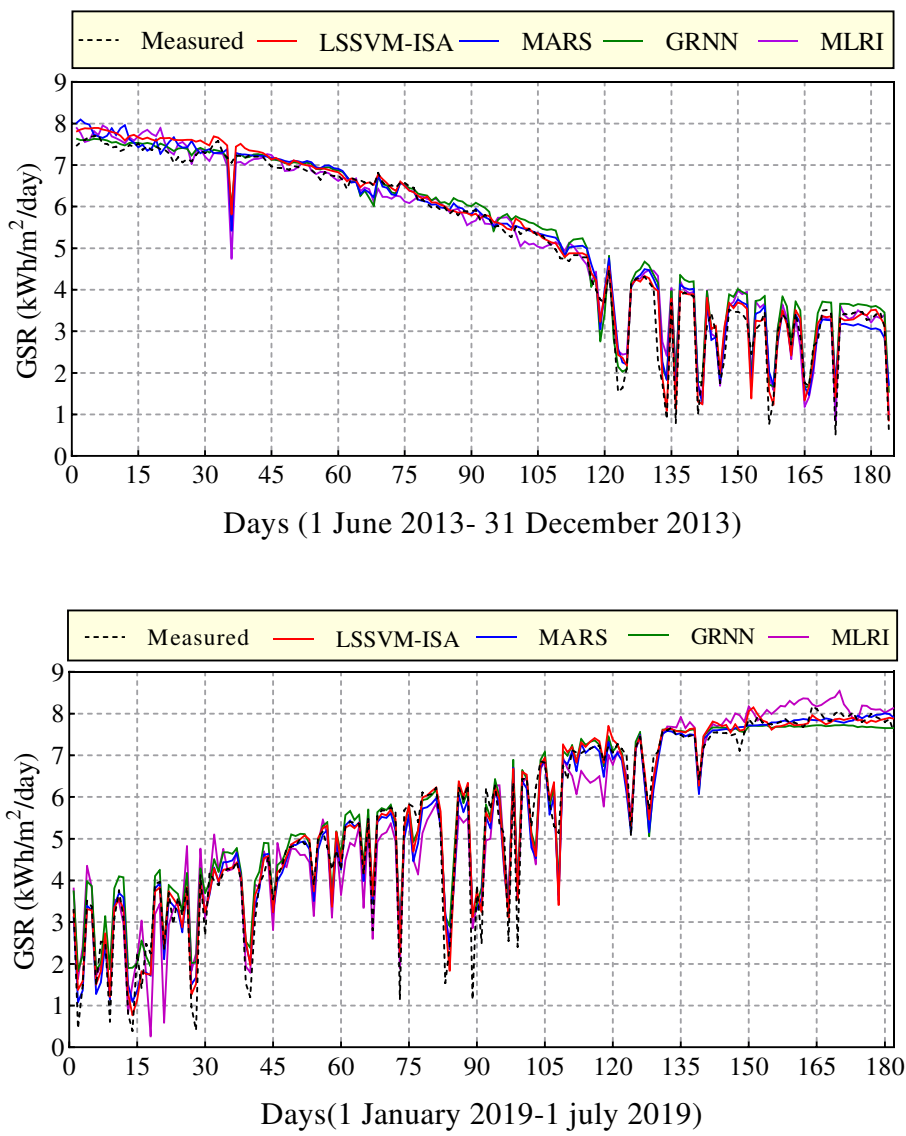

Fig.11. Comparison of the predictive and measured daily solar radiation with all developed AI models throughout (1 June 2013-31 December 2013) and (1 July 2017-1 July 2019) at the training and testing datasets 
(A)

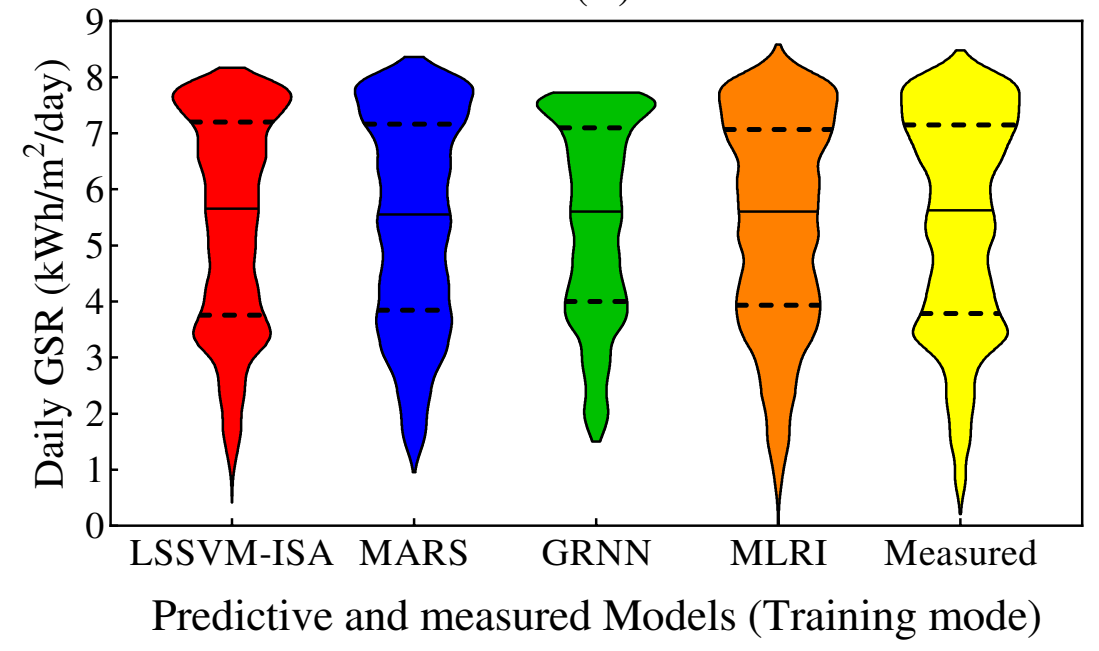

(B)

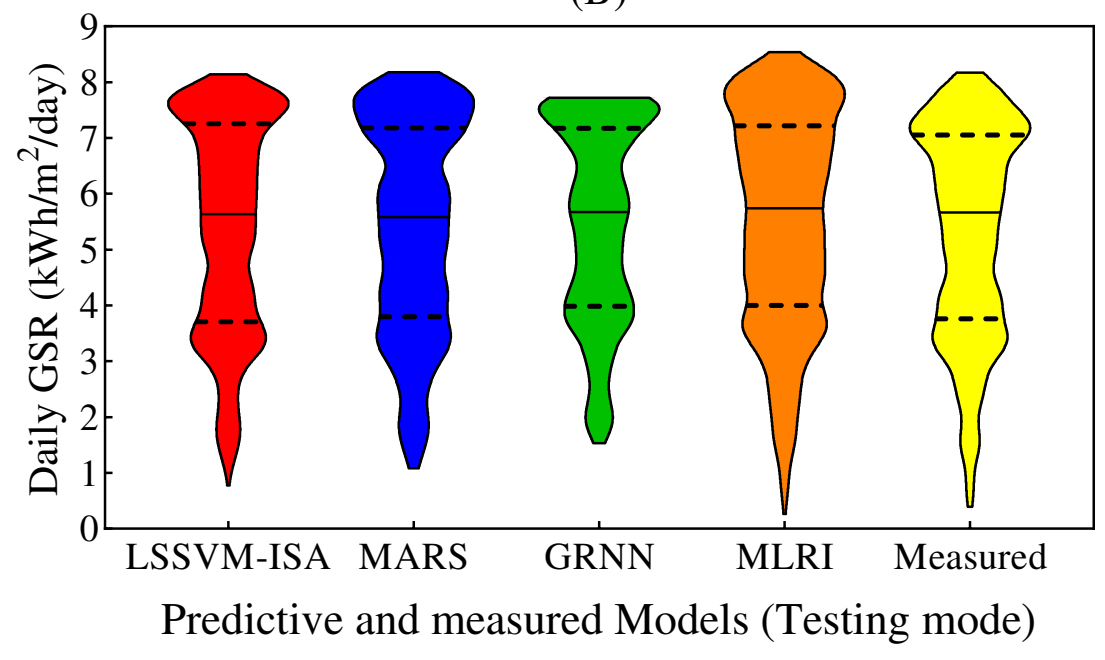

Fig.12. The violin plots of the predicted and measured daily GSR values for the best combination of each data-driven model.

484

In the next validation graphical tools, the Taylor diagrams for evaluating the robustness of the developed predictive models in training and testing period of the simulation were plotted in Fig.13. According to findings in Fig.13, the locus of data obtained from the LSSVM-ISA model is in the closet distance to the target point compared to those of the other data-driven methods in both training and testing phases. This fact is due to having the highest correlation coefficients $(\mathrm{R}=0.974$ and 0.980$)$, and the minimal difference of standard deviations ( $S_{d}=1.887$ and 1.873). The MARS and MLRI models have closer standard 
492 deviation to the target than the GRNN model. It is noteworthy that the standard deviation ( $493 S_{d}$ ) of the observed GSR values for the training and testing datasets is 1.880 and 1.738 , respectively.
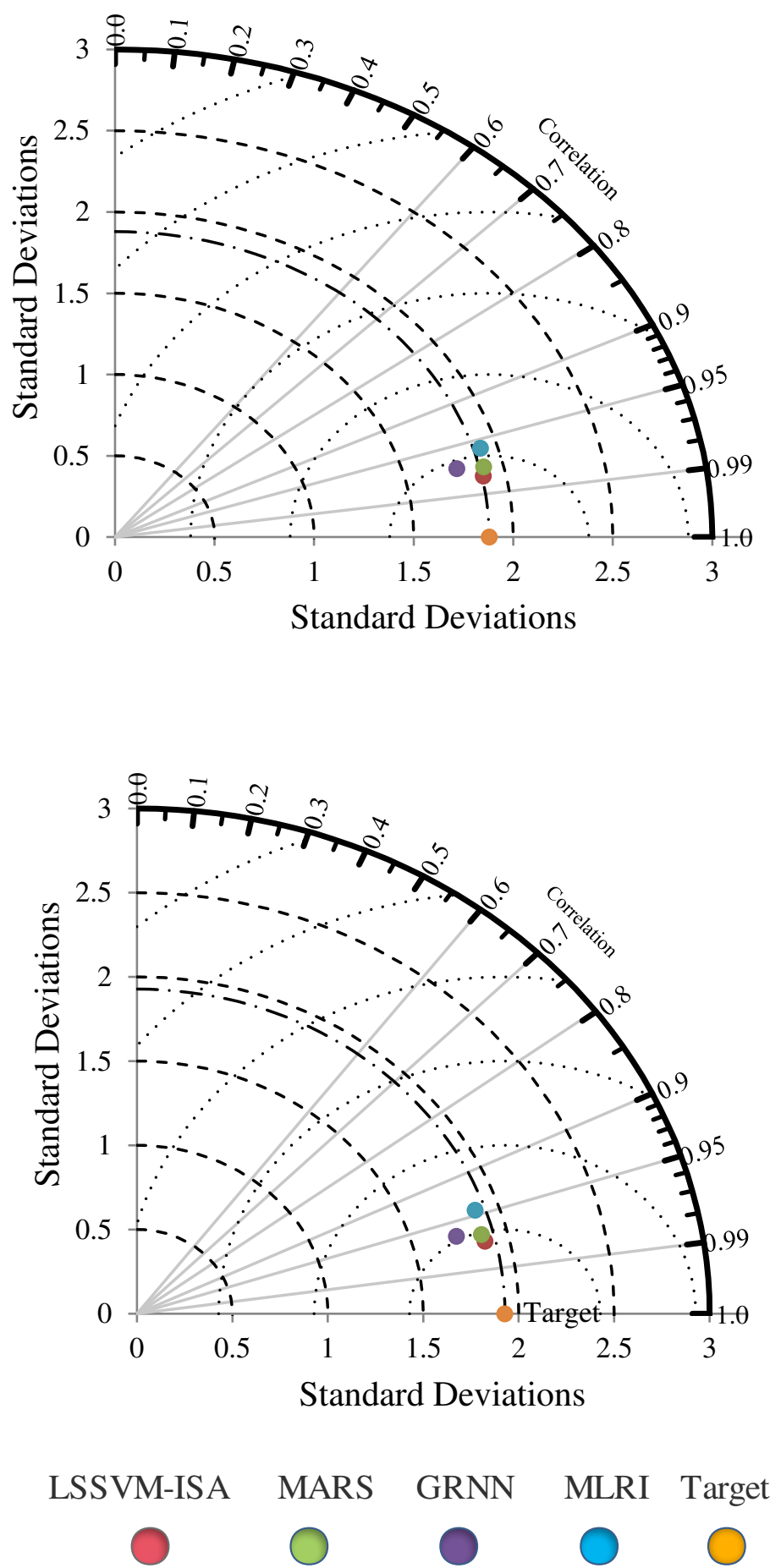

Fig.13. The Taylor diagram of the training and testing modes for LSSVM-ISA,

MARS, GRNN, and MLRI for forecasting the GSR. 
In this part of the study, a comprehensive error analysis was conducted to evaluate the accuracy and reliability of current AI models. The relative deviation value by formula ( $\left.D_{r}=\left(G S R_{\mathrm{i}}-G S R_{\mathrm{o}}\right) / G S R_{\mathrm{o}}\right)$ was displayed versus observed GSR for training and testing period deviation for the LSSVM-ISA model by $-3.35 \leq D_{r} \leq 0.526$ is less than the MARS by $-5.80 \leq D_{r} \leq 0.582$, GRNN by $-6.20 \leq D_{r} \leq 0.550$ and for MLRI by $-4.47 \leq D_{r} \leq 1.260$.

501 Close examination of the error distribution plots vividly shows that for $G S R>4$ all understudy predictive models have reliable performance and acceptable accuracy in forecasting daily GSR and the relative deviation restricted in the range of $-1 \leq D_{r} \leq 0.520$.

(a)

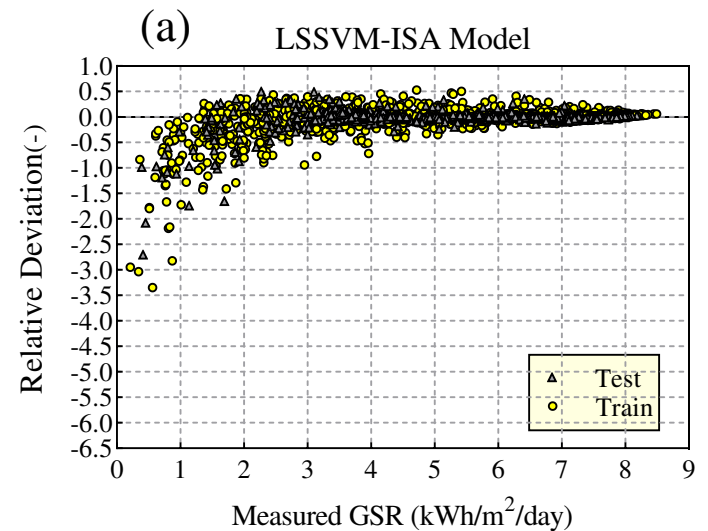

(c)

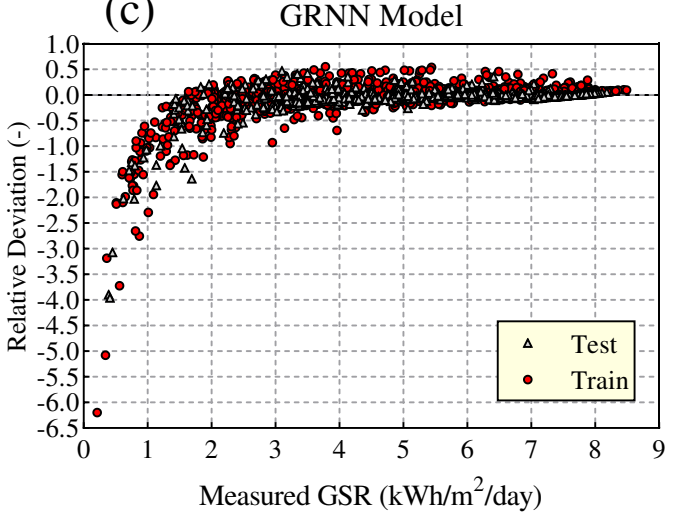

(b) MARS Model
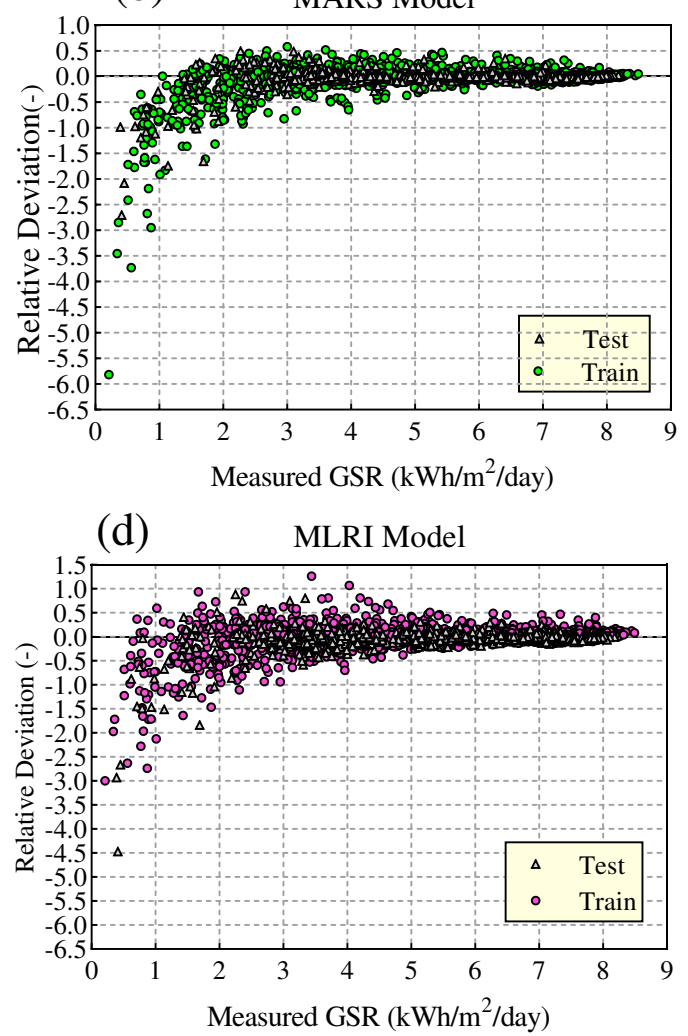

Fig. 14. The relative deviation plots of the developed data-driven models for predicting GSR: (a) LSSVM-ISA, (b) MARS, (c) GRNN, and (d) MLRI. 
Finally, a substantial error criterion is carried out to the better vision of the quantitative performance of all proposed models, which expresses the amount of cumulative absolute percent of error frequency (Fig.15). LSSVM-ISA model can predict $75 \%$ of the daily GSR data with absolute relative error less than $6.1 \%$ whereas, $75 \%$ of the MARS, GRNN, and MLRI models as the second, third and fourth most accurate approaches, provided prediction errors less than or equal to $8.2 \%, 9.74 \%$, and $11.56 \%$, respectively. Also, all the provided models can assess $90 \%$ of the data with an absolute relative error of less than $25 \%$, which implies the reliability of all data-driven approaches for the prediction of daily GSR. It is vividly clear that the results of LSSVM-ISA are in the most satisfactory agreement with observed data sets in comparison with all the provided models.

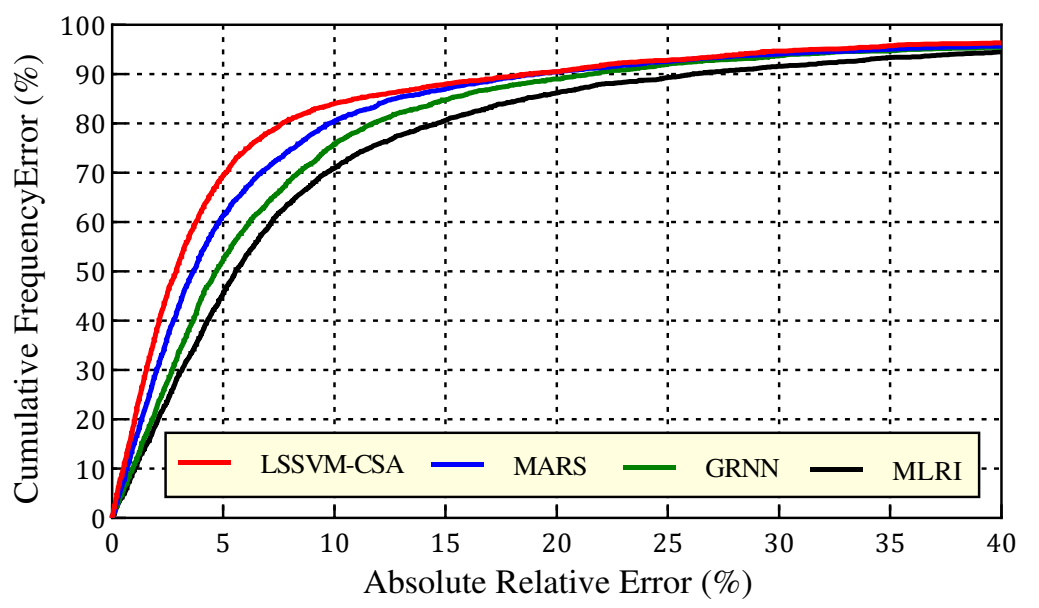

Fig.15. Percentage of cumulative frequency of proposed AI models versus the absolute percentage of relative error in forecasting GSR.

\section{Validation of the model with traditional approaches}

517 In order to investigate the accuracy of the empirical equations in comparison with the AIbased methods used in the research, nine empirical equations were examined and evaluated, which were introduced in Table 1 . The inputs of the selected equations are the same as the AI-based models utilized in this research. The coefficients of the empirical equations are 
521 calculated using the ordinary least square (OLS) method separately, and their values are

522 given for each equation in Table 13. According to Table 13, the Bristow and Campbell

523 (Bristow \&Campbell 1984) equation with a mean absolute percentage error (MAPE) of

$52414.811 \%$ provides more accurate results than other equations. The MAPE of Goodin et al.

525 (Goodin et al. 1999) and Hunt equations (Hunt et al. 1998) are 14. 843\% and 14.857\%,

526 respectively.

Table 13. Coefficient and accuracy of empirical equations to predict GSR

\begin{tabular}{|c|c|c|c|c|c|c|c|c|c|}
\hline Model & $\mathrm{a}$ & $\mathrm{b}$ & $\mathrm{c}$ & $\mathrm{d}$ & e & $\mathrm{R}$ & RMSE & MAPE\% & NS \\
\hline $\begin{array}{c}\text { Swartman and Ogunlade } \\
\text { (Swartman \&Ogunlade } \\
\text { 1967) }\end{array}$ & 6.08 & 1.8 & -0.065 & - & - & 0.814 & 1.115 & 21.775 & 0.662 \\
\hline $\begin{array}{c}\text { Hargreaves (Hargreaves } \\
1981 \text { ) }\end{array}$ & 0.158 & - & - & - & - & 0.919 & 0.754 & 17.011 & 0.845 \\
\hline $\begin{array}{c}\text { Bristow and Campbell } \\
\text { (Bristow \&Campbell 1984) }\end{array}$ & 0.708 & 0.015 & 1.818 & - & - & 0.925 & 0.728 & 14.811 & 0.856 \\
\hline $\begin{array}{c}\text { De Jong and Stewart (Jong } \\
\text { \&Stewart 1993) }\end{array}$ & 0.162 & 0.490 & -0.010 & -0.010 & - & 0.925 & 0.727 & 15.473 & 0.856 \\
\hline Allen (Allen 1997) & 0.158 & - & - & - & - & 0.919 & 0.754 & 17.012 & 0.845 \\
\hline $\begin{array}{l}\text { Donatelli and Campbell } \\
\text { (Donatelli \&Campbell } \\
\text { 1998) }\end{array}$ & 0.665 & 0.006 & 3.526 & - & - & 0.911 & 0.791 & 15.501 & 0.830 \\
\hline Hunt (Hunt et al. 1998) & 0.159 & -0.053 & - & - & - & 0.919 & 0.754 & 16.984 & 0.845 \\
\hline Hunt (Hunt et al. 1998) & 0.144 & 0.012 & -0.135 & 0.002 & 0.079 & 0.927 & 0.719 & 14.875 & 0.859 \\
\hline $\begin{array}{l}\text { Goodin,Hutchinson, } \\
\text { anderlip and Knapp } \\
\text { (Goodin et al. 1999) }\end{array}$ & 0.681 & 0.011 & 2.846 & - & - & 0.921 & 0.751 & 14.843 & 0.847 \\
\hline
\end{tabular}

527

528 Table 14 shows a comparison between the best results of each model. According to Table 14,

529 AI-based models have performed better than the empirical and MLRI models. LSSVM-ISA

530 model with MAPE $=8.233 \%$ has the least error among models. 
Table 14. Comparison between the best empirical correlation and AI models

\begin{tabular}{ccccc}
\hline Model & $\mathrm{R}$ & RMSE & MAPE\% & NS \\
\hline Best LSSVM-ISA & 0.980 & 0.391 & 8.233 & 0.957 \\
Best MARS & 0.974 & 0.426 & 9.003 & 0.948 \\
Best GRNN & 0.970 & 0.471 & 9.740 & 0.937 \\
Best MLRI & 0.956 & 0.584 & 11.567 & 0.903 \\
Best Empirical & 0.925 & 0.728 & 14.811 & 0.856 \\
\hline
\end{tabular}

532

533 Table 15 shows MAPE percent error for different empirical equations used at this research

534 and error improvement by the best LSSVM-ISA model. The results of Table 15 show that the

535 best LSSVM-ISA model has been able to reduce the MAPE error rate compared to empirical

536 models significantly. A comparison of the best empirical model (Bristow and Campbell

537 (Bristow \&Campbell 1984)) and the best LSSVM-ISA model shows a $6.578 \%$ reduction in

538 MAPE percent.

Table 15. Error improvement by best LSSVM-ISA model compared to empirical equations

\begin{tabular}{ccc}
\hline Model & MAPE\% & Error improvement by LSSVM-ISA \% \\
\hline $\begin{array}{c}\text { Swartman and Ogunlade (Swartman } \\
\text { \&Ogunlade 1967) }\end{array}$ & 21.775 & 13.542 \\
$\begin{array}{c}\text { Hargreaves (Hargreaves 1981) } \\
\text { Bristow and Campbell (Bristow } \\
\text { \&Campbell 1984) }\end{array}$ & 17.011 & 8.778 \\
$\begin{array}{c}\text { De Jong and Stewart (Jong \&Stewart } \\
\text { 1993) }\end{array}$ & 14.811 & 6.578 \\
Allen (Allen 1997) & 17.012 & 7.240 \\
$\quad$ Donatelli and Campbell (Donatelli & 15.501 & 8.779 \\
$\quad \&$ Campbell 1998) & 16.984 & 6.968 \\
Hunt (Hunt et al. 1998) & 14.875 & 8.751 \\
Hunt (Hunt et al. 1998) & 14.843 & 6.642 \\
Goodin, Hutchinson, erlip and Knapp \\
(Goodin et al. 1999)
\end{tabular}




\section{Uncertainty}

In this section, the uncertainty analysis of the utilize models in predicting global solar radiation is examined and evaluated. The error value of each sample is calculated from the relation $e_{j}=G S R_{p}-G S R_{o}$. The mean value of the error of the relation is calculated using $\bar{e}=$ $\sum_{j=1}^{n} e_{j}$ and finally, the standard deviation of the estimation error is calculated from the relation $S_{d e}=\sqrt{\left(e_{j}-\bar{e}\right)^{2} / n-1}$. If the value of $\bar{e}$ is negative, it indicates that the model underestimates the predicted values, and its positive value indicates the overestimation of the model. High values of $s_{e}$ indicate the high scattering of the model error and increasing it will increase the uncertainty of the model prediction.

Confidence intervals for the estimation values of the models can be determined using the values $\bar{e}$ and $S_{e}$. Considering the $\pm 1.96 S_{e}$, values of $95 \%$ confidence intervals are obtained. Table 16 shows the mean values of estimation error, standard error deviation, and $95 \%$ error confidence intervals. In all five models used in the present study, except for the empirical equation, the mean value of the prediction error is positive, which indicates that the model is overestimating predicting values. Among the applied models, the best empirical equation has the lowest mean value of the prediction error with a value of -0.011 . Among AI-based models, LSSVM-ISA and MARS have the lowest average error $(\bar{e}=0.074)$. The LMRI method has the highest average error value $(\bar{e}=0.207)$. The lowest value of the uncertainty band \pm 0.792 is for the LSSVM-ISA model, which indicates that this model has a lower uncertainty. The highest uncertainty band \pm 1.427 is for the Bristow and Campbell (Bristow \&Campbell 1984) equation, which indicates more uncertainty about the results of the empirical model than other models. 
Table 16. Uncertainty estimates for GSR for best of each model

\begin{tabular}{cccc}
\hline Model & $\begin{array}{c}\text { Mean prediction } \\
\text { error } \bar{e}\end{array}$ & $S_{e}$ & $\begin{array}{c}\text { Width of uncertainty } \\
\text { band }\end{array}$ \\
\hline Best LSSVM-ISA & 0.074 & 0.404 & \pm 0.792 \\
Best MARS & 0.074 & 0.426 & \pm 0.835 \\
Best GRNN & 0.132 & 0.469 & \pm 0.919 \\
Best MLRI & 0.207 & 0.587 & \pm 1.150 \\
Best Empirical & -0.011 & 0.728 & \pm 1.427 \\
\hline
\end{tabular}

564

\section{Conclusions}

Given the importance of accurately estimating solar radiation in the design of solar energy systems, a novel hybrid data-driven approach comprised of LSSVM coupled with improved simulated annealing (ISA) approach (LSSVM-ISA) is developed to accurately predict the daily global solar radiation (GSR) over the period of 10 years (from 01-July-2009 to 1- July -2019) at Ahvaz station, in Iran. In this research, the predictive input variable was the day of the year (1 to 366), average daily temperature $\left(\mathrm{T}_{\mathrm{ave}},{ }^{\circ} \mathrm{C}\right)$, sunshine hours $\left(\mathrm{S}_{\mathrm{h}}, \mathrm{hr}\right)$, relative humidity $\left(\mathrm{R}_{\mathrm{h}, \%}\right)$, average wind velocity $\left(\mathrm{W}_{\mathrm{s}}, \mathrm{m} / \mathrm{s}\right)$ at $10 \mathrm{~m}$ and $\mathrm{GSR}\left(\mathrm{Kw}-\mathrm{h} / \mathrm{m}^{2} /\right.$ day $)$ was considered as a target for ten input combinations. According to the obtained results, LSSVM-ISA model in the combination (No.5; comprised of day, $\mathrm{S}_{\mathrm{h}}, \mathrm{T}_{\mathrm{ave}}$, and $\mathrm{R}_{\mathrm{h}}$ ) due to having highest $R(0.980)$ and NS (0.957) and lowest $R M S E\left(0.391 \mathrm{Kw}-\mathrm{h} / \mathrm{m}^{2} / \mathrm{day}\right)$ and MAPE (8.233\%) for testing modes outperformed the MARS, GRNN and MLRI model in forecasting daily GSR. The MARS model, in combination (No.7; comprising day, $S_{h}$ and $R_{h}$ ) in terms of $\left(R=0.974, R M S E=0.426 \mathrm{Kw}-\mathrm{h} / \mathrm{m}^{2} /\right.$ day, $M A P E=9.003 \%$, and $\left.\mathrm{NS}=0.948\right)$ was identified as the second accurate predictive approach for daily GSR forecasting. Also, the GRNN model as third best rank carried out the best performance in combination (No.10; including day and $\mathrm{S}_{\mathrm{h}}$ ) provided in terms of $\mathrm{R}=0.971, \mathrm{RMSE}=0.469 \mathrm{Kw}-\mathrm{h} / \mathrm{m}^{2} / \mathrm{day}, M A P E=11.384 \%$, and $\mathrm{NS}=0.938$ ) and eventually MLRI model in the combination (No.6) consist of all predictors excluding the relative humidity $\left(\mathrm{R}_{\mathrm{h}}\right)$ in terms of $\left(\mathrm{R}=0.958, \mathrm{RMSE}=0.587 \mathrm{Kw}-\mathrm{h} / \mathrm{m}^{2} / \mathrm{day}, M A P E=12.706 \%\right.$, 
and NS=0.902). According to (Lewis 1982), for judgment of the accuracy of the GSR

585

586

587

588

589

590

591

592

593

594

595

596

597

598

599

600

601

602

603

604

605

606

607

608

609

610

forecasting procedure, the LSSVM-ISA and MARS models by having MAPE $<10 \%$ are identified as high accurate forecasting tools and GRNN and MLRI model by $10 \leq M A P E \leq 20$ are classified as good predictor data-driven model to assess the daily GSR. Besides, a comparison between all models in 10 combinations demonstrated that the day of the year and sunshine duration $\left(\mathrm{S}_{\mathrm{h}}\right)$ due to existing in any the best combination performance are identified as the most effective predictive variables in the daily GSR forecasting process.

Besides, comparing the obtained results of the empirical equations with the AI models indicated that the AI models, especially the LSSVM-ISA method $(\mathrm{R}=0.98, \mathrm{RMSE}=0.391$ $\mathrm{Kw}-\mathrm{h} / \mathrm{m}^{2} /$ day, $\mathrm{MAP} \%=8.23$, and NS $\left.=0.957\right)$, can predict the GSR more accurate than the empirical methods. Finally, the uncertainty analysis showed that the proposed LSSVM-ISA has the lowest uncertainty $( \pm 0.792)$ compared with the other AI methods. This demonstrates that the proposed method is more reliable and precise to predict the GSR.

\section{Declarations}

- Ethics approval and consent to participate: "Not applicable"

- Consent for publication: "Not applicable"

- Availability of data and materials: "Not applicable"

- Competing interests: There is no conflict of interest.

- Funding: There is no funding.

- Authors' contributions:

Mehdi Jamei: Conceptualization, modeling, data Formal analysis, writing up the main manuscript, Software, revision editing. Iman Ahmadianfar: Methodology, Introduction, Mozhdeh Jamei: writing up the main manuscript, data visualization; Masoud Karbasi: writing up the main manuscript, revision editing. Ali Asghar Heidari: Supervision, writing up the main manuscript, revision editing. Huling Chen: Supervision, revision editing. 


\section{References}

612 Alizamir M, Kim S, Kisi O, Zounemat-Kermani M (2020): A comparative study of several machine learning based non-linear regression methods in estimating solar radiation: Case studies of the USA and Turkey regions. Energy, 117239

Allen RG (1997): Self-calibrating method for estimating solar radiation from air temperature. Journal of Hydrologic engineering 2, 56-67

Anonymous (!!! INVALID CITATION !!!):

Behrang M, Assareh E, Ghanbarzadeh A, Noghrehabadi A (2010): The potential of different artificial neural network (ANN) techniques in daily global solar radiation modeling based on meteorological data. Solar Energy 84, 1468-1480

Belaid S, Mellit A (2016): Prediction of daily and mean monthly global solar radiation using support vector machine in an arid climate. Energy Conversion and Management 118, 105-118

Bristow KL, Campbell GS (1984): On the relationship between incoming solar radiation and daily maximum and minimum temperature. Agricultural and forest meteorology 31, 159-166

Chen G, Fu K, Liang Z, Sema T, Li C, Tontiwachwuthikul P, Idem R (2014): The genetic algorithm based back propagation neural network for MMP prediction in CO2-EOR process. Fuel 126, 202-212

Chen R, Ersi K, Yang J, Lu S, Zhao W (2004): Validation of five global radiation models with measured daily data in China. Energy Conversion and Management 45, 1759-1769

Citakoglu H (2015): Comparison of artificial intelligence techniques via empirical equations for prediction of solar radiation. Computers and Electronics in Agriculture 118, 28-37

Coulton C, Chow J (1993): Interaction effects in multiple regression. Journal of Social Service Research 16, 179-199

Deo RC, Wen X, Qi F (2016): A wavelet-coupled support vector machine model for forecasting global incident solar radiation using limited meteorological dataset. Applied Energy 168, 568593

Donatelli M, Campbell G (1998): A simple model to estimate global solar radiation, Proceedings of the 5th European Society of Agronomy Congress (Zima M, Bartosova M eds), Nitra, Slovak, pp. 133-134

Elagib NA, Mansell MG (2000): New approaches for estimating global solar radiation across Sudan. Energy Conversion and Management 41, 419-434

Fan J, Wang X, Wu L, Zhou H, Zhang F, Yu X, Lu X, Xiang Y (2018): Comparison of Support Vector Machine and Extreme Gradient Boosting for predicting daily global solar radiation using temperature and precipitation in humid subtropical climates: A case study in China. Energy Conversion and Management 164, 102-111 
Fan J, Wu L, Ma X, Zhou H, Zhang F (2020): Hybrid support vector machines with heuristic algorithms for prediction of daily diffuse solar radiation in air-polluted regions. Renewable Energy 145, 2034-2045

Friedman JH (1991): Multivariate adaptive regression splines. The annals of statistics, 1-67

Friedman JH, Roosen CB (1995): An introduction to multivariate adaptive regression splines. Sage Publications Sage CA: Thousand Oaks, CA

George D (2011): SPSS for windows step by step: A simple study guide and reference, 17.0 update, 10/e. Pearson Education India

Goodin DG, Hutchinson J, Vanderlip RL, Knapp M (1999): Estimating solar irradiance for crop modeling using daily air temperature data. Agronomy Journal 91, 845-851

Gürel AE, Ağbulut Ü, Biçen Y (2020): Assessment of machine learning, time series, response surface methodology and empirical models in prediction of global solar radiation. Journal of Cleaner Production, 122353

Han H, Cui X, Fan Y, Qing H (2019): Least squares support vector machine (LS-SVM)-based chiller fault diagnosis using fault indicative features. Applied Thermal Engineering 154, 540-547

Hargreaves G (1981): Responding to tropical climates. In: The 1980-81 Food and Climate Review. The Food and Climate Forum, Aspen Institute for Humanistic Studies. Boulder, USA., 29-32

Hunt L, Kuchar L, Swanton C (1998): Estimation of solar radiation for use in crop modelling. Agricultural and Forest Meteorology 91, 293-300

Ibrahim IA, Khatib T (2017): A novel hybrid model for hourly global solar radiation prediction using random forests technique and firefly algorithm. Energy Conversion and Management 138, $413-425$

IRIMO

Jaccard J, Turrisi R, Jaccard J (2003): Interaction effects in multiple regression. Sage

Ji M, Jin Z, Tang H (2006): An improved simulated annealing for solving the linear constrained optimization problems. Applied mathematics and computation 183, 251-259

Jong RD, Stewart D (1993): Estimating global solar radiation from common meteorological observations in western Canada. Canadian Journal of Plant Science 73, 509-518

Kirkpatrick S, Gelatt CD, Vecchi MP (1983): Optimization by simulated annealing. science 220, 671680

Kisi O (2014): Modeling solar radiation of Mediterranean region in Turkey by using fuzzy genetic approach. Energy 64, 429-436

Kisi O, Heddam S, Yaseen ZM (2019): The implementation of univariable scheme-based air temperature for solar radiation prediction: New development of dynamic evolving neuralfuzzy inference system model. Applied Energy 241, 184-195 
Leathwick J, Rowe D, Richardson J, Elith J, Hastie T (2005): Using multivariate adaptive regression splines to predict the distributions of New Zealand's freshwater diadromous fish. Freshwater Biology 50, 2034-2052

Lewis CD (1982): Industrial and business forecasting methods: A practical guide to exponential smoothing and curve fitting. Butterworth-Heinemann

Li DH, Chen W, Li S, Lou S (2019): Estimation of hourly global solar radiation using Multivariate Adaptive Regression Spline (MARS)-A case study of Hong Kong. Energy 186, 115857

Liu X, Mei X, Li Y, Wang Q, Jensen JR, Zhang Y, Porter JR (2009): Evaluation of temperature-based global solar radiation models in China. Agricultural and forest meteorology 149, 1433-1446

Menges HO, Ertekin C, Sonmete MH (2006): Evaluation of global solar radiation models for Konya, Turkey. Energy Conversion and Management 47, 3149-3173

Mohammadi K, Shamshirband S, Kamsin A, Lai P, Mansor Z (2016): Identifying the most significant input parameters for predicting global solar radiation using an ANFIS selection procedure. Renewable and Sustainable Energy Reviews 63, 423-434

Mohanta A, Patra K (2019): MARS for Prediction of Shear Force and Discharge in Two-Stage Meandering Channel. Journal of Irrigation and Drainage Engineering 145, 04019016

Moradi I (2009): Quality control of global solar radiation using sunshine duration hours. Energy 34, $1-6$

Mostafavi ES, Ramiyani SS, Sarvar R, Moud HI, Mousavi SM (2013): A hybrid computational approach to estimate solar global radiation: an empirical evidence from Iran. Energy 49, 204210

Nash JE, Sutcliffe JV (1970): River flow forecasting through conceptual models part I-A discussion of principles. Journal of hydrology 10, 282-290

Prescott J (1940): Evaporation from a water surface in relation to solar radiation. Trans. Roy. Soc. S. Aust. 46, 114-118

Rahimikhoob A (2010): Estimating global solar radiation using artificial neural network and air temperature data in a semi-arid environment. Renewable Energy 35, 2131--2135

Ramsami P, Oree V (2015): A hybrid method for forecasting the energy output of photovoltaic systems. Energy Conversion and Management 95, 406-413

Samadianfard S, Majnooni-Heris A, Qasem SN, Kisi O, Shamshirband S, Chau K-w (2019): Daily global solar radiation modeling using data-driven techniques and empirical equations in a semi-arid climate. Engineering Applications of Computational Fluid Mechanics 13, 142-157

Shamshirband S, Mohammadi K, Tong CW, Petković D, Porcu E, Mostafaeipour A, Ch S, Sedaghat A (2016): RETRACTED ARTICLE: Application of extreme learning machine for estimation of wind speed distribution. Climate Dynamics 46, 1893-1907

Specht DF (1991): A general regression neural network. IEEE transactions on neural networks 2, 568576 
Suykens JA, Vandewalle J (1999): Least squares support vector machine classifiers. Neural processing letters 9, 293-300

Swartman R, Ogunlade O (1967): Solar radiation estimates from common parameters. Solar energy $11,170-172$

Taylor KE (2001): Summarizing multiple aspects of model performance in a single diagram. Journal of Geophysical Research: Atmospheres 106, 7183-7192

Wang L, Wu C, Gu X, Liu H, Mei G, Zhang W (2020): Probabilistic stability analysis of earth dam slope under transient seepage using multivariate adaptive regression splines. Bulletin of Engineering Geology and the Environment, 1-13

WMO (2014): Guide to Meteorological Instruments and Methods of observation. World Meteorological Organization

Yu X (2020): Prediction of chemical toxicity to Tetrahymena pyriformis with four-descriptor models. Ecotoxicology and Environmental Safety 190, 110146

Zhang W, Goh AT (2016): Multivariate adaptive regression splines and neural network models for prediction of pile drivability. Geoscience Frontiers 7, 45-52

Zheng G, Zhang W, Zhou H, Yang P (2020): Multivariate adaptive regression splines model for prediction of the liquefaction-induced settlement of shallow foundations. Soil Dynamics and Earthquake Engineering 132, 106097

Zhu B, Ye S, Jiang M, Wang P, Wu Z, Xie R, Chevallier J, Wei Y-M (2019): Achieving the carbon intensity target of China: A least squares support vector machine with mixture kernel function approach. Applied energy 233, 196-207 


\section{Figures}

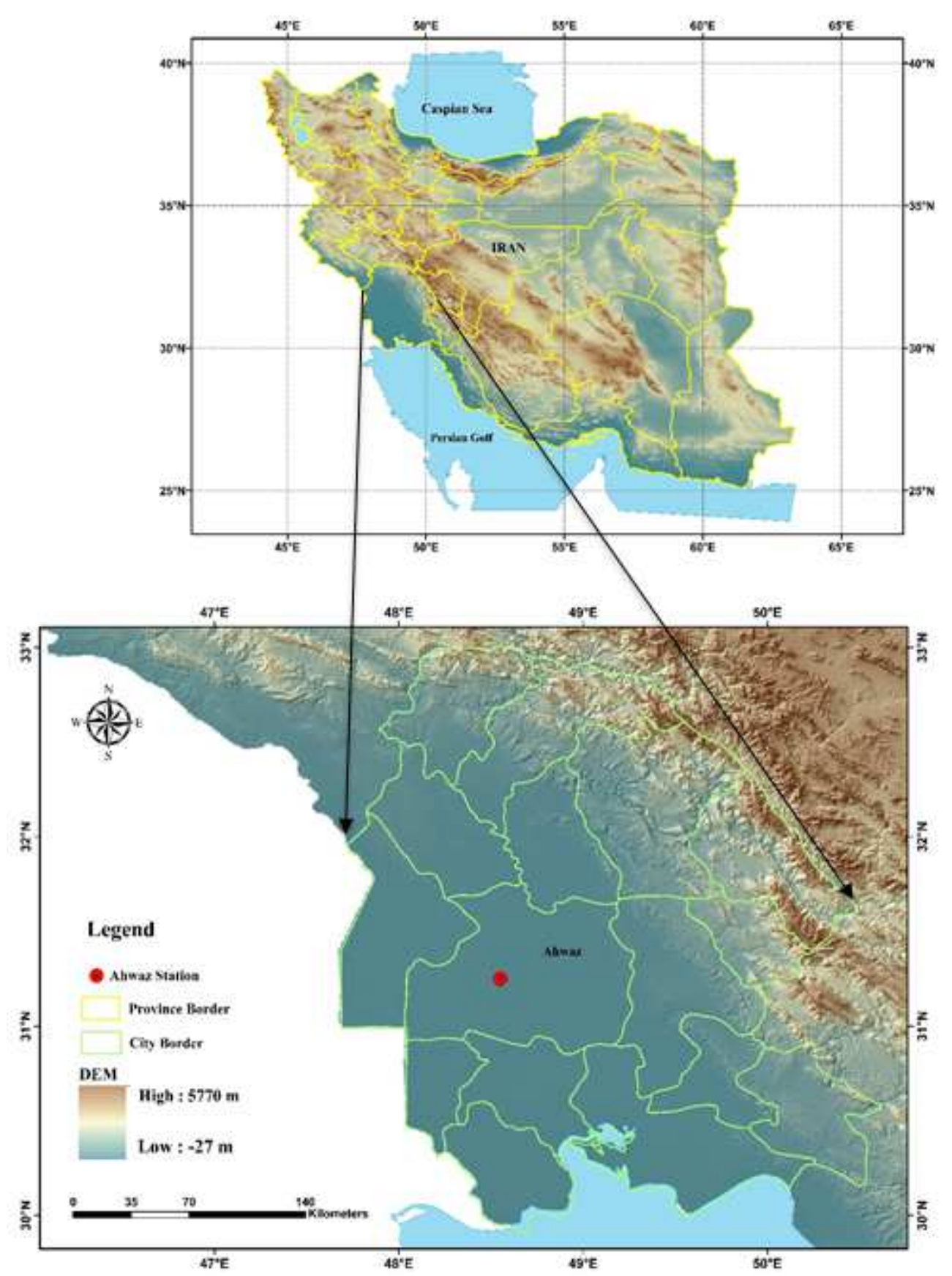

\section{Figure 1}

Study area: location of Ahvaz synoptic station. Note: The designations employed and the presentation of the material on this map do not imply the expression of any opinion whatsoever on the part of Research Square concerning the legal status of any country, territory, city or area or of its authorities, or concerning the delimitation of its frontiers or boundaries. This map has been provided by the authors. 


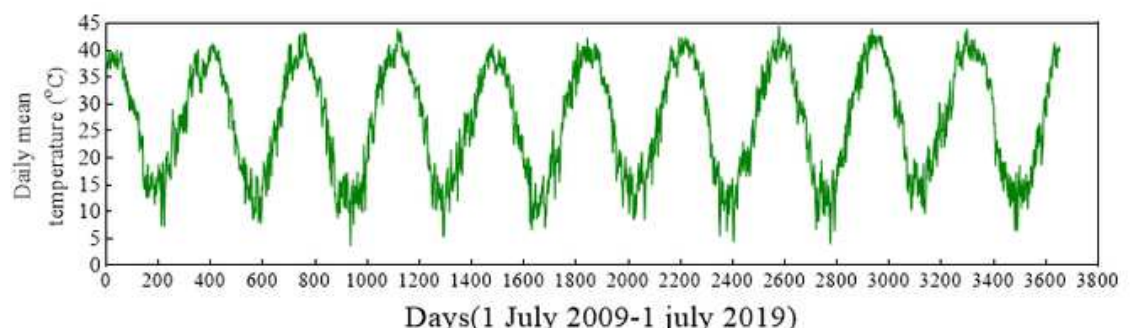

Days(1 July 2009-1 july 2019)
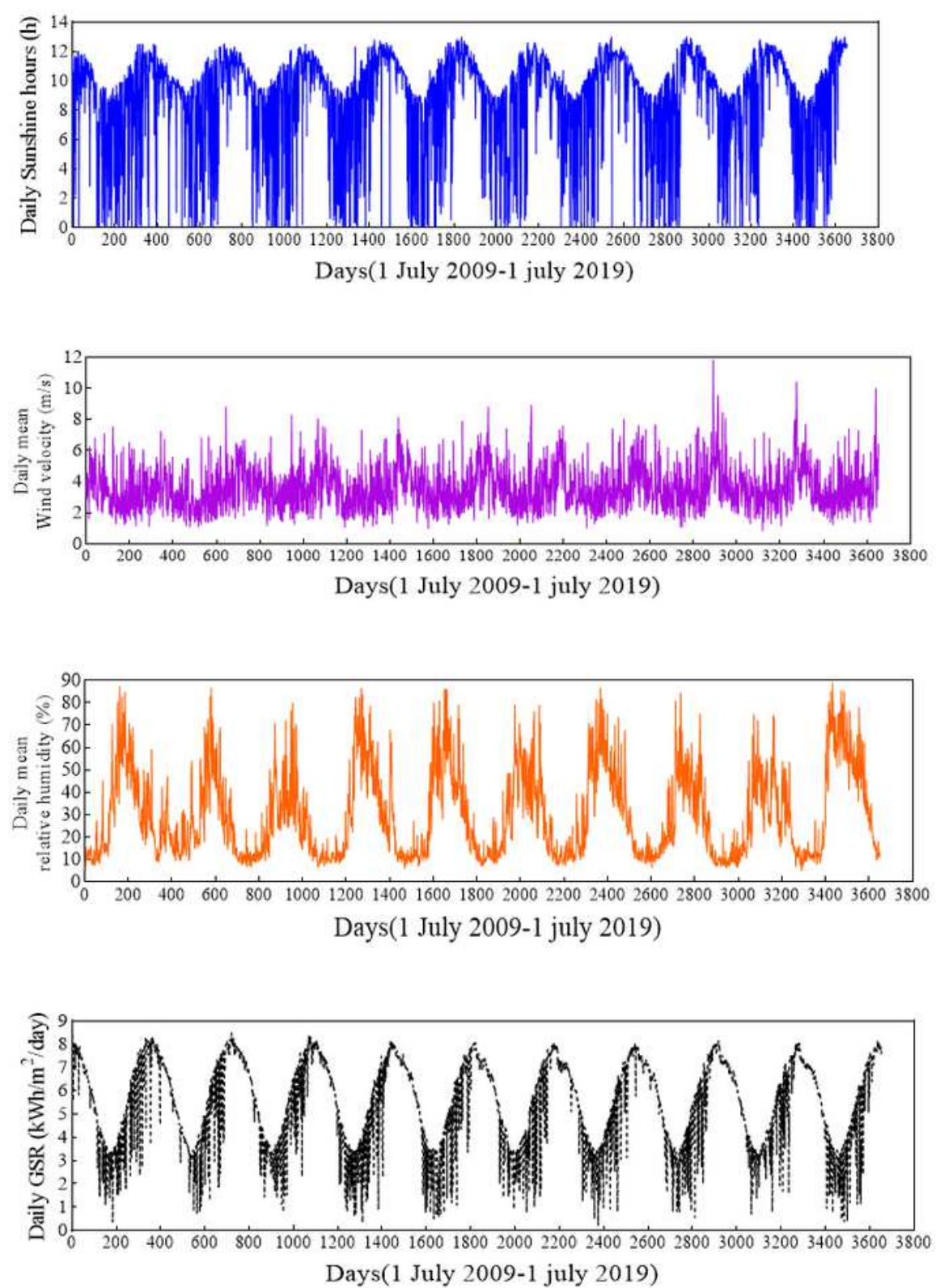

\section{Figure 2}

The measured predictive and output variable over 10 years (1 July 2009-1 July 2019) at Ahvaz synoptic station. 

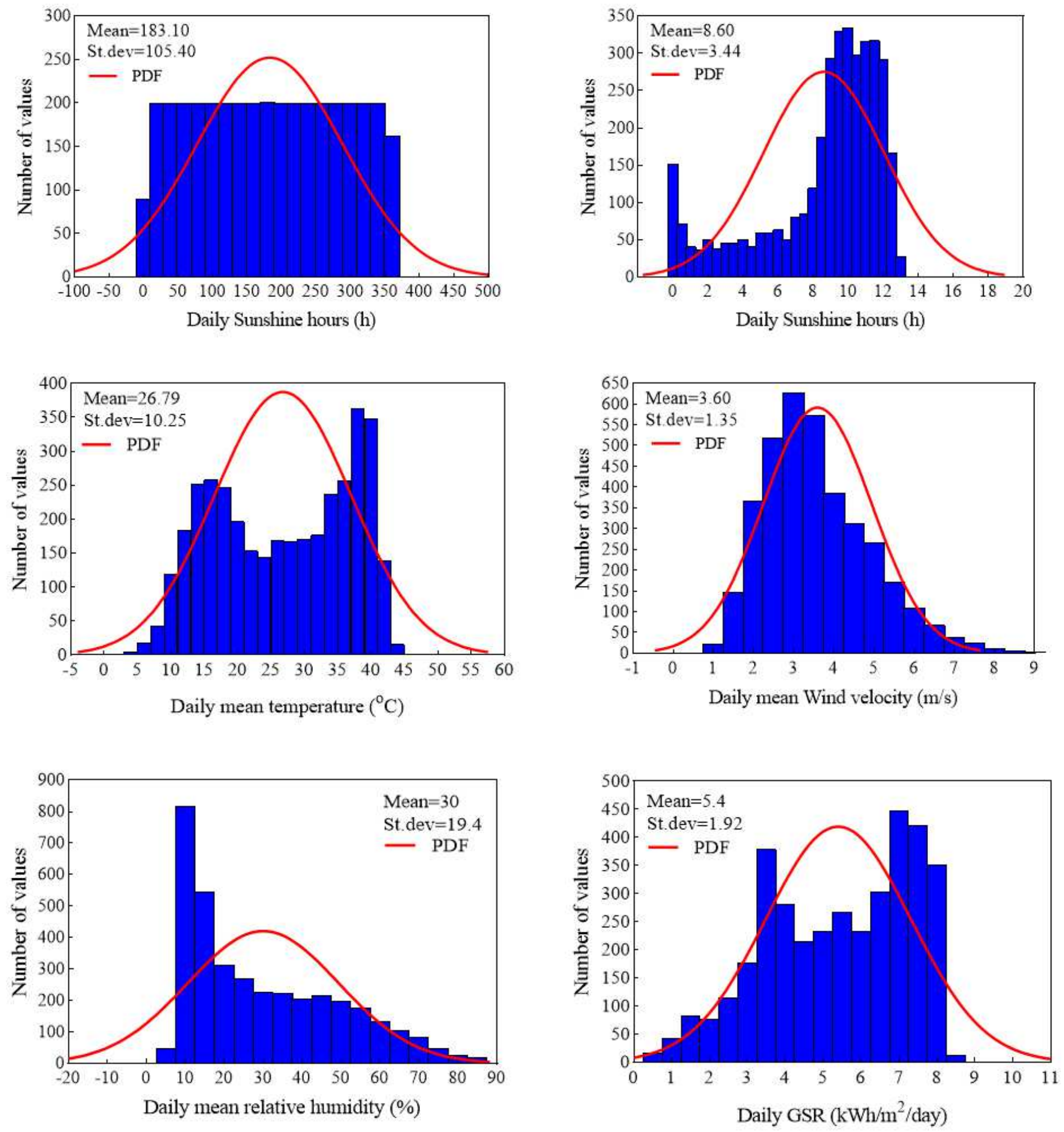

\section{Figure 3}

The histogram of the frequency and probability density function of the predictive and objective variable 


\section{Correlation Matrix}

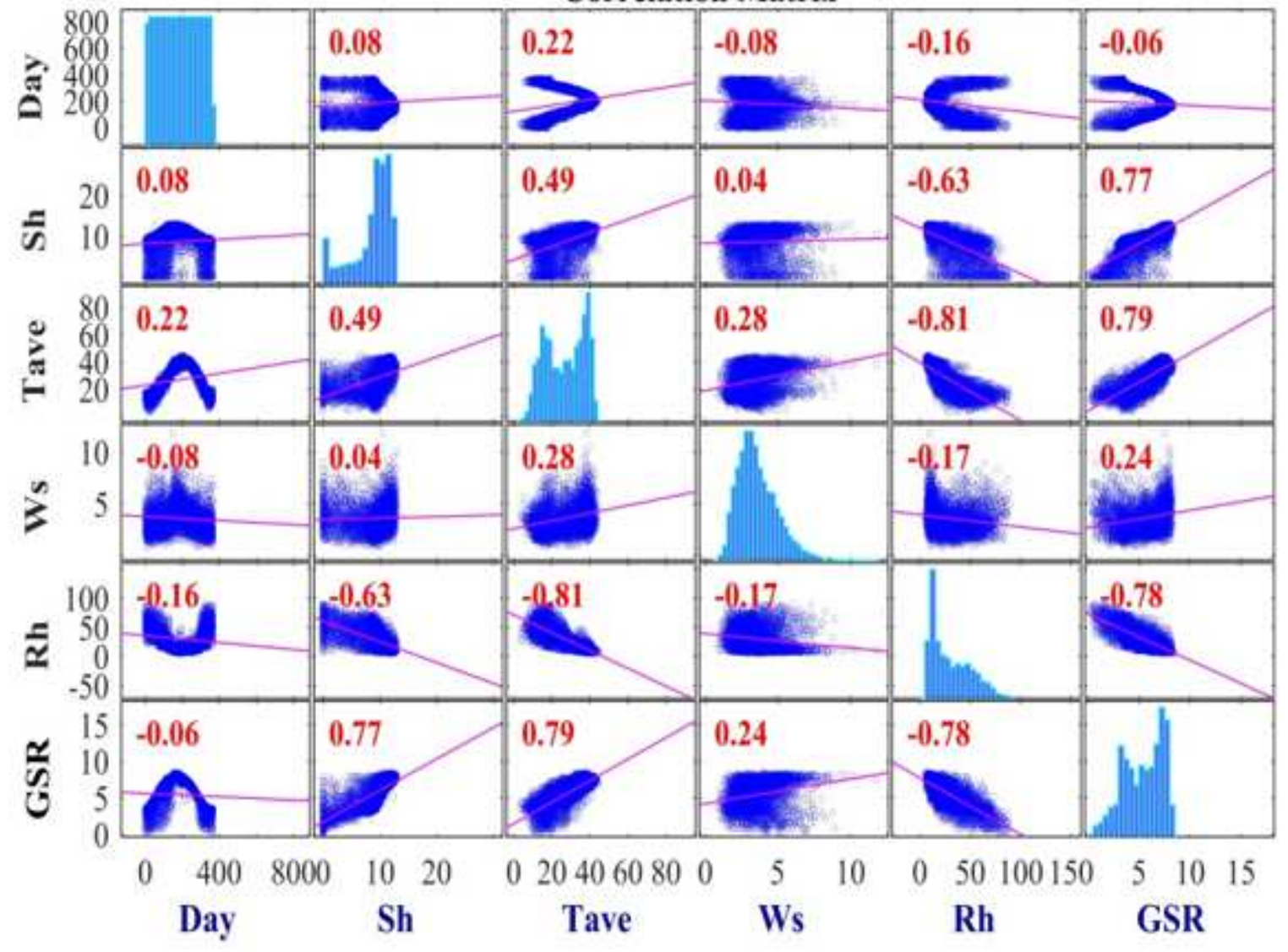

Figure 4

The correlation matrix of the implemented variables 


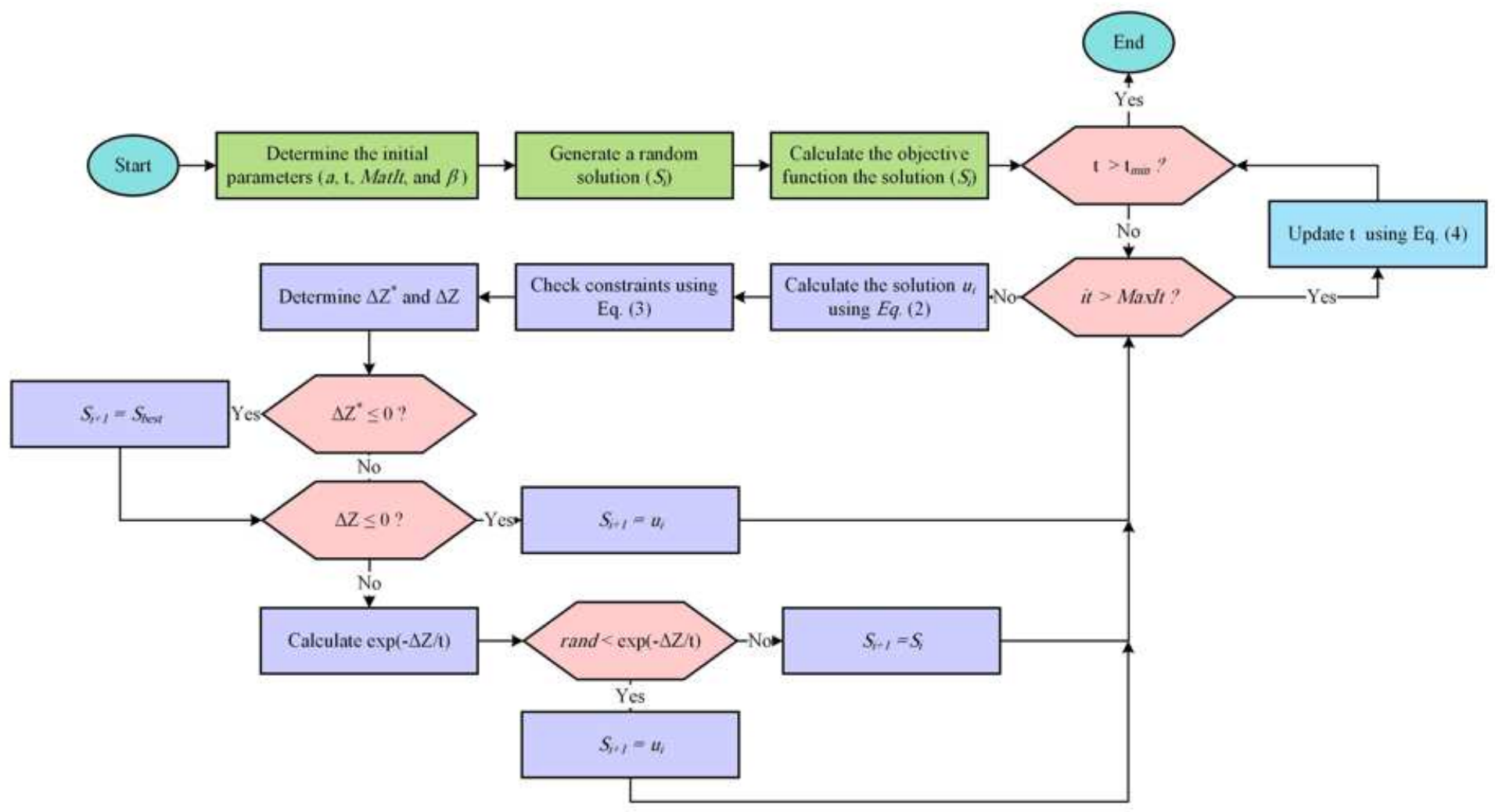

Figure 5

Flowchart of the ISA algorithm 


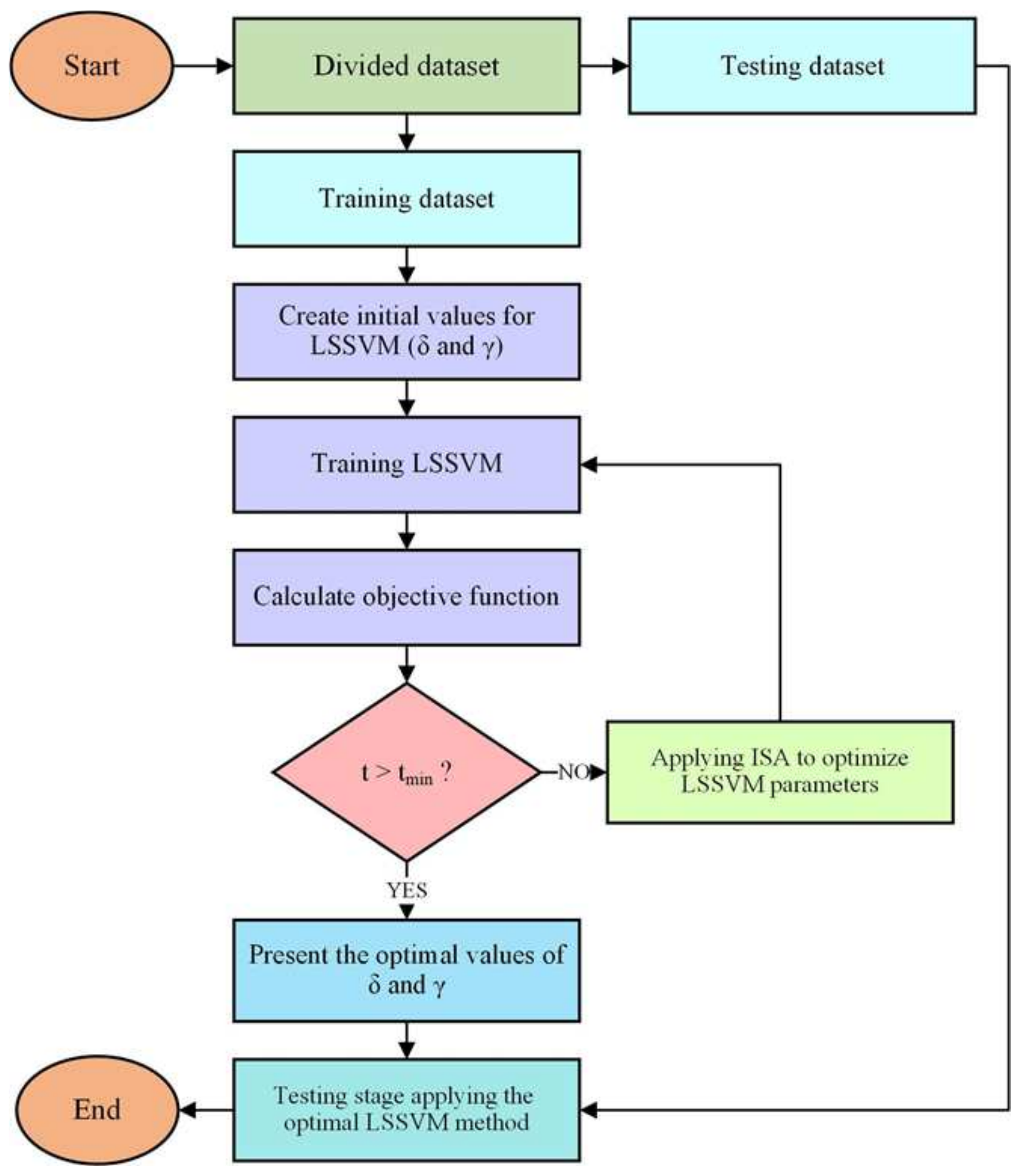

Figure 6

Flowchart of the LSSVM-ISA method 


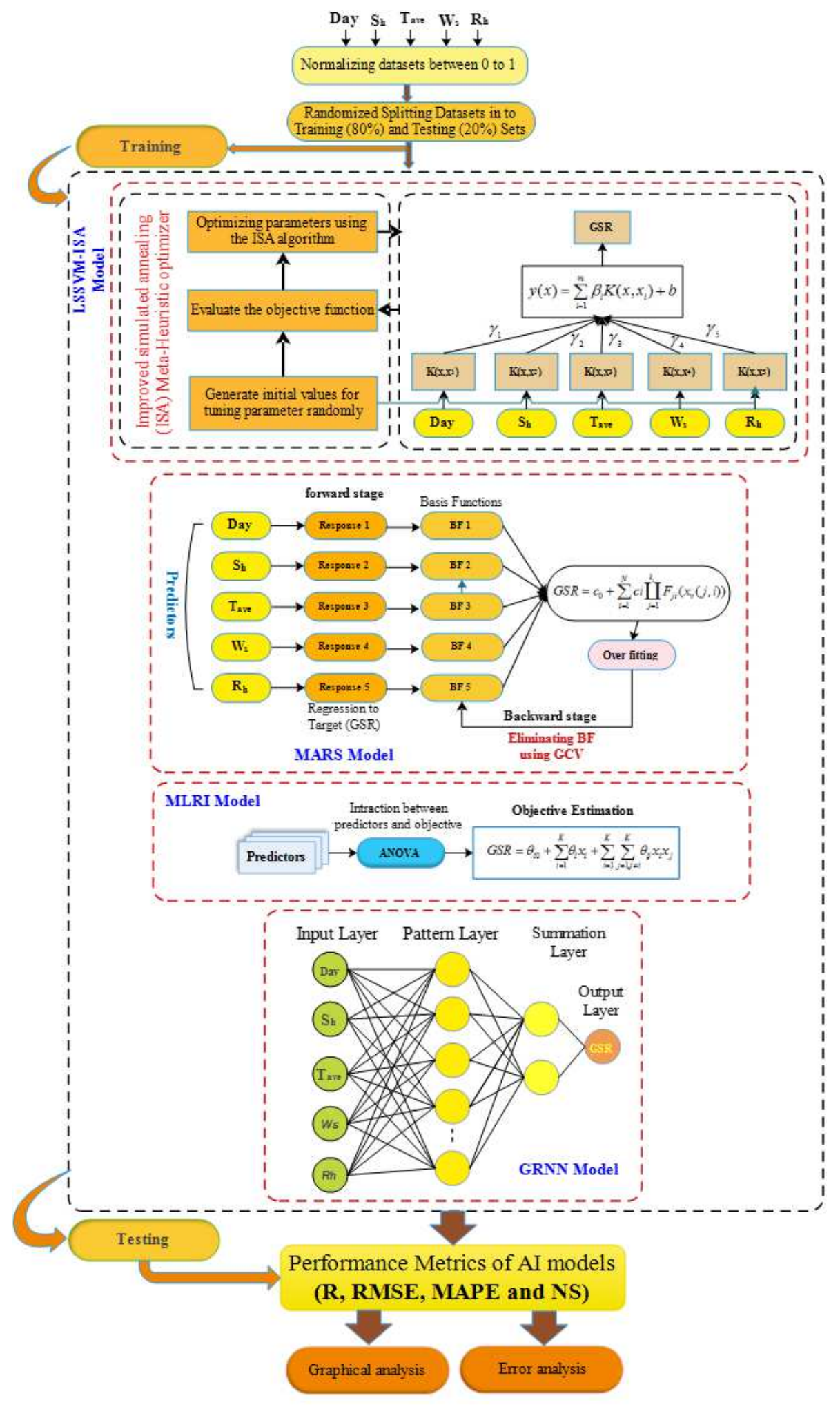

\section{Figure 7}

The flowchart of data-driven models to forecast the daily GSR 

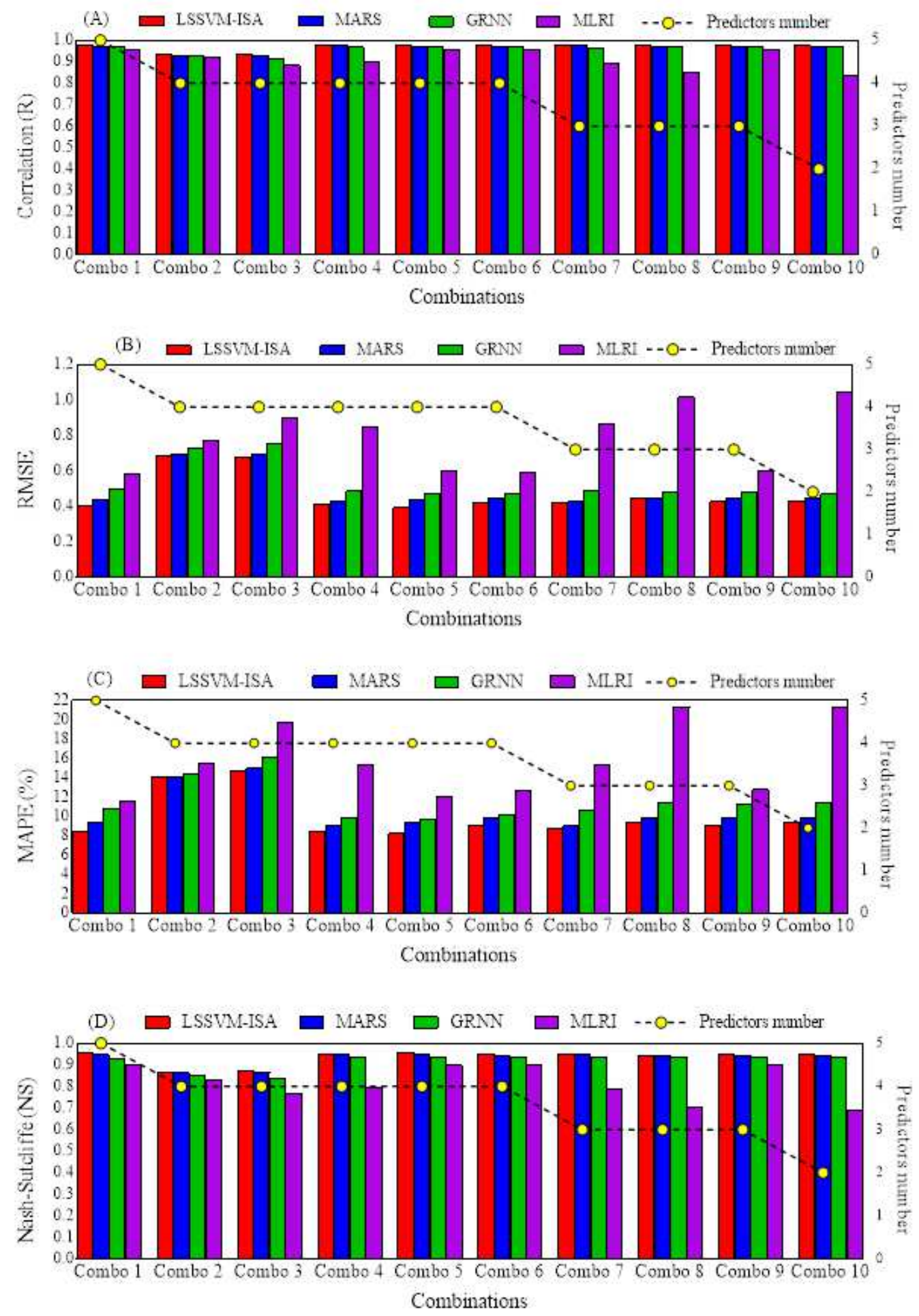

\section{Figure 8}

The correlation (R), RMSE, MAPE, and NS values for all Al models in 10 combinations versus predictors number 
Training mode

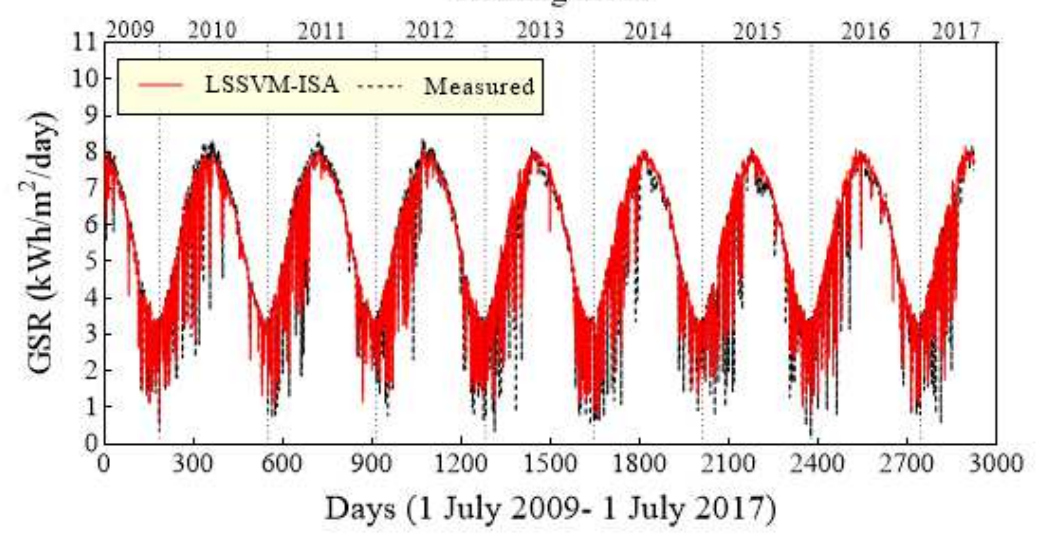

Testing mode

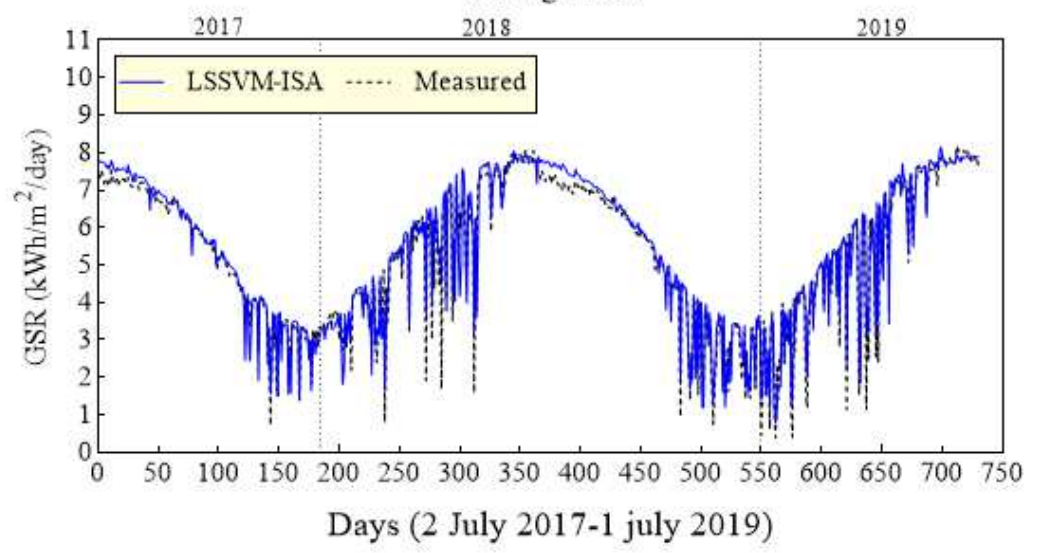

LSSVM-ISA-Training mode
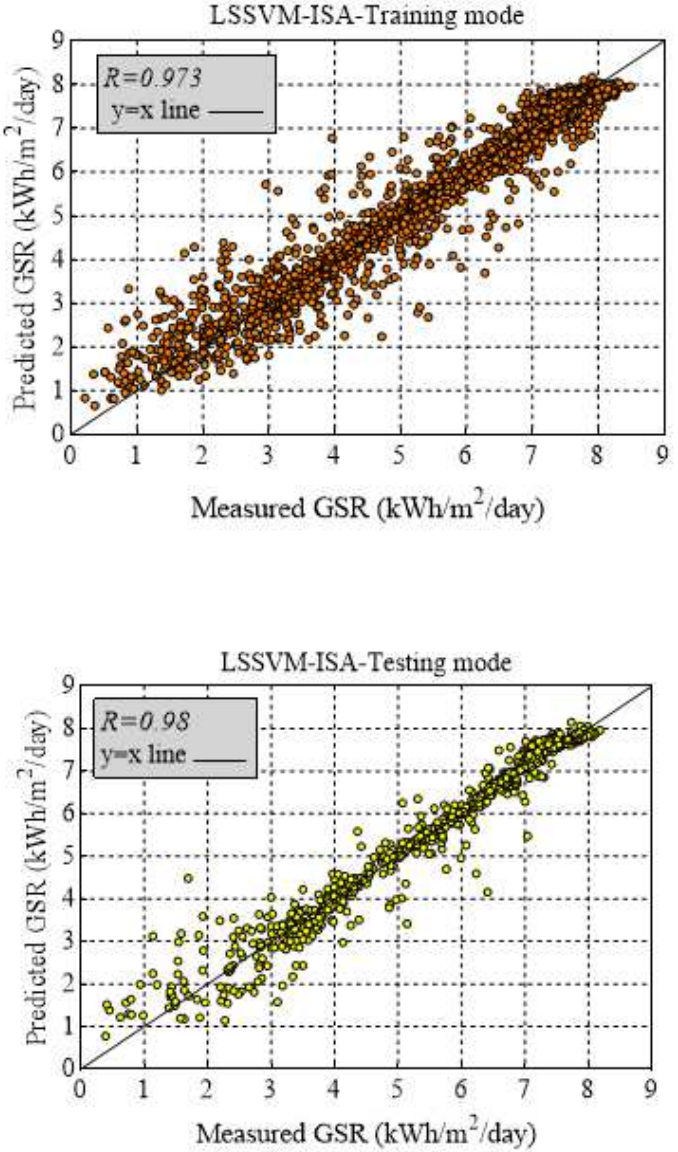

Figure 9

The scatter plots of GSR (Right); Comparison of the measured and predicted GSR (Left) using of LSSVMISA model for both training and testing datasets 

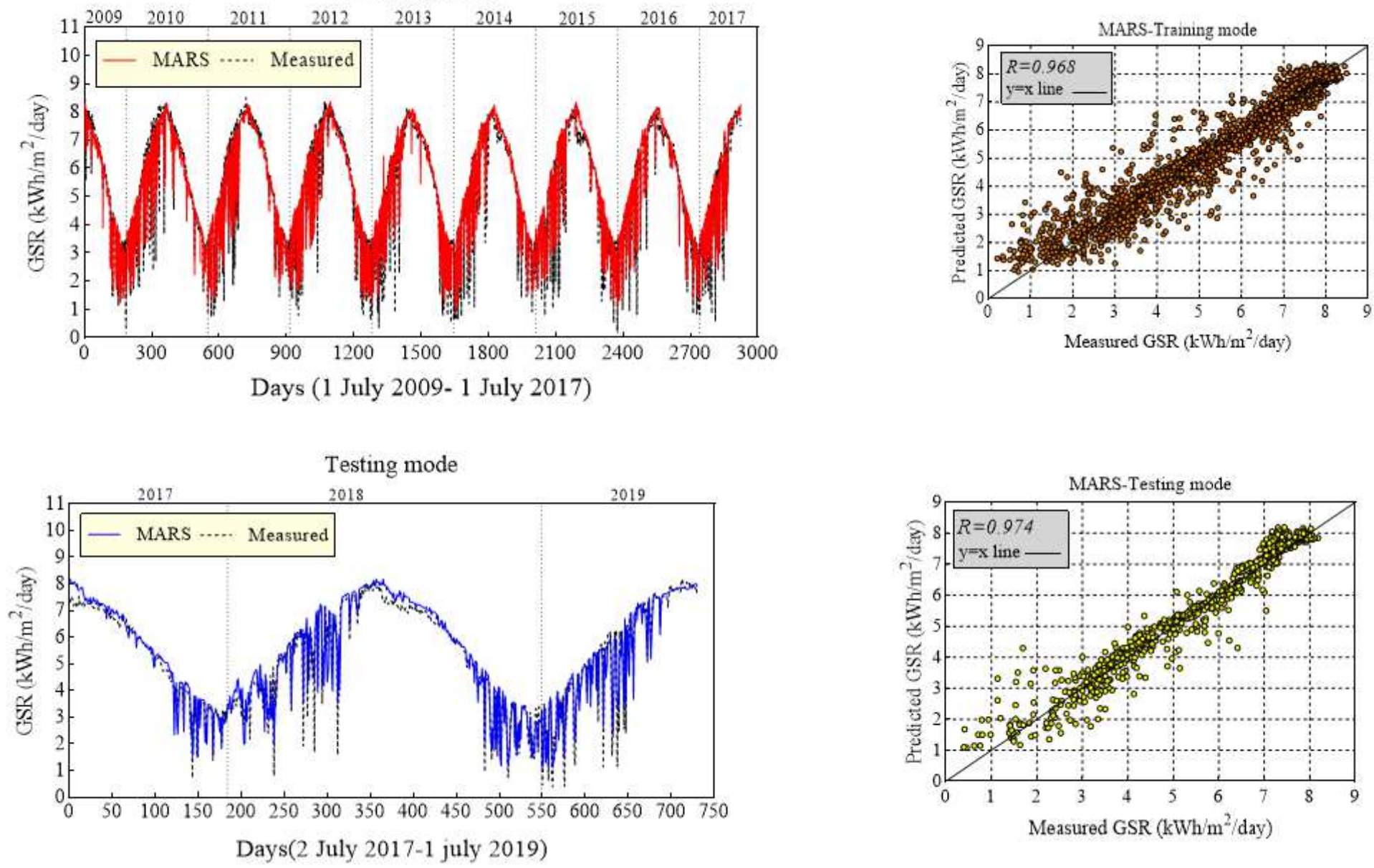

\section{Figure 10}

The scatter plots of GSR (Right); Comparison of the measured and predicted GSR (Left) using of MARS model for both training and testing datasets 

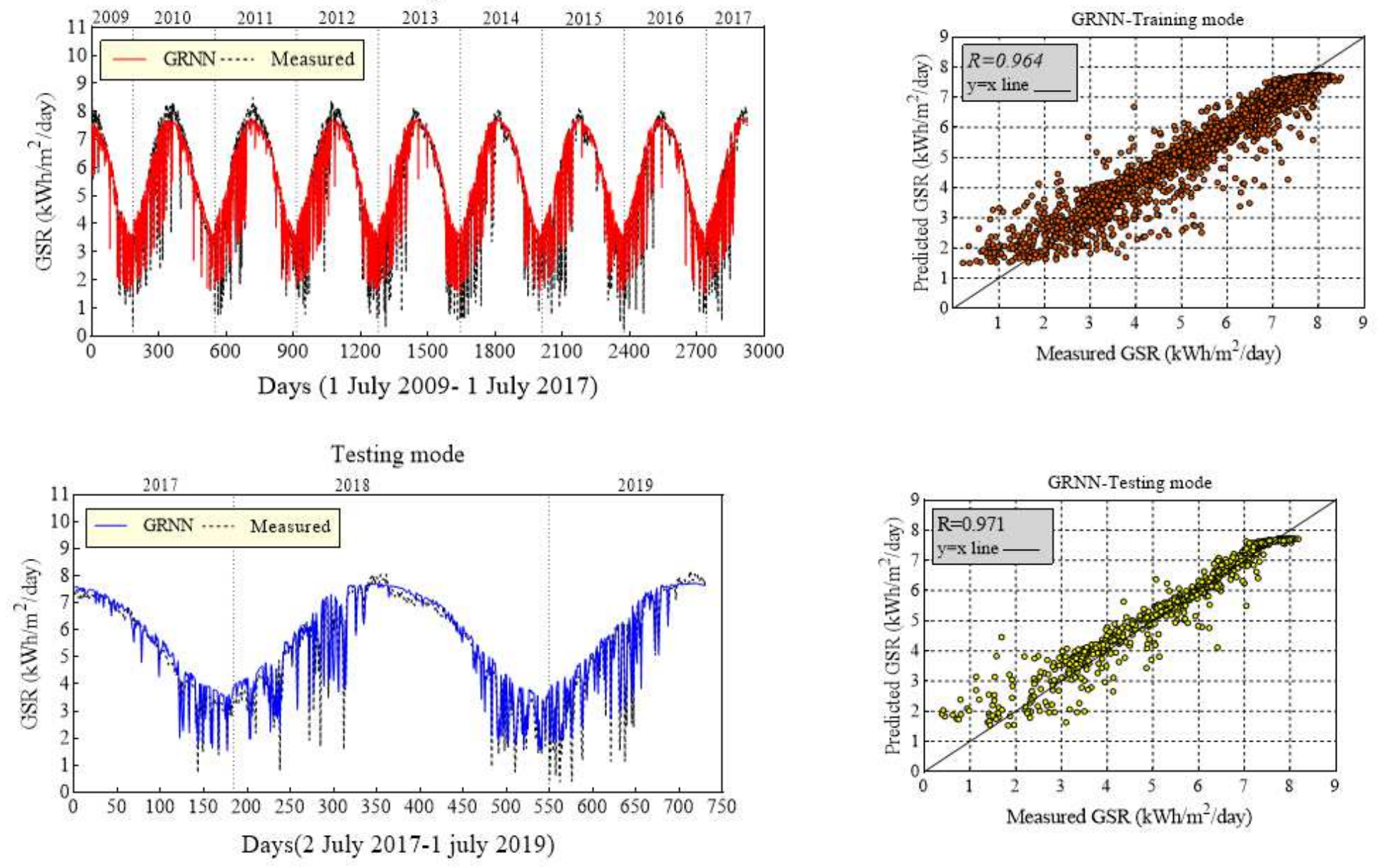

\section{Figure 11}

The scatter plots of GSR (Right); Comparison of the measured and predicted GSR (Left) using of GRNN model for both training and testing datasets 
Training mode

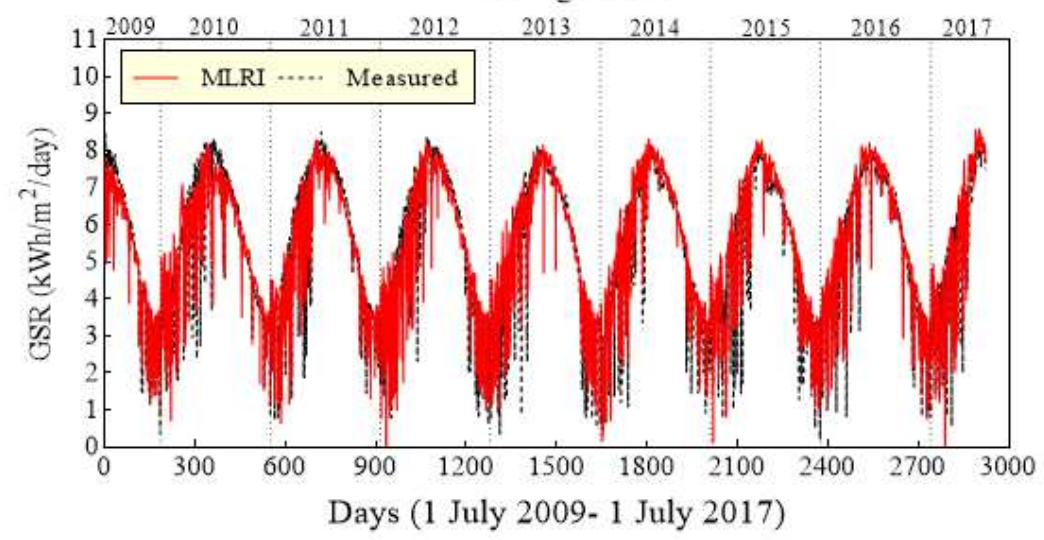

Testing mode

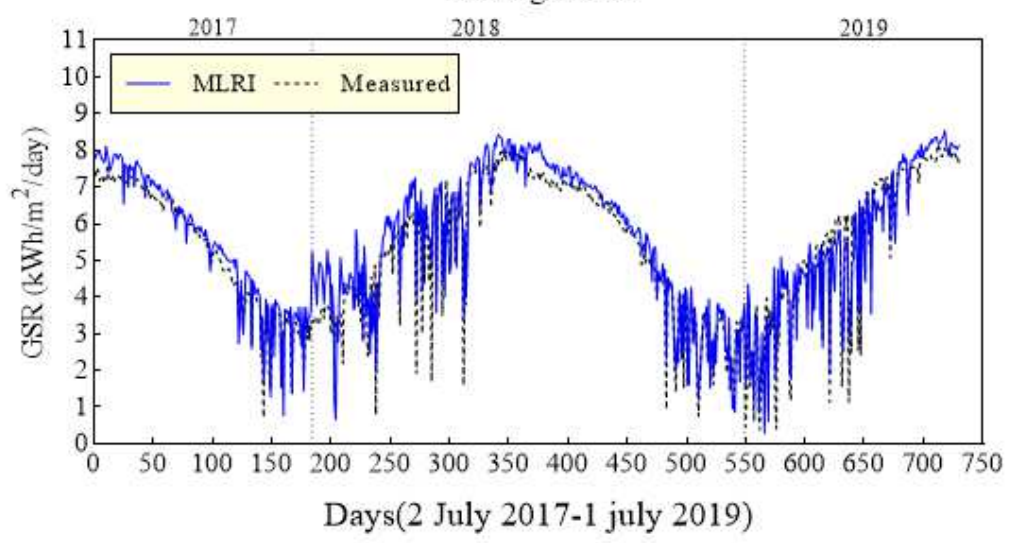

MLRI-Training mode
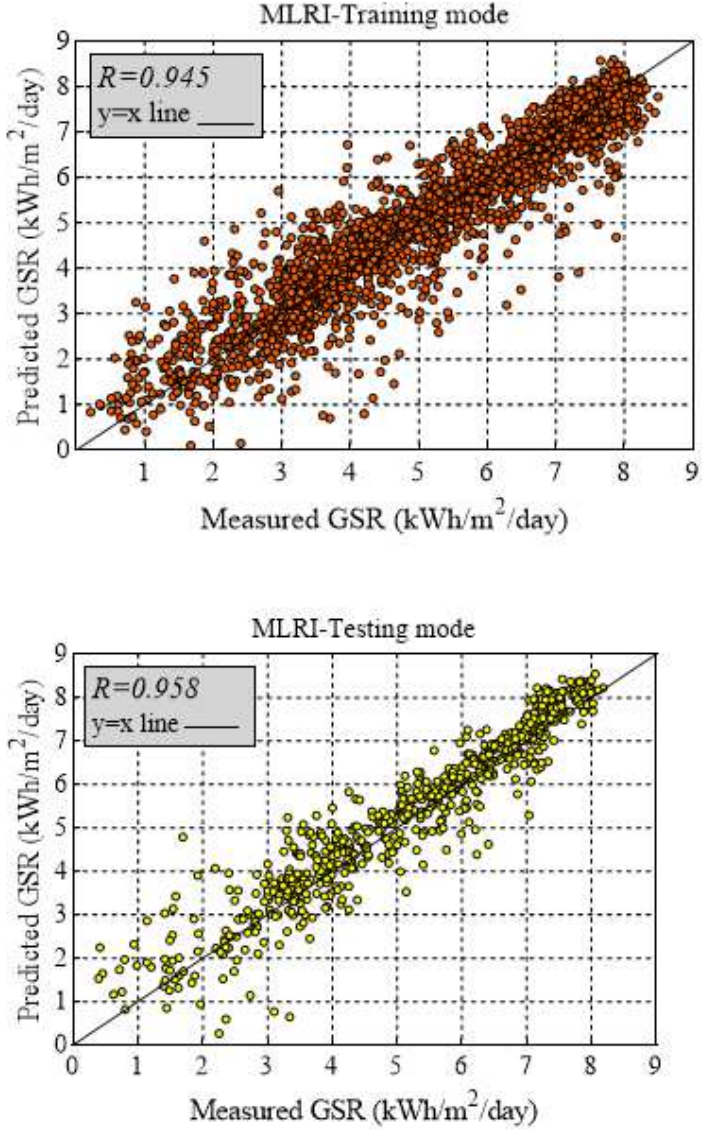

Figure 12

The scatter plots of GSR (Right); Comparison of the measured and predicted GSR (Left) using of MLRI model for both training and testing datasets 

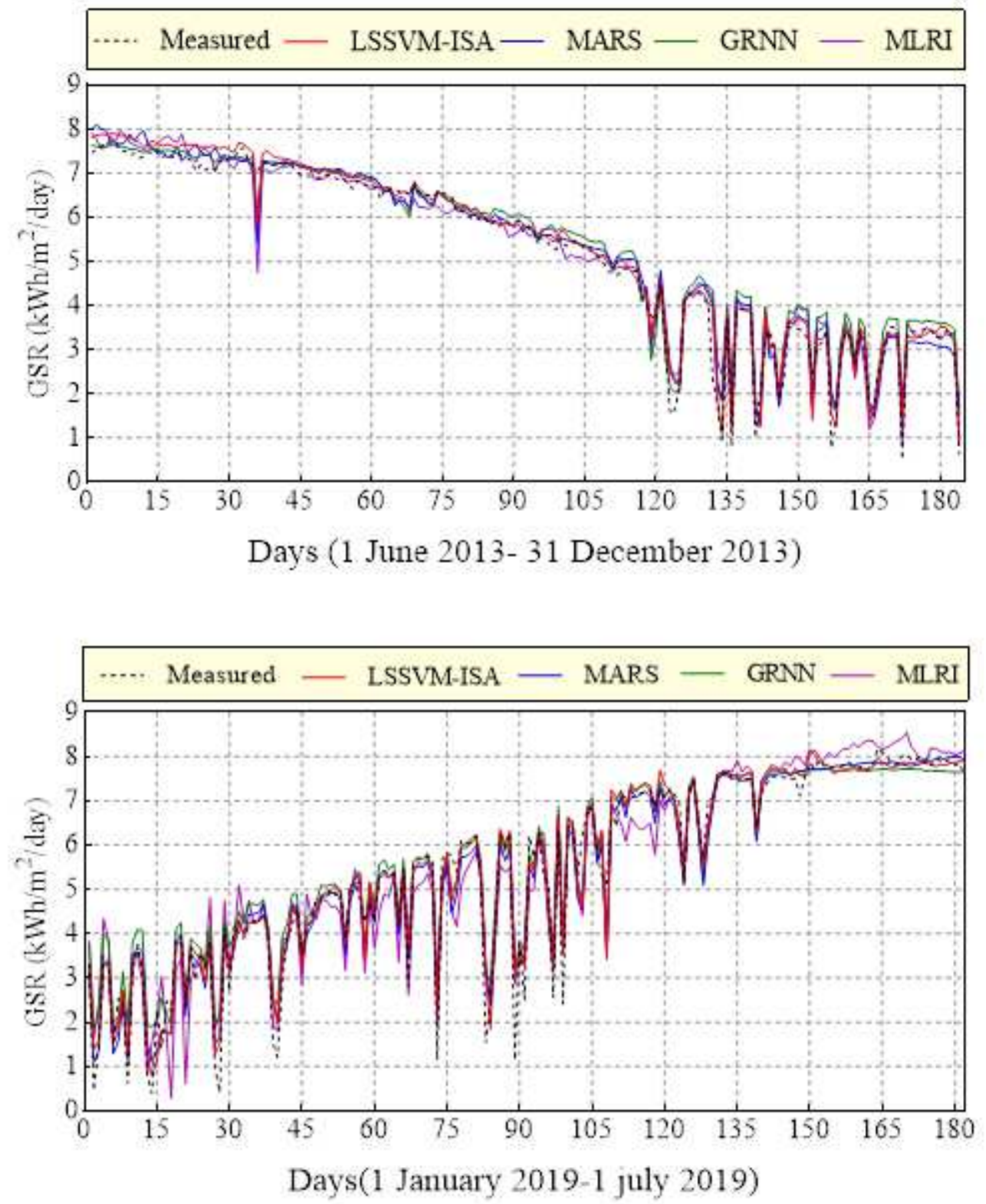

Figure 13

Comparison of the predictive and measured daily solar radiation with all developed Al models throughout (1 June 2013-31 December 2013) and (1 July 2017-1 July 2019) at the training and testing datasets 
(A)

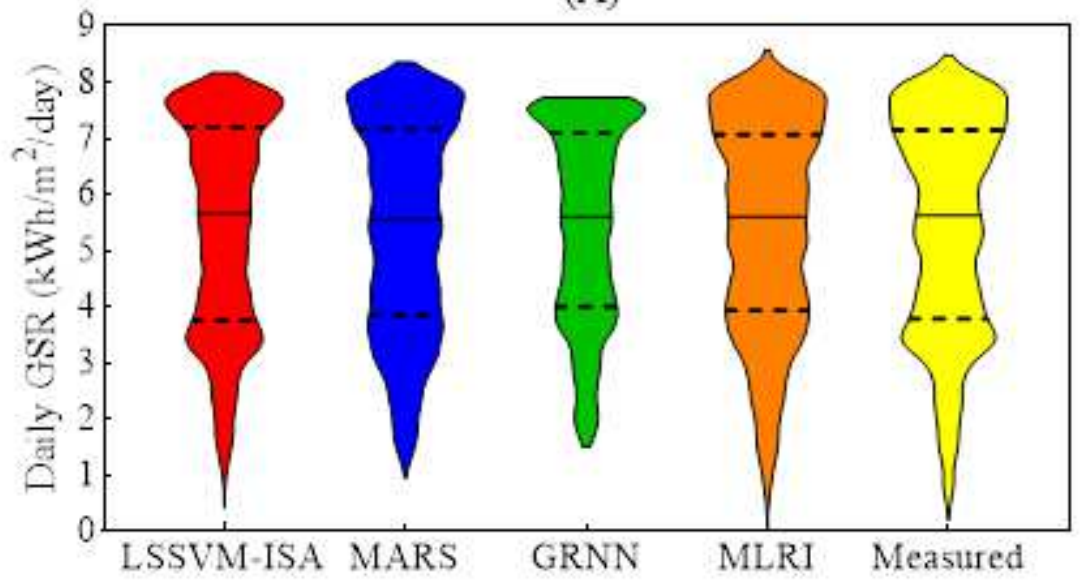

Predictive and measured Models (Training mode)

(B)

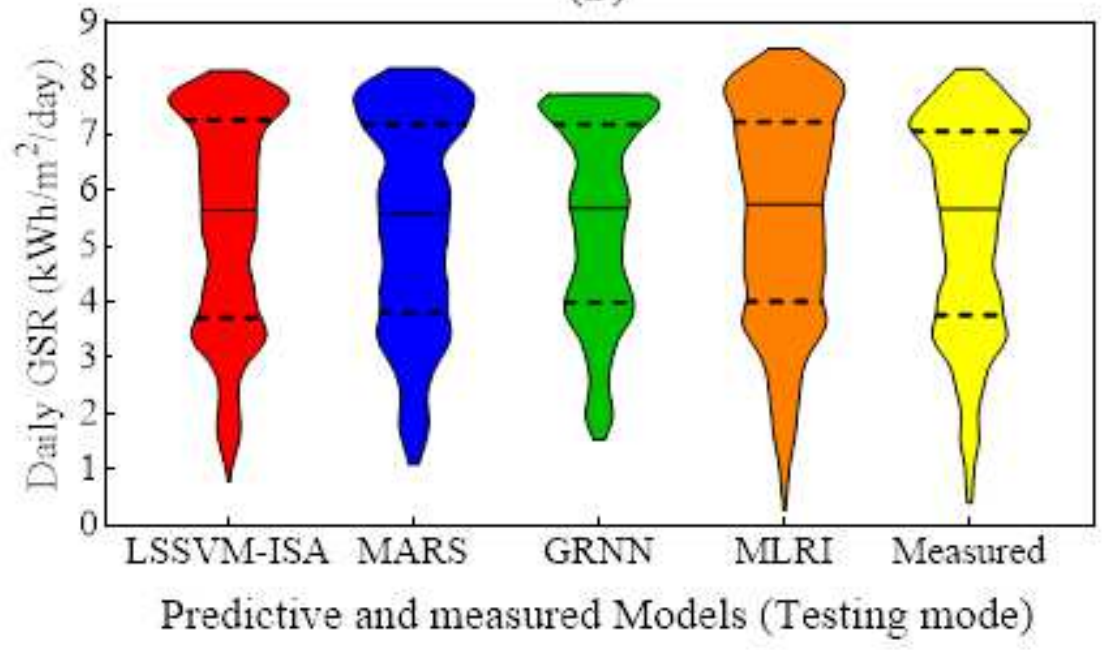

Figure 14

The violin plots of the predicted and measured daily GSR values for the best combination of each datadriven model. 

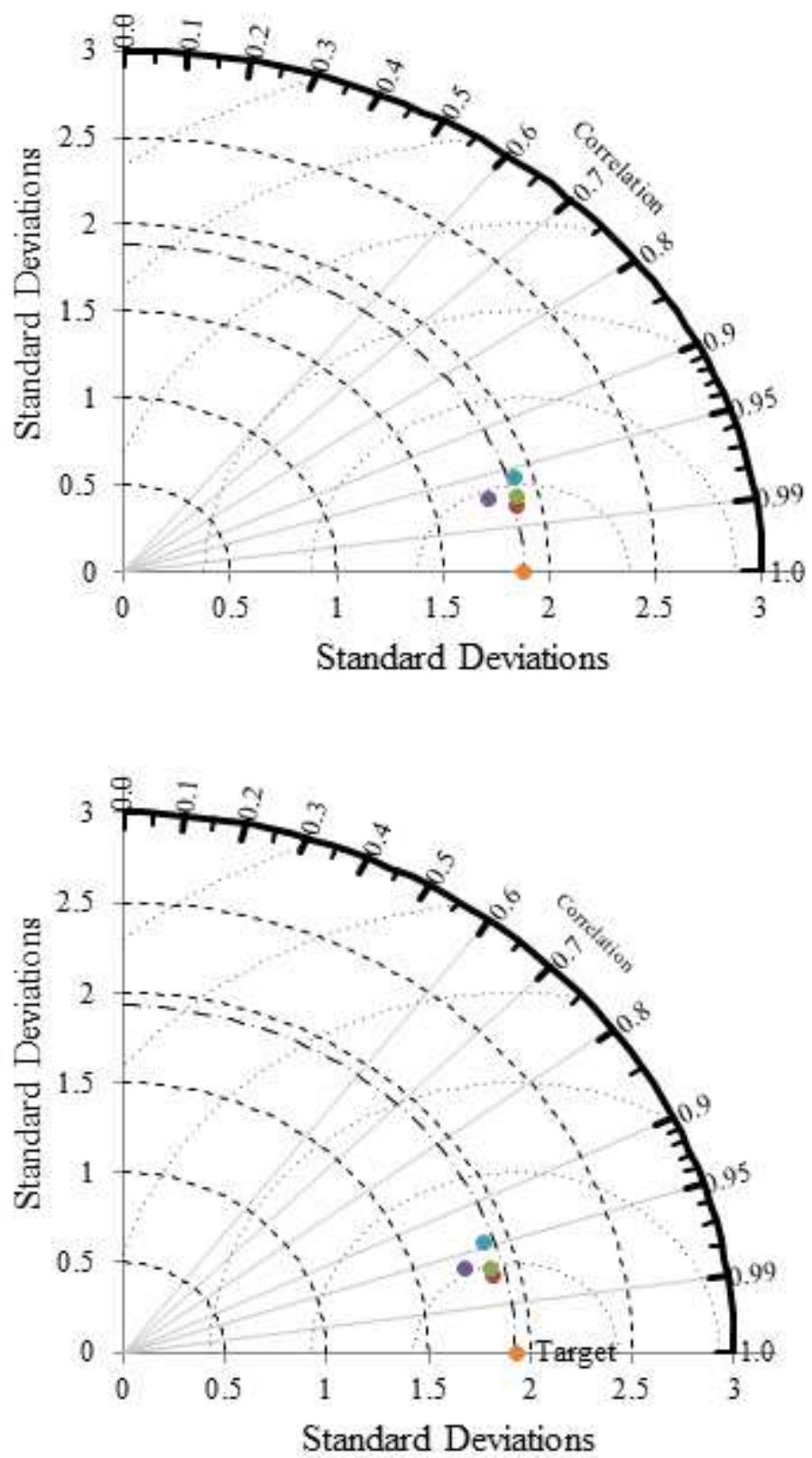

LSSVM-ISA MARS GRNN MLRI Target

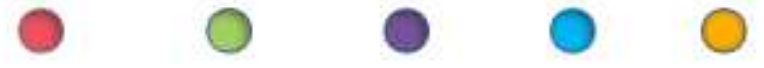

\section{Figure 15}

The Taylor diagram of the training and testing modes for LSSVM-ISA, MARS, GRNN, and MLRI for forecasting the GSR. 
(a)

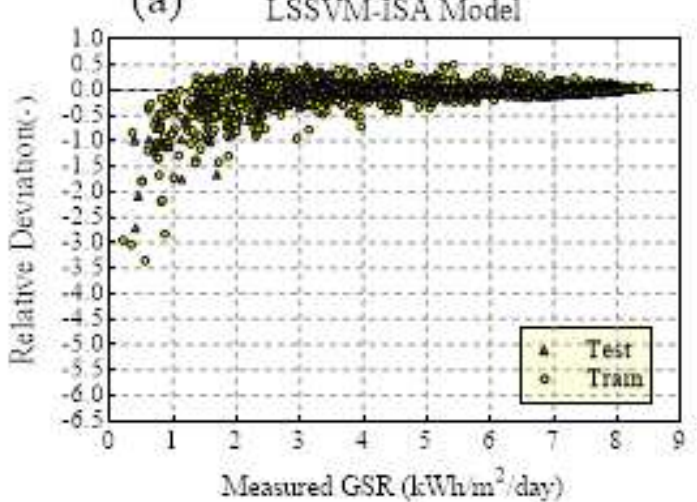

(c)

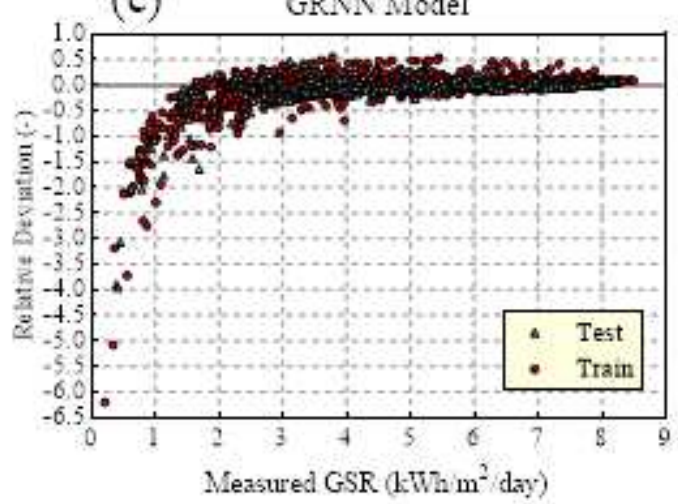

(b)

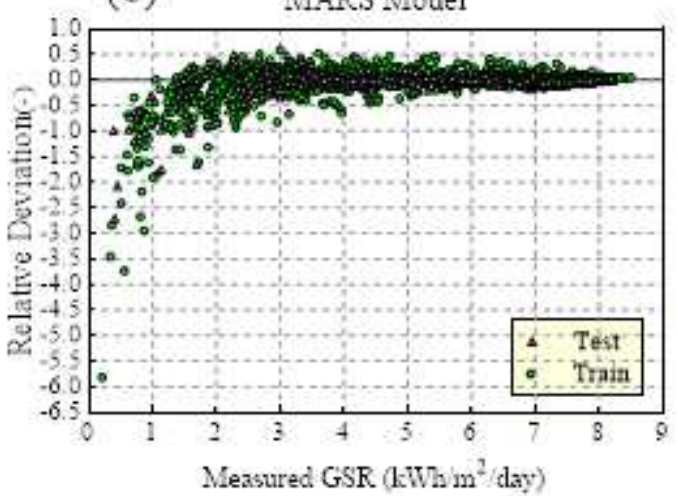

(d)

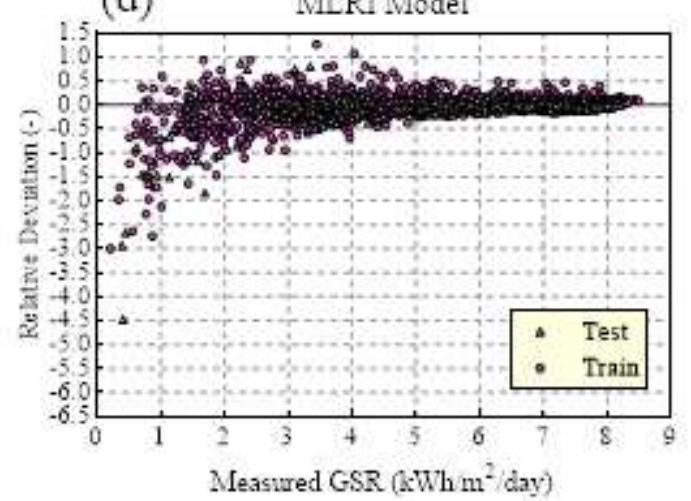

Figure 16

The relative deviation plots of the developed data-driven models for predicting GSR: (a) LSSVM-ISA, (b) MARS, (c) GRNN, and (d) MLRI. 


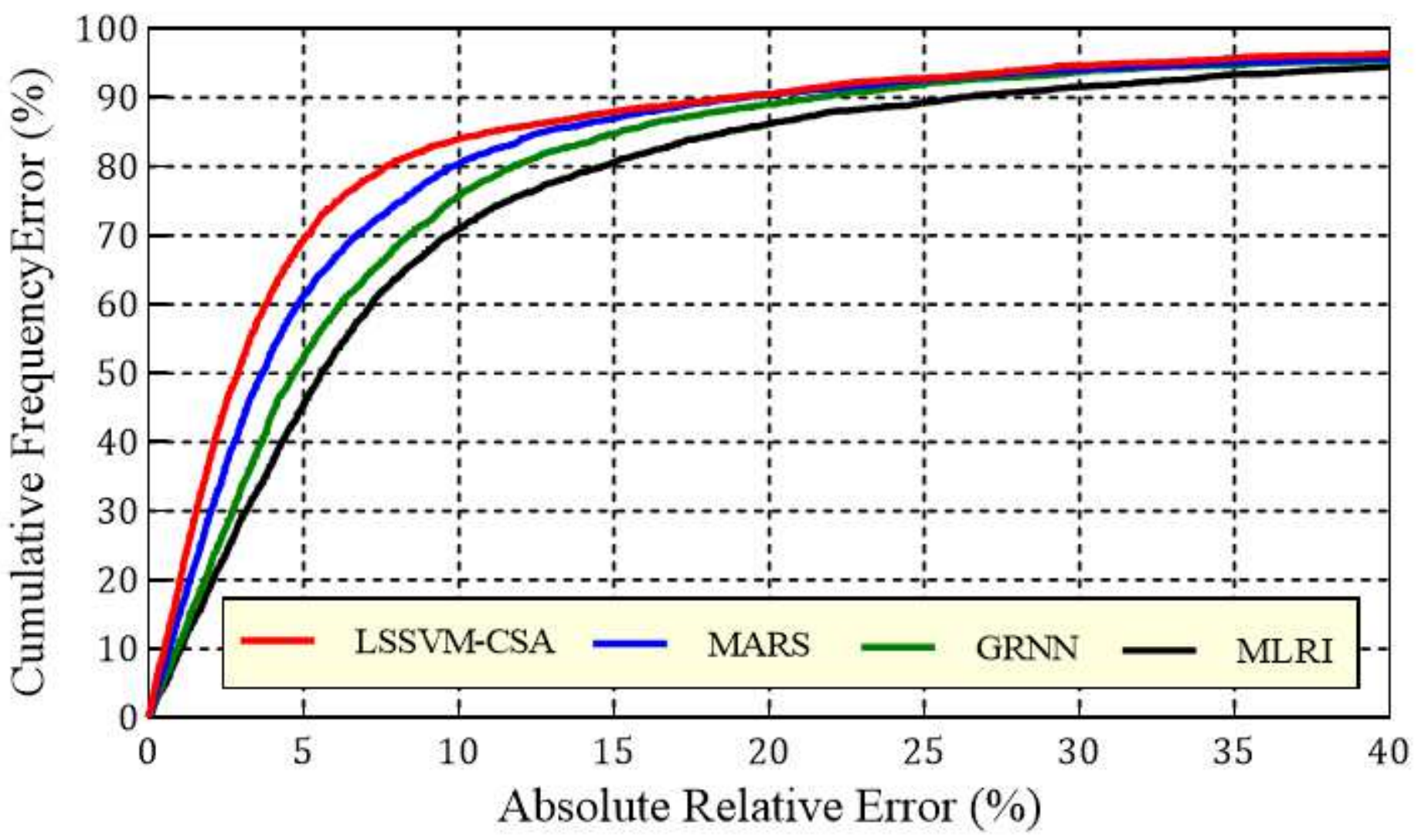

Figure 17

Percentage of cumulative frequency of proposed Al models versus the absolute percentage of relative error in forecasting GSR. 